\title{
Planning Implications Related to Sterilization-Sensitive Science Investigations Associated with Mars Sample Return (MSR)
}

\author{
Prof. Michael A. Velbel, ${ }^{1,2}$ Prof. Charles S. Cockell, ${ }^{3}$ Dr. Daniel P. Glavin, ${ }^{4}$ Dr. Bernard Marty, ${ }^{5}$ \\ Dr. Aaron B. Regberg, ${ }^{6}$ Dr. Alvin L. Smith, ${ }^{7}$ Prof. Nicholas J. Tosca, ${ }^{8}$ Prof. Meenakshi Wadhwa, ${ }^{7,9}$ \\ Dr. Gerhard Kminek, ${ }^{10}$ Dr. Michael A. Meyer, ${ }^{11}$ Dr. David W. Beaty, ${ }^{7}$ Dr. Brandi Lee Carrier, \\ Dr. Timothy Haltigin, ${ }^{12}$ Dr. Lindsay E. Hays, ${ }^{11}$ Dr. Carl B. Agee, ${ }^{13}$ Dr. Henner Busemann, ${ }^{14}$ \\ Dr. Barbara Cavalazzi, ${ }^{15}$ Dr. Vinciane Debaille, ${ }^{16}$ Dr. Monica M. Grady, ${ }^{17}$ Dr. Ernst Hauber, ${ }^{18}$ \\ Dr. Aurore Hutzler, ${ }^{10}$ Dr. Francis M. McCubbin, ${ }^{6}$ Dr. Lisa M. Pratt, ${ }^{19}$ Dr. Caroline L. Smith, ${ }^{20,21}$ \\ Prof. Roger E. Summons, ${ }^{22}$ Dr. Timothy D. Swindle, ${ }^{23}$ Dr. Kimberly T. Tait, ${ }^{24}$ Prof. Arya Udry, ${ }^{25}$ \\ Prof. Tomohiro Usui, ${ }^{26}$ Dr. Frances Westall, ${ }^{27}$ and Dr. Maria-Paz Zorzano ${ }^{28,29}$
}

\footnotetext{
${ }^{1}$ Michigan State University, Earth and Environmental Sciences, East Lansing, Michigan, USA.

${ }^{2}$ Smithsonian Institution, Department of Mineral Sciences, National Museum of Natural History, Washington, DC, USA.

${ }^{3}$ University of Edinburgh, Centre for Astrobiology, School of Physics and Astronomy, Edinburgh, UK.

${ }_{5}^{4}$ NASA Goddard Space Flight Center, Solar System Exploration Division, Greenbelt, Maryland, USA.

${ }^{5}$ Université de Lorraine, CNRS, CRPG, Nancy, France.

${ }^{6}$ NASA Johnson Space Center, Astromaterials Research and Exploration Science Division, Houston, Texas, USA.

${ }^{7}$ Jet Propulsion Laboratory, California Institute of Technology, Pasadena, California, USA.

${ }^{8}$ University of Cambridge, Department of Earth Sciences, Cambridge, UK.

${ }^{9}$ Arizona State University, Tempe, Arizona, USA.

${ }^{10}$ European Space Agency, Noordwijk, The Netherlands.

${ }^{11}$ NASA Headquarters, Mars Sample Return Program, Washington, DC, USA.

${ }^{12}$ Canadian Space Agency, Saint-Hubert, Quebec, Canada.

${ }^{13}$ University of New Mexico, Institute of Meteoritics, Albuquerque, New Mexico, USA.

${ }^{14}$ ETH Zürich, Institute of Geochemistry and Petrology, Zürich, Switzerland.

${ }^{15}$ Università di Bologna, Dipartimento di Scienze Biologiche, Geologiche e Ambientali, Bologna, Italy.

${ }^{16}$ Université Libre de Bruxelles, Bruxelles, Belgium.

${ }^{17}$ The Open University, Milton Keynes, UK.

${ }^{18}$ German Aerospace Center (DLR), Institute of Planetary Research, Berlin, Germany.

${ }^{19}$ Indiana University Bloomington, Earth and Atmospheric Sciences, Bloomington, Indiana, USA.

${ }^{20}$ Natural History Museum, Department of Earth Sciences, London, UK.

${ }_{22}^{21}$ University of Glasgow, School of Geographical and Earth Sciences, Glasgow, UK.

${ }^{22}$ Massachusetts Institute of Technology, Earth, Atmospheric and Planetary Sciences, Cambridge, Massachusetts, USA.

${ }^{23}$ University of Arizona, Lunar and Planetary Laboratory, Tucson, Arizona, USA.

${ }^{24}$ Royal Ontario Museum, Department of Natural History, Toronto, Ontario, Canada.

${ }^{25}$ University of Nevada Las Vegas, Las Vegas, Nevada, USA.

${ }^{26}$ Japan Aerospace Exploration Agency (JAXA), Institute of Space and Astronautical Science (ISAS), Chofu, Tokyo, Japan.

${ }^{27}$ Centre National de la Recherche Scientifique (CNRS), Centre de Biophysique Moléculaire, Orléans, France.

${ }^{28}$ Centro de Astrobiologia (CSIC-INTA), Torrejon de Ardoz, Spain.

${ }^{29}$ University of Aberdeen, Department of Planetary Sciences, School of Geosciences, King's College, Aberdeen, UK.
}

This paper was written by the MSR Science Planning Group 2 (MSPG2) working under a Terms of Reference from NASA and ESA.

(C) Michael A. Velbel et al., 2021; Published by Mary Ann Liebert, Inc. This Open Access article is distributed under the terms of the Creative Commons License (http://creativecommons.org/licenses/by/4.0), which permits unrestricted use, distribution, and reproduction in any medium, provided the original work is properly cited. 


\section{Table of Contents}

Abstract

Executive Summary

1. Introduction

1.1 Background

1.2 Scope of the report

1.3 Science goals

1.4 Key assumptions

2. Sterilization Techniques

2.1 Dry heat

2.2 Gamma $(\gamma)$ irradiation

2.3 Alternative sterilization techniques

2.4 Lethal processes, collateral damage, and criteria for choosing a sterilization method

2.5 Refinement of investigation strategies by sterilization sensitivity

3. Sterilization-Sensitive Science I: Extant or Recent Life

3.1 Background

3.2 Sterilization by dry heat

3.3 Sterilization by gamma $(\gamma)$ irradiation

3.4 Conclusions

4. Sterilization-Sensitive Science II: Organic Molecular Biosignatures

4.1 Background

4.2 Sterilization by dry heat

4.3 Sterilization by gamma $(\gamma)$ irradiation

4.4 Conclusions

5. Sterilization-Sensitive Science III: Geological Materials

5.1 Background

5.2 "Water" and its constituents in minerals and amorphous solids

5.3 Sterilization by dry heat

5.4 Sterilization by gamma $(\gamma)$ irradiation

5.5 Fluid inclusions

5.6 Physical, inorganic chemical, isotopic, and mineral biosignatures

5.7 Igneous and metamorphic rocks and minerals

5.8 Conclusions

6. Analysis of Gas Samples

6.1 Background

6.2 Sterilization by dry heat

6.3 Sterilization by gamma $(\gamma)$ irradiation

6.4 Sterilization by filtration

6.5 Conclusions

7. Implications for the SRF

7.1 Background

7.2 Key Assumptions

7.3 Support in the SRF for sterilization sensitive measurements-Processes

7.4 Support in the SRF for sterilization sensitive measurements-Instruments

7.5 Agnostic biosignatures

8. Conclusions

9. Recommendations for Future Work

Acknowledgments

Disclosure Statement

Funding Information

References

Acronyms Used

\section{Abstract}

The NASA/ESA Mars Sample Return (MSR) Campaign seeks to establish whether life on Mars existed where and when environmental conditions allowed. Laboratory measurements on the returned samples are useful if what is measured is evidence of phenomena on Mars rather than of the effects of sterilization conditions. This report establishes that there are categories of measurements that can be fruitful despite sample sterilization and other categories that cannot. 
Sterilization kills living microorganisms and inactivates complex biological structures by breaking chemical bonds. Sterilization has similar effects on chemical bonds in non-biological compounds, including abiotic or prebiotic reduced carbon compounds, hydrous minerals, and hydrous amorphous solids. We considered the sterilization effects of applying dry heat under two specific temperature-time regimes and the effects of $\gamma$-irradiation.

Many measurements of volatile-rich materials are sterilization sensitive-they will be compromised by either dehydration or radiolysis upon sterilization. Dry-heat sterilization and $\gamma$-irradiation differ somewhat in their effects but affect the same chemical elements. Sterilization-sensitive measurements include the abundances and oxidation-reduction (redox) states of redox-sensitive elements, and isotope abundances and ratios of most of them. All organic molecules, and most minerals and naturally occurring amorphous materials that formed under habitable conditions, contain at least one redox-sensitive element. Thus, sterilization-sensitive evidence about ancient life on Mars and its relationship to its ancient environment will be severely compromised if the samples collected by Mars 2020 rover Perseverance cannot be analyzed in an unsterilized condition.

To ensure that sterilization-sensitive measurements can be made even on samples deemed unsafe for unsterilized release from containment, contingency instruments in addition to those required for curation, timesensitive science, and the Sample Safety Assessment Protocol would need to be added to the Sample Receiving Facility (SRF). Targeted investigations using analogs of MSR Campaign-relevant returned-sample types should be undertaken to fill knowledge gaps about sterilization effects on important scientific measurements, especially if the sterilization regimens eventually chosen are different from those considered in this report.

\section{Executive Summary}

A high priority of the planned NASA/ESA Mars Sample Return Campaign is to establish whether life on Mars exists or existed where and when allowed by paleoenvironmental conditions. To answer these questions from analyses of the returned samples would require measurement of many different properties and characteristics by multiple and diverse instruments. Planetary Protection requirements may determine that unsterilized subsamples cannot be safely released to non-Biosafety Level-4 (BSL-4) terrestrial laboratories. Consequently, it is necessary to determine what, if any, are the negative effects that sterilization might have on sample integrity, specifically the fidelity of the subsample properties that are to be measured. Sample properties that do not survive sterilization intact should be measured on unsterilized subsamples, and the Sample Receiving Facility (SRF) should support such measurements.

This report considers the effects that sterilization of subsamples might have on the science goals of the MSR Campaign. It assesses how the consequences of sterilization affect the scientific usefulness of the subsamples and hence our ability to conduct high-quality science investigations. We consider the sterilization effects of (a) the application of dry heat under two temperature-time regimes $\left(180^{\circ} \mathrm{C}\right.$ for 3 hours; $250^{\circ} \mathrm{C}$ for $30 \mathrm{~min}$ ) and (b) $\gamma$-irradiation (1 MGy), as provided to us by the NASA and ESA Planetary Protection Officers (PPOs).

Measurements of many properties of volatile-rich materials are sterilization sensitive- they would be compromised by application of either sterilization mode to the subsample. Such materials include organic molecules, hydrous minerals (crystalline solids), and hydrous amorphous (non-crystalline) solids. Either proposed sterilization method would modify the abundances, isotopes, or oxidation-reduction (redox) states of the six most abundant chemical elements in biological molecules (i.e., carbon, hydrogen, nitrogen, oxygen, phosphorus, and sulphur, CHNOPS), and of other key redox-sensitive elements that include iron ( $\mathrm{Fe})$, other first-row transition elements (FRTE), and cerium (Ce). As a result of these modifications, such evidence of Mars' life, paleoenvironmental history, potential habitability, and potential biosignatures would be cor- rupted or destroyed. Modifications of the abundances of some noble gases in samples heated during sterilization would also reset scientifically important radioisotope geochronometers and atmospheric-evolution measurements.

Sterilization is designed to render terminally inactive (kill) all living microorganisms and inactivate complex biological structures (including bacterial spores, viruses, and prions). Sterilization processes do so by breaking certain presterilization chemical bonds (including strong $\mathrm{C}-\mathrm{C}, \mathrm{C}-\mathrm{O}$, $\mathrm{C}-\mathrm{N}$, and $\mathrm{C}-\mathrm{H}$ bonds of predominantly covalent character, as well as weaker hydrogen and van der Waals bonds) and forming different bonds and compounds, disabling the biological function of the pre-sterilization chemical compound.

The group finds the following:

- No sterilization process could destroy the viability of cells whilst still retaining molecular structures completely intact. This applies not only to the organic molecules of living organisms, but also to most organic molecular biosignatures of former life (molecular fossils). As a matter of biological principle, any sterilization process would result in the loss of biological and paleobiological information, because this is the mechanism by which sterilization is achieved. Thus, almost all life science investigations would be compromised by sterilizing the subsample by either mode.

- Sterilization by dry heat at the proposed temperatures would lead to changes in many of the minerals and amorphous solids that are most significant for the study of paleoenvironments, habitability, potential biosignatures, and the geologic context of life-science observations.

- Gamma-( $\gamma$-)irradiation at even sub-MGy doses induces radiolysis of water. The radiolysis products (e.g., free radicals) react with redox-sensitive chemical species of interest for the study of paleoenvironments, habitability, and potential biosignatures, thereby adversely affecting measurements of those species.

- Heat sterilization and radiation also have a negative effect on CHNOPS and redox-sensitive elements. MSPG2 was unable to identify with confidence any measurement of abundances or oxidation-reduction 
states of CHNOPS elements, other redox-sensitive elements (e.g., Fe and other FRTE; Ce), or their isotopes that would be affected by only one, but not both, of the considered sterilization methods.

Measurements of many attributes of volatile-rich subsamples are sterilization sensitive to both heat and $\gamma$ irradiation. Such a measurement is not useful to Mars science if what remains in the subsample is evidence of sterilization conditions and effects instead of evidence of conditions on Mars. Most measurements relating to the detection of evidence for extant or extinct life are sterilization sensitive. Many measurements other than those for life-science seek to retrieve Mars' paleoenvironmental information from the abundances or oxidation-reduction states of CHNOPS elements, other redox-sensitive elements, or their isotopes (and some noble gases) in returned samples. Such measurements inform scientific interpretations of (paleo)atmosphere composition and evolution, (paleo)surface water origin and chemical evolution, potential (paleo)habitability, (paleo)groundwater-porewater solute chemistry, origin and evolution, potential biosignature preservation, metabolic element or isotope fractionation, and the geologic, geochronological, and geomorphic context of life-sciences observations. Most such measurements are also sterilization sensitive. The sterilization-sensitive attributes cannot be meaningfully measured in any such subsample that has been sterilized by heat or $\gamma$-irradiation. Unless such subsamples are deemed biohazard-safe for release to external laboratories in unsterilized form, all such measurements must be made on unsterilized samples in biocontainment. An SRF should have the capability to carry out scientific investigations that are sterilization-sensitive to both PPO-provided sterilization methods (Figure SE1).

The following findings have been recognized in the Report. Full explanations of the background, scope, and justification precede the presentation of each Finding in the Section identified for that Finding. One or more Findings follow our assessment of previous work on the effects of each provided sterilization method on each of three broad categories of measurement types-biosignatures of extant or ancient life, geological evidence of paleoenvironmental conditions, and gases. Findings are designated Major if they explicitly refer to both PPO-provided sterilization methods or have specific implications for the functionalities that need to be supported within an SRF.

FINDING SS-1: More than half of the measurements described by iMOST for investigation into the presence of (mostly molecular) biosignatures (iMOST Objectives 2.1, 2.2 and 2.3) in returned martian samples are sterilizationsensitive and therefore cannot be performed with acceptable analytical precision or sensitivity on subsamples sterilized either by heat or by $\gamma$-irradiation at the sterilization $p a$ rameters supplied to MSPG2. That proportion rises to $86 \%$ of the measurements specific to the investigation of extant or recent life (iMOST Objective 2.3) (see Section 2.5).

This Finding supersedes Finding \#4 of the MSPG Science in Containment report (MSPG, 2019).

FINDING SS-2: Almost three quarters (115 out of 160; $72 \%)$ of the measurements described by iMOST for science investigations not associated with Objective 2 but associated with Objectives concerning geological phe- nomena that include past interactions with the hydrosphere (Objectives 1 and 3) and the atmosphere (Objective 4) are sterilization-tolerant and therefore can (generally) be performed with acceptable analytical precision or sensitivity on subsamples sterilized either by heat or by $\gamma$-irradiation at the sterilization parameters supplied to MSPG2 (see Section 2.5).

This Finding supports Finding \#6 of the MSPG Science in Containment report (MSPG, 2019). MSPG2 endorses the previously proposed strategy of conducting as many measurements as possible outside the SRF where the option exists.

FINDING SS-3: Suggested strategies for investigating the potential for extant life in returned martian samples lie in understanding biosignatures and, more importantly, the presence of nucleic acid structures (DNA/RNA) and possible agnostic functionally similar information-bearing polymers. A crucial observation is that exposure of microorganisms to temperatures associated with sterilization above those typical of a habitable surface or subsurface environment results in a loss of biological information. If extant life is a target for subsample analysis, sterilization of material via dry heat would likely compromise any such analysis (see Section 3.2).

FINDING SS-4: Suggested strategies for investigating the potential for extant life in returned martian samples lie in understanding biosignatures, including the presence of nucleic acid structures (DNA/RNA) and possible agnostic functionally similar information-bearing polymers. A crucial observation is that exposure of microorganisms to $\gamma$-radiation results in a loss of biological information through molecular damage and/or destruction. If extant life is a target for subsample analysis, sterilization of material via $\gamma$-radiation would likely compromise any such analysis (see Section 3.3).

FINDING SS-5: Suggested strategies for investigating biomolecules in returned martian samples lie in detection of a variety of complex molecules, including peptides, proteins, DNA (deoxyribonucleic acid) and RNA (ribonucleic acid), as well as compounds associated with cell membranes such as lipids, sterols, and fatty acids and their geologically stable reaction products (hopanes, steranes, etc.) and possible agnostic functionally similar information-bearing polymers. Exposure to temperatures above MSR Campaign-Level Requirements for sample temperature, up to and including sterilization temperatures, results in a loss of biological information. If the presence of biosignatures is a target for subsample analysis, sterilization of material via dry heat would likely compromise any such analysis (see Section 4.2).

FINDING SS-6: Suggested strategies for investigating biomolecules in returned martian samples lie in detection of a variety of complex molecules, including peptides, proteins, DNA (deoxyribonucleic acid) and RNA (ribonucleic acid), and compounds associated with cell membranes such as lipids, sterols and fatty acids and their geologically stable reaction products (hopanes, steranes, etc.) and possible agnostic functionally similar information-bearing polymers. Exposure to radiation results in a loss of biological information. If the presence of biosignatures is a target for subsample analysis, sterilization of material via $\gamma$-irradiation would likely compromise any such analysis (see Section 4.3). 


\section{The SRF: A Key Strategy}

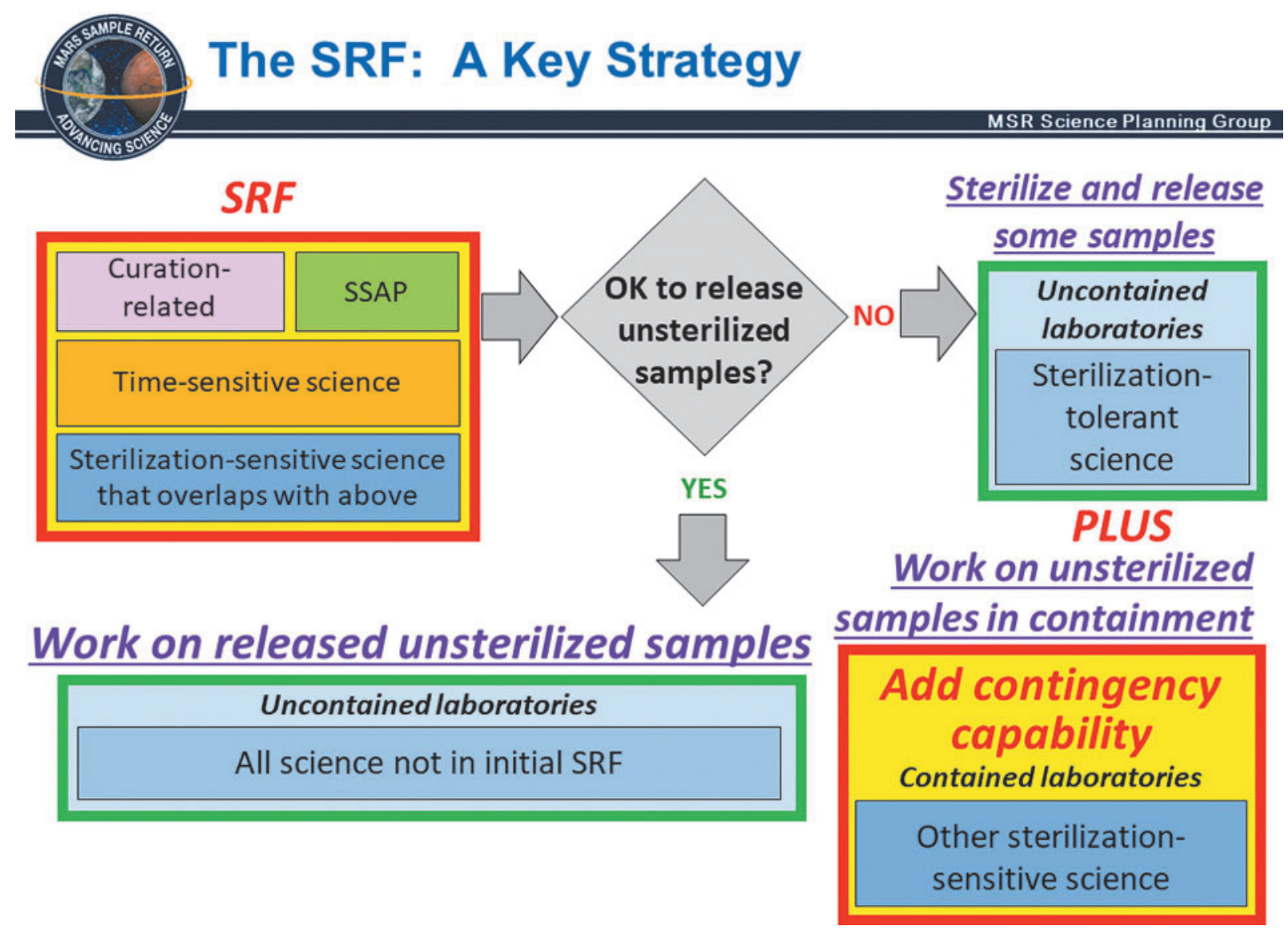

FIG. SE1. A key SRF strategy is that the SRF is designed to initially accommodate only the measurements and analyses that cannot reasonably be made outside of biocontainment, including those required for initial sample characterization, Sample Safety Assessment Protocol (SSAP) tests, and time-sensitive science. Two scenarios are shown for sterilizationsensitive measurements that are contingent upon SSAP determination that sample is safe for unsterilized release (green YES path to uncontained outside laboratories) or unsafe for unsterilized release (red NO path to uncontained outside laboratories for sterilization tolerant science PLUS contained contingency laboratories enabling sterilization sensitive MSR Campaign measurements on unsterilized samples that cannot be deemed safe for release from containment). From Carrier et al. (2022).

MAJOR FINDING SS-7: The use of heat or $\gamma$-irradiation sterilization should be avoided for subsamples intended to be used for organic biosignature investigations (for extinct or extant life). Studies of organic molecules from extinct or extant life (either indigenous or contaminants, viable or dead cells) or even some organic molecules derived from abiotic chemistry cannot credibly be done on subsamples that have been sterilized by any means. The concentrations of amino acids and other reduced organic biosignatures in the returned martian samples may also be so low that additional heat and/or $\gamma$-irradiation sterilization would reduce their concentrations to undetectable levels. It is a very high priority that these experiments be done on unsterilized subsamples inside containment (see Section 4.4).

FINDING SS-8: Solvent extraction and acid hydrolysis at $\sim 100^{\circ} \mathrm{C}$ of unsterilized martian samples will inactivate any biopolymers in the extract and would not require additional heat or radiation treatment for the subsamples to be rendered sterile. Hydrolyzed extracts should be safe for analysis of soluble free organic molecules outside containment and may provide useful information about their origin for biohazard assessments; this type of approach, if approved, is strongly preferred and endorsed (see Section 4.4).
FINDING SS-9: Minerals and amorphous materials formed by low temperature processes on Mars are highly sensitive to thermal alteration, which leads to irreversible changes in composition and/or structure when heated. Exposure to temperatures above MSR Campaign-Level Requirements for sample temperature, up to and including sterilization temperatures, has the potential to alter them from their as-received state. Sterilization by dry heat at the proposed sterilization temperatures would lead to changes in many of the minerals that are most significant for the study of paleoenvironments, habitability, and potential biosignatures or biosignature hosts. It is crucial that the returned samples are not heated to temperatures above which mineral transitions occur (see Section 5.3).

FINDING SS-10: Crystal structure, major and non-volatile minor element abundances, and stoichiometric compositions of minerals are unaffected by $\gamma$-irradiation of up to $0.3-1$ MGy, but crystal structures are completely destroyed at 130 MGy. Measurements of these specific properties cannot be acquired from subsamples $\gamma$-irradiated at the notional 1 MGy dose-they are sterilization-sensitive (see Section 5.4).

FINDING SS-11: Sterilization by $\gamma$-irradiation (even at sub-MGy doses) results in significant changes to the redox 
state of elements bound within a mineral lattice. Redoxsensitive elements include $\mathrm{Fe}$ and other first-row transition elements (FRTE) as well as $\mathrm{C}, \mathrm{H}, \mathrm{N}, \mathrm{O}, \mathrm{P}$ and $\mathrm{S}$. Almost all minerals and naturally occurring amorphous materials that formed under habitable conditions, including the ambient paleotemperatures of Mars' surface or shallow subsurface, contain at least one of these redox-sensitive elements. Therefore, measurements and investigations of the listed properties of such geological materials are sterilization sensitive and should not be performed on $\gamma$ irradiated subsamples (see Section 5.4).

FINDING SS-12: A significant fraction of investigations that focus on high-temperature magmatic and impactrelated processes, their chronology, and the chronology of Mars' geophysical evolution are sterilization-tolerant. While there may be a few analyses involved in such investigations that could be affected to some degree by heat sterilization, most of these analyses would not be affected by sterilization involving $\gamma$-irradiation (see Section 5.6).

MAJOR FINDING SS-13: Scientific investigations of materials containing hydrous or otherwise volatile-rich minerals and/or X-ray amorphous materials that formed or were naturally modified at low (Mars surface-/nearsurface) temperature are sterilization-sensitive in that they would be compromised by changes in the abundances, redox states, and isotopes of CHNOPS and other volatiles (e.g., noble gases for chronometry), FRTE, and $\mathrm{Ce}$, and cannot be performed on subsamples that have been sterilized by either dry heat or $\gamma$-irradiation (see Section 5.7).

MAJOR FINDING SS-14: It would be far preferable to work on sterilized gas samples outside of containment, if the technical issues can all be worked out, than to build and operate a large gas chemistry laboratory inside containment. Depending on their reactivity (or inertness), gases extracted from sample tubes could be sterilized by dry heat or $\gamma$-irradiation and analyzed outside containment. Alternatively, gas samples could be filtered through an inert grid and the filtered gas analyzed outside containment (see Section 6.5).

MAJOR FINDING SS-15: It is fundamental to the campaign-level science objectives of the Mars Sample Return Campaign that the SRF support characterization of samples returned from Mars that contain organic matter and/or minerals formed under habitable conditions that include the ambient paleotemperatures of Mars' surface or subsurface $\left(<\sim 200^{\circ} \mathrm{C}\right)$ - such as most clays, sulfates, and carbonates-in laboratories on Earth in their as-receivedat-the-SRF condition (see Section 7.1).

MAJOR FINDING SS-16: The search for any category of potential biosignature would be adversely affected by either of the proposed sterilization methods (see Section 7.1).

MAJOR FINDING SS-17: Carbon, hydrogen, nitrogen, oxygen, sulfur, phosphorus, and other volatiles would be released from a subsample during the sterilization step. The heat and $\gamma$-ray sterilization chambers should be able to monitor weight loss from the subsample during sterilization. Any gases produced in the sample headspace and sterilization chamber during sterilization should be captured and contained for future analyses of the chemical and stable isotopic compositions of the evolved elements and compounds for all sterilized subsamples to characterize and document fully any sterilization-induced alter- ation and thereby recover some important information that would otherwise be lost (see Section 7.2).

This report shows that most of the sterilization-sensitive iMOST measurement types are among either the iMOST objectives for life detection and life characterization (half or more of the measurements for life-science sub-objectives are critically sterilization sensitive) or the iMOST objectives for inferring paleoenvironments, habitability, preservation of potential biosignatures, and the geologic context of lifescience observations (nearly half of the measurements for sub-objectives involving geological environments, habitability, potential biosignature preservation, and gases/volatiles are critically sterilization sensitive) (Table 2; see Beaty et al., 2019 for the full lists of iMOST objectives, goals, investigations, and sample measurement types). Sterilizationsensitive science about ancient life on Mars and its relationship to its ancient environment will be severely impaired or lost if the samples collected by Perseverance cannot be analyzed in an unsterilized condition.

\section{Summary:}

- The SRF should have the capability to carry out or otherwise support scientific investigations that are sensitive to both PPO-provided sterilization methods.

- Measurements of most life-sciences and habitabilityrelated (paleoenvironmental) phenomena are sensitive to both PPO-provided sterilization modes. (Major Finding SS-7, SS-15, SS-16 and Finding SS-1, SS-3, SS-4, SS-5, SS-6, SS-9, SS-11, SS-13) If subsamples for sterilization-sensitive measurement cannot be deemed safe for release, then additional contingency analytical capabilities are needed in the SRF to complete MSR Campaign measurements of sterilizationsensitive sample properties on unsterilized samples in containment (Figure SE1, below).

- Measurements of high-temperature (low-volatile) phenomena are tolerant of both PPO-provided sterilization modes (Finding SS-12). Subsamples for such measurements may be sterilized and released to laboratories outside containment without compromising the scientific value of the measurements.

- Capturing, transporting, and analyzing gases is important and will require careful design of apparatus. Doing so for volatiles present as headspace gases and a dedicated atmosphere sample will enable important atmospheric science (Major Finding SS-14). Similarly, capturing and analyzing gases evolved during subsample sterilization (i.e., gas from the sterilization chamber) would compensate for some sterilization-induced loss of science data from volatile-rich solid (geological) subsamples (Finding SS-14, SS-17; other options incl. SS-8).

\section{Introduction}

\subsection{Background}

$\mathbf{T}$ He FIRST ELEMENT of the NASA/ESA Mars Sample Return (MSR) Campaign is currently underway, with the launch of NASA's Mars 2020 mission in late July 2020. This mission carried the Perseverance rover to a successful landing in Jezero Crater in February 2021. Part of the rover's mission is to collect material from different regions of Jezero 
Crater (and possibly beyond) to look for evidence of ancient life (Farley et al., 2020). For a combination of reasons, including high perchlorate abundance (Hecht et al., 2009; Glavin et al., 2013), low water activity (Rummel et al., 2014), and bombardment of the surface by ionizing radiation (Hassler, 2013), it is unlikely that extant or extinct martian life is (or was) abundant in surface rocks and soils. However, remains of ancient life or its molecular biomarkers may have accumulated in sediments, then subsequently been buried, becoming consolidated as rocks that have since been exhumed by erosion of overburden such that rock at, or near, the present surface may contain evidence of past surface or subsurface life. Hence, sampling the variety of rock types and sedimentary depositional environments exposed in Jezero Crater will focus mainly on drilling cores of ancient rocks from the accessible outcrops. The cores will be contained in sample tubes that will be deposited in one or more caches. The sample tubes have interior diameters of $1.3 \mathrm{~cm}$ with maximum possible lengths of $7.6 \mathrm{~cm}$, giving each a maximum capacity of $10 \mathrm{~cm}^{3}$ of sample material (Moeller et al., 2021). An intact core of basalt fully occupying the tube would weigh $\sim 30 \mathrm{~g}$; porous rocks, fragmented samples, or regolith could fully occupy the tube with as little as $\sim 10 \mathrm{~g}$ of solid sample; and tubes only partially filled could contain even less.

The next stage of the MSR Campaign is a program of two flight missions currently scheduled to launch as early as 2026; between them, the assets of the missions would land on Mars, collect the cached samples, transport them to, and then store them in, a capsule on the Mars Ascent Vehicle (MAV). The MAV would lift off from Mars' surface and, once in orbit, release the capsule (the Orbiting Sample container; OS) for subsequent capture and containment into a second capsule held by the spacecraft that would return the samples to Earth. The elaborate transfer mechanism is designed to ensure that the outer surfaces of any object that has been exposed on the surface of Mars would not be exposed on Earth's surface until held within a secure biosafety facility ("Breaking the Chain"). This process also involves sterilization of the seam of the containment vessel and any material associated with the seam.

Arrival back at Earth could potentially be as early as Sept. 2031. The OS, within its retaining capsule inside the Earth Entry Vehicle (EEV), would be released into Earth's atmosphere, landing at a site such as the Utah Test and Training Range (UTTR), pending the outcome of the NEPA review process and confirmation of a location. The sequence of events between capsule landing and the opening of the OS, and the location(s) where these would occur, are still being planned; however, it is known that the OS and the sample tubes contained within would move to a primary Sample Receiving Facility (SRF). (See Haltigin et al., 2021, section 2, for a more detailed overview of the MSR Campaign, and Carrier et al., 2022, for the current understanding of planning for the SRF). In the SRF, the OS would be opened and the samples extracted from their tubes and characterized.

A key early step would be to evaluate whether the samples contain anything that is hazardous to Earth's environment. Before any material can leave the SRF, it must have been through a sample safety assessment to ensure that planetary protection protocols have been met. The Sample
Safety Assessment Protocol (SSAP) would be carried out within a containment facility operated to rigorous standards, such as Biosafety Level (BSL) 4 containment, inside the SRF and is expected to include measurement of a number of the sterilization-sensitive attributes highlighted in Sections 3 and 4 of this report. If the samples were determined to be non-hazardous, the next stage in the MSR Campaign would be distribution of subsamples to analytical laboratories of the international scientific community for comprehensive, high-precision, high-accuracy analyses. However, if one or more samples are determined to be hazardous, or even if the safety tests return an ambiguous result, it may not be possible to study them in unmodified form in external uncontained laboratories. The first iteration of the Mars Sample Return Science Planning Group (MSPG, 2019) pointed out that an effective strategy to deal with such a scenario would be to sterilize subsamples and send them out to uncontained laboratories external to the SRF. This strategy has a number of advantages as it would not require all laboratory functionalities to be built into the SRF, significantly reducing the design requirements and associated costs of the SRF.

Thoroughly sterilizing subsamples prior to distribution for analysis would meet the stringent public health safety and planetary protection protocols governing subsample release. However, sterilization has the capacity to change the primary characteristics of material within samples-that is, after all, its purpose-especially organic compounds. This could lead to incorrect inferences drawn about the chemistry of Mars, most particularly its potential for hosting life (or precursor chemical species). So, some analyses must be performed on unsterilized subsamples, that is, within containment in the SRF. An important question then becomes, not so much which sample is sterilization sensitive, but which investigation and corresponding measurements are sterilization sensitive. Another way of looking at things is to rephrase the question: What are the characteristics of a subsample that would render it worthless for a specific investigation if it were to be sterilized? The answer for each case depends on both the sample and the specific measurement required for the specific science investigation. The characteristics or attributes of a material that might cause it to be sterilization sensitive might include the occurrence of CHNOPS-containing phases ${ }^{1}$, hydrated minerals, organic compounds, etc.

This report is the outcome of a series of meetings held between a specialist group of members of the second (phase 2) MSR Science Planning Group (MSPG2). The Sterilization Effects Focus Group (SE-FG), a subgroup of MSPG2, had bi-weekly and supplemental ad hoc team meetings (all virtual) between July and November 2020 to investigate the potential effects of sterilization on material returned from Mars and how those effects might impact on the science

${ }^{1}$ CHNOPS $=$ Carbon, Hydrogen, Nitrogen, Oxygen, Phosphorus and Sulphur, the six most abundant chemical elements in biological molecules. Oxidation-reduction (redox) phenomena among these elements and their compounds can mediate electron transfer and storage of chemical energy for biological processes. Most of these elements, along with redox-sensitive elements in the environment (e.g., $\mathrm{Fe}, \mathrm{Mn}$ ), also occur in rocks and their crystalline (mineral) and non-crystalline ("amorphous") constituents. 
goals of the MSR campaign. The report should feed into the decision-making strategy that would inform as to which analyses are undertaken in containment and, hence, which functionalities should be designed into the SRF.

\subsection{Scope of the report}

The report considers the effects that sterilization of subsamples might have on the science goals of the MSR program. It assesses whether the consequences of sterilization affect the sample integrity (scientific usefulness) of the subsamples and, hence. our ability to conduct high quality science investigations. The essential purpose of this report is to establish that there are certain sectors of MSR returnedsample science investigations that can accept the consequences of sample sterilization (depending how it is done), and certain other sectors that cannot. It does not discuss the relative efficacies of different sterilization procedures; neither does it make any judgment on which sterilization procedure could or should be used on returned samples. The present state of knowledge and planning regarding sterilization, including the relationship between initial sample characterization workflow and SSAP, is briefly addressed elsewhere in the collection of papers of which this report is a part (e.g., for SSAP, see overview in Carrier et al., 2022, and details in Kminek et al., 2022a; for initial sample characterization and curation workflow, see Tait et al., 2022). The COSPAR SSAP Working Group (Kminek et al., 2022b) worked simultaneously with MSPG2 but independently from it. The relationship between SSAP on the one hand and sample sterilization and sample release decisions on the other is being, or would be, considered by other MSR Campaign planning groups and is outside the scope of this report.

Definition: Subsample. We use the term "sample" to include subsamples. We use the term "subsample" for a split from material within a sample tube, sub-divided from the larger sample, and processed to be allocated for specific scientific investigations. Homogeneous samples will be easy to sub-divide; heterogenous (inhomogeneous) samples will require extra attention. Some information about the homogeneity of the samples will be available from the robotic instrumental analyses made during sampling on Mars; the most useful information on the returned samples themselves will be acquired during the thorough initial sample characterization and preliminary examination during curation (Tait et al., 2022). Individual subsamples may be processed differently, depending on the specific requirements of each proposed analytical measurement. The size or mass of a subsample will be the minimal amount needed for a specific proposed measurement or technique (Tait et al., 2022). Our working assumption is that subsamples would be considered for sterilization, not the entire contents of a returned sample tube.

Definition: Sterilization sensitive vs. sterilization tolerant. Samples may be changed by sterilization to different extents and in different ways. For example, most samples that contain volatile elements would lose volatiles when heated above a given temperature determined by the conditions under which they formed. Volatiles released by sterilization would leave behind degraded organic molecules and devolatilized minerals and amorphous solids, which could react with and change the properties of surrounding materials in the sample. It follows, therefore, that the question to be asked of each subsample to be analyzed is as follows:

Is sterilization of the subsample an acceptable step in the preparation of the subsample for the proposed measurement?

Consider a single subsample that is being prepared for a specific measurement for a specific investigation (Figure 1):

- If the sample has a property that would be modified by sterilization, that property is sterilization sensitive. If the sample has a property that would be modified by

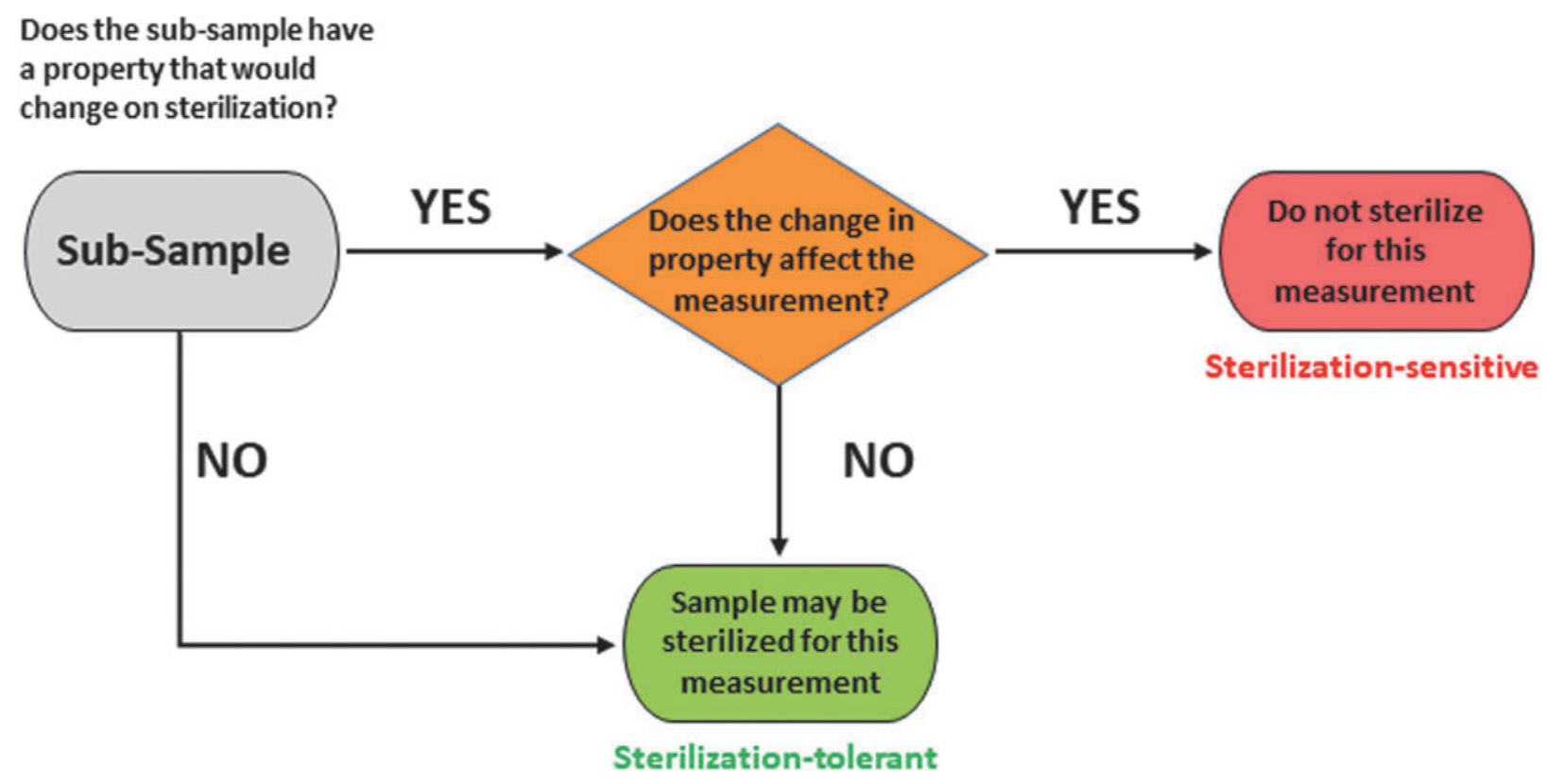

FIG. 1. Decision-making chart for whether the scientific usefulness of a subsample will be damaged for a specific measurement if sterilized. 
sterilization and the specific investigation requires measurement of the unmodified property to be scientifically useful, then the measurement is critically sterilization sensitive. For example, if a specific investigation required measurement of the original water content of a subsample, then a subsample sterilized by dry heat $180^{\circ} \mathrm{C}$ would be unsuitable for the required measurement because the sterilization process drives off water; the subsample, the measurement, and the investigation would be critically sterilization sensitive.

- In contrast, if the sample has a property that would be modified by sterilization (is sterilization sensitive) but the specific investigation requires measurement of some other property that would not be modified by sterilization, then the measurement's target property can be usefully measured even on a sterilized subsample; such a measurement is sterilization tolerant. For example, if a specific investigation required measurement of the $\mathrm{Nd}$ and $\mathrm{Sm}$ isotopic compositions of a subsample, then a subsample sterilized by dry heat $180^{\circ} \mathrm{C}$ would be suitable for the required measurement because $\mathrm{Nd}$ and $\mathrm{Sm}$ isotopic compositions are unaffected by dry heat sterilization at $180^{\circ} \mathrm{C}$; the subsample, the measurement, and the investigation would be sterilization tolerant.

- If a subsample lacks any property that would be modified by sterilization, then no science measurement would be affected by sterilization, and any measurement would be sterilization tolerant.

Clearly, it is not sufficient to characterize a sample as sterilization sensitive or sterilization tolerant without explicit and specific consideration of the property that is to be measured. It is, therefore, necessary to consider the effect of using a sterilized vs. unsterilized subsample for each specific type of measurement. Figure 1 summarizes a decision chart for determining whether the scientific usefulness of a subsample will be damaged for a specific measurement if sterilized.

\subsection{Science goals}

The science goals of a Mars Sample Return campaign have been discussed many times over past decades. Many of the resulting reports can be found on the Mars Exploration Program Analysis Group (MEPAG) website (https:// mepag.jpl.nasa.gov). Most recently, the International MSR Objectives and Samples Team (iMOST) prepared a comprehensive set of objectives supported by a detailed list of investigation strategies to address the objectives (Beaty et al., 2019); the report was compiled and published prior to selection of Jezero Crater as the landing site for the M2020 mission. Table 1 is an abbreviated version of the objectives. In the original table, Objective 1 had 5 sub-objectives that related to different, specific geological environments (sedimentary, hydrothermal, magmatic, etc.). Nearly two dozen unique sample types and sample-suites were identified for investigation under Objective 1. These sub-objectives may be updated and sample suites and associated investigation strategies modified now that Jezero Crater is known to be the site from which material will be collected.

All investigation strategies associated with Objective 2 seek the organic matter (OM)-bearing subsets of sample types identified for Objective 1. (There is also some overlap with samples and sample suites sought for Objectives 3-7). The M2020 mission team will select samples for collection and caching with the iMOST Objectives in mind, although the decision about which samples would be retrieved (and the basis on which those decisions are made) has not yet been formulated. In this report, the iMOST report (Beaty et al., 2019) will be used as a starting point for identifying the types of measurements that could be adversely affected by sterilization. We consider four categories of material that are likely to be affected by sterilization: extant or extinct life, molecular prospective biosignatures, geological materials (including other-than-molecular prospective biosignatures), and gases/volatiles.

Table 1. The Proposed Objectives for MSR Campaign. See Beaty et al. (2019) for the full list.

\begin{tabular}{|c|c|}
\hline \multicolumn{2}{|l|}{ Proposed Objectives } \\
\hline $\begin{array}{l}\text { 1. Geological } \\
\text { environment(s) }\end{array}$ & $\begin{array}{l}\text { Interpret the primary geologic processes and history that formed the martian } \\
\text { geologic record, with an emphasis on the role of water. }\end{array}$ \\
\hline 2. Life & $\begin{array}{l}\text { Assess and interpret the potential biological history of Mars, including assaying } \\
\text { returned samples for the evidence of life. }\end{array}$ \\
\hline $\begin{array}{l}\text { 2.1. Carbon } \\
\text { chemistry }\end{array}$ & $\begin{array}{l}\text { Assess and characterize carbon, including possible organic and pre-biotic } \\
\text { chemistry. }\end{array}$ \\
\hline $\begin{array}{l}\text { 2.2.Ancient } \\
\text { biosignatures }\end{array}$ & $\begin{array}{l}\text { Assess for the presence of biosignatures of past life at sites that hosted habitable } \\
\text { environments and could have preserved any biosignatures. }\end{array}$ \\
\hline $\begin{array}{l}\text { 2.3.Modern } \\
\text { biosignatures }\end{array}$ & $\begin{array}{l}\text { Assess the possibility that any life forms detected are still alive or were recently } \\
\text { alive. }\end{array}$ \\
\hline 3. Geochronology & Determine the evolutionary timeline of Mars. \\
\hline 4. Volatiles & $\begin{array}{l}\text { Constrain the inventory of martian volatiles as a function of geologic time and } \\
\text { determine the ways in which these volatiles have interacted with Mars as a } \\
\text { geologic system. }\end{array}$ \\
\hline $\begin{array}{l}\text { 5. Planetary-scale } \\
\text { geology }\end{array}$ & $\begin{array}{l}\text { Reconstruct the history of Mars as a planet, elucidating those processes that have } \\
\text { affected the origin and modification of the crust, mantle, and core. }\end{array}$ \\
\hline $\begin{array}{l}\text { 6. Environmental } \\
\text { hazards }\end{array}$ & $\begin{array}{l}\text { Understand and quantify the potential martian environmental hazards to future } \\
\text { human exploration and the terrestrial biosphere. }\end{array}$ \\
\hline 7. ISRU & $\begin{array}{l}\text { Evaluate the type and distribution of in situ resources to support potential future } \\
\text { Mars Exploration. }\end{array}$ \\
\hline
\end{tabular}




\subsection{Key assumptions}

- Mars 2020 Science Requirements include constraints that sample temperatures will not exceed $60^{\circ} \mathrm{C}$ (required) or $40^{\circ} \mathrm{C}$ (desired) (Beaty et al., 2019, their Table A3.1). The maximum allowable temperature for the samples during transport to Earth is likely to be set at a maximum of $30^{\circ} \mathrm{C}$.

○ Compliance is assumed for all MSR functions prior to delivery of the samples to the SRF.

$\circ$ The SRF will be operated at temperatures also compliant with MSR Science Requirements (Tait et al., 2022).

- This report examines the effects of sterilization on samples and science measurements, including mainly, but not limited to, deleterious effects of temperatures associated with sterilization that would result from subsample exposure to temperatures that exceed MSR Science Requirements after receipt at the SRF.

- Invasive analyses or sample preparations modify some (usually physical) attributes of a subsample, including, but not limited to, changing or destroying spatial distributions and associations and patterns that are contexts for very small-scale, spatially resolved analytical observations. Destructive methods consume or destroy at least part, and often all, of the subsample as part of the measurement. Less invasive-destructive methods must precede more invasive-destructive methods (e.g., Kminek et al., 2014). Zolensky et al. (2008) described how increased levels of sample destructiveness determine the order in which analyses on a given sample are done.

- As defined above, a measurement of a specific sample property is defined as sterilization sensitive if the fidelity of that specific sample property to preserve or record evidence of processes or conditions on Mars (sample integrity) is lost upon sterilization. A specific measurement is sterilization tolerant if the sample property to be measured is unaffected by sterilization. Whether a sterilized sample is suitable for accurately making a given measurement depends on both the specific properties of the subsample and the specific measurement to be made.

- It is subsamples that would be considered for sterilization, not the entire contents of a returned sample tube.

- Sterilization modes to be employed in the SRF will be similar in lethality and chemical effects to the two notional sterilization methods this group was charged to consider.

- The atmosphere in each sterilization chamber in the SRF may be a vacuum or consist of isotopically wellcharacterized inert or noble gas.

\section{Sterilization Techniques}

Sterilization is a validated process used to render a sterilization product free from viable organisms, including viruses and spores (ISO 11139:2018, 3.277; U.S. Department of Health and Human Services et al., 2020). The effectiveness of a given sterilization process is validated by the population reduction of a specified bioindicator (e.g.,
World Health Organization (WHO), 2019). In industry standards, sterilization is associated with an accepted sterilization assurance level (SAL), which is the probability of a single viable microorganism occurring on an item after sterilization (ISO 11139:2018, 3.275). Inactivation is broader in scope and meaning; inactivation renders organisms non-viable and unable to grow and/or multiply, and includes biological molecules, structures, and entities that are capable of proliferation (i.e., prions, genomic transfer elements, and viruses) (ISO 11139:2018, 3.172; (U.S. Department of Health and Human Services et al., 2020). For discussions in this paper, the definition of sterilization and inactivation will be used interchangeably when considering whole organisms and complex biological molecules.

Sterilization of subsamples from habitable and potentially once-inhabited field sites is in many ways similar to sterilization of terrestrial soils, which are by definition habitable and inhabited. "The objective of soil sterilization is to destroy/eliminate microbial cells while, at the same time, not significantly altering the chemical and physical characteristics of the soil" (Wolf and Skipper, 1994, as stated in Trevors, 1996). Restated for relevance to MSR: The objective of sample sterilization is to destroy/eliminate the ability of microorganisms and complex biological molecules to function and replicate/reproduce while, at the same time, not significantly altering other investigation-relevant chemical and physical characteristics of the sample.

The most widely used sterilization methods inactivate key biological molecules by breaking chemical bonds (Rummel et al., 2002). There is a variety of sterilization techniques, which can be divided into either physical or chemical methods (Figure 2). For planetary protection purposes, this report focuses mainly on the physical sterilization techniques that have previously been identified as suitable for application to space hardware and to returned martian samples (e.g., Rummel et al., 2002; Frick et al., 2014; Leuko et al., 2017); the suitability of such techniques for environmental samples consisting of mixtures of multiple organic compounds and multiple minerals remains to be explored ( $c f$. complex results of Bank et al., 2008). This report considers mainly dry heat sterilization (Section 2.1) and $\gamma$-irradiation sterilization (Section 2.2). NASA and ESA PPOs provided notional sterilization methods and parameters for this study; therefore, we mainly consider the sterilization effects of (a) the application of dry heat under two temperature-time regimes $\left(180^{\circ} \mathrm{C}\right.$ for 3 hours; $250^{\circ} \mathrm{C}$ for $30 \mathrm{~min}$ ) and (b) gamma $(\gamma)$ irradiation (100 Mrad; $1 \mathrm{MGy}$ ) (G. Kminek, written communication, 9 July 2020). The two PPO-provided techniques are highly penetrative into bulk materials and act on organic compounds in slightly different ways, which may open pathways for tailored sterilization procedures. We examine how sterilization affects our ability to address the science goals of the MSR Campaign by discussing the impact these conditions would have on chemical bonds of organic molecules and solid geological materials and the integrity of sterilized samples for scientific analyses of the returned samples. Several alternatives are briefly explored for specific samples and measurement types. For example, one proposed alternative to the aforementioned physical means could be chemical sterilization, via $\mathrm{HCl}$ hydrolysis and inactivation of biopolymers, which is 


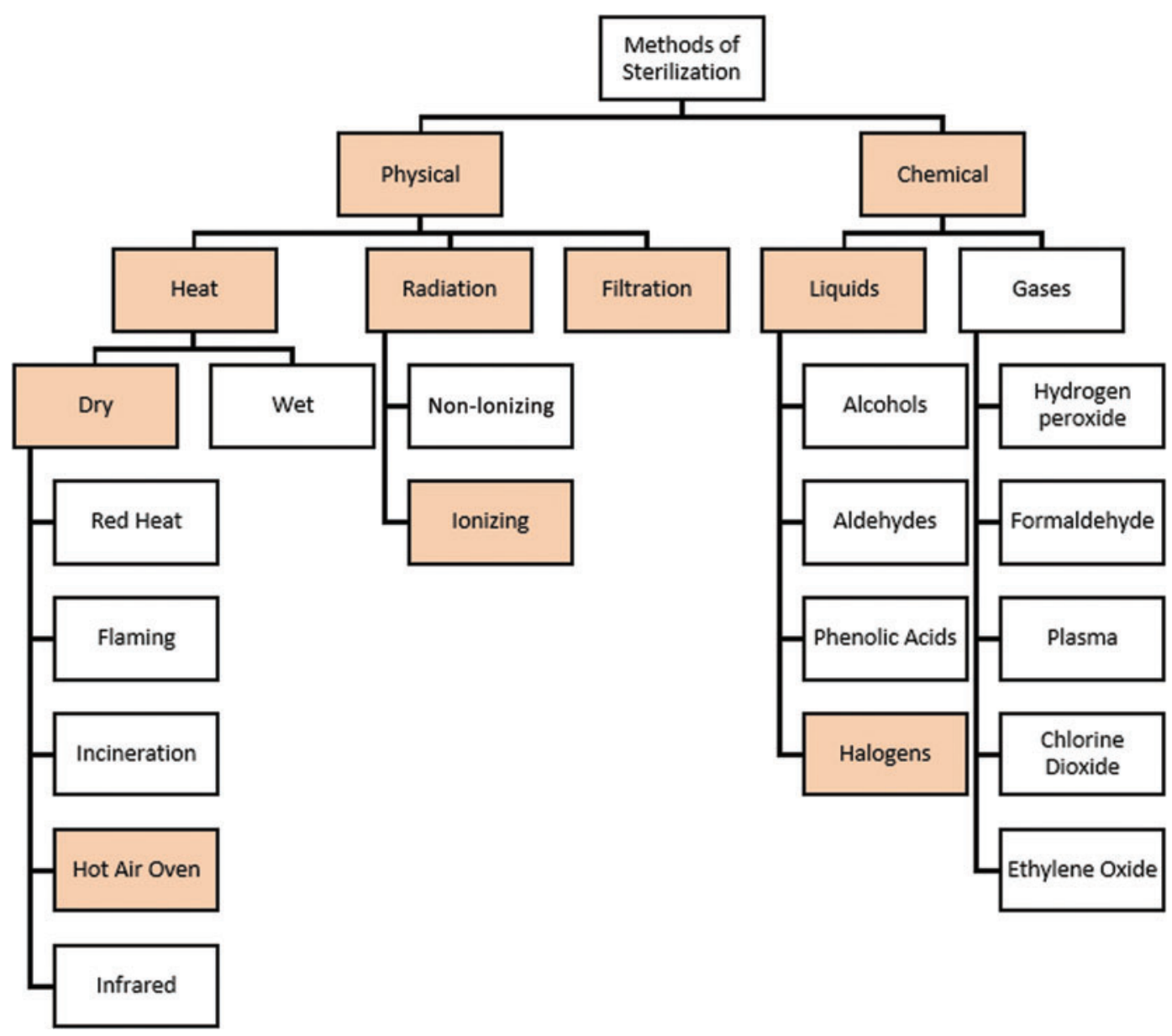

FIG. 2. A schematic overview of the most used methods for sterilization. Figure adapted from Leuko et al. (2017). Filled boxes are the methods referred to by Leuko et al. (2017) that are closest to the PPO-provided and promising alternative sterilization methods considered in this report. Two different notional (PPO-provided) temperature-time regimens of dry heat under vacuum or inert gas are considered here instead of the hot air oven. The specific ionizing radiation considered is that provided by the PPOs. The possibility of sterilization by solvent extraction and acid hydrolysis is related to the specific chemical halogen process considered. Filtration of gases is also considered.

discussed in Section 2.3. Gas filtration, which may prove useful for sterilizing gaseous samples, is discussed in Section 6.4 .

\subsection{Dry heat}

Investigations on the effects of high-temperature sterilization go back several decades. Much of the pioneering literature comes from the pre-molecular biology era when bacterial and soil physiology received considerable attention. Some of these papers remain reliable and inform present-day soil sterilization protocols. We note that the survival of microorganisms after high-temperature sterilization, as documented in older literature, is almost certainly conservatively low; improved culturing methods would be likely to reveal a larger number of organisms that survive, not fewer.

Heating material in the absence of water (dry heat) is an appropriate sterilization technique for non-aqueous samples that are thermally stable (Clark, 2004). Dry heat sterilizes materials by causing denaturation of proteins and other macromolecules within the cell (Allwood and Rus- sell, 1970). In addition, the oxidation of molecules is another pathway to molecular destruction that leads to loss of viability.

Material (either sealed or temporarily closed for sterilization; WHO, 2019) is placed in an oven and heated at temperatures between $160-180^{\circ} \mathrm{C}$ for up to 3 hours. The higher the temperature, the shorter the required heating time. Samples that are more sensitive to higher temperature can still be sterilized by dry heat, but for a longer period of time at lower temperature. It is important that the relative humidity of the system is controlled, otherwise hydrolysis rather than oxidation might occur.

Our trade studies considered two dry heat sterilization regimens, one at $180^{\circ} \mathrm{C}$ for 3 hours (e.g., WHO, 2019), the other at $250^{\circ} \mathrm{C}$ for $30 \mathrm{~min}$, both agreed and provided by the NASA and ESA PPOs (G. Kminek, ESA PPO written communication, 9 July 2020). The atmosphere in the dry heat chamber was not specified. The sterilization that is typically used for Dry Heat Microbial Reduction (DHMR) for forward PP is usually done in vacuum, but DHMR can also be done in a laboratory ambient atmosphere. For the MSR Campaign and the SRF, obviously vacuum would be 
most preferable to avoid contamination, although sterilization in some isotopically well characterized inert gas is also possible. Gases such as $\mathrm{N}_{2}$ and $\mathrm{Ar}$ are commonly used where inert gases are required but could interfere with measurement of the martian isotope inventories of these elements in the returned samples ( $c f$. Swindle et al., 2021).

\section{2. $\operatorname{Gamma}(\gamma)$ irradiation}

For material that is sensitive to any elevated temperature, sterilization by irradiation is a more appropriate technique. The process through which sterilization is induced is ionization of molecules within the material. In living organisms, this leads to damage to DNA and an inability to replicate. The most common radiation method is the use of $\gamma$ rayshigh-energy, uncharged electromagnetic radiation produced from the decay of certain radioactive isotopes. The nuclear source most used for sterilization is ${ }^{60} \mathrm{Co}$. A dose of $\sim 25$ kGy (2.5 Mrad) kills most microorganisms (Simmons, 2012). The dose considered in this report is 1 MGy (100 Mrad), agreed and provided by the NASA and ESA PPOs (G. Kminek, written communication, 9 July 2020). This dose exceeds most doses previously reported from experimental studies of microbial radiation tolerance. Assuming a dose rate similar to that used by Allen et al. (1999), this irradiation dose could take between 3 and 20 days.

Radiation (non-ionizing and ionizing) has been shown to cause severe damage to microbial structures (vegetative and spore). However, some terrestrial microbes can withstand high doses of ionizing radiation. Deinococcus radiodurans is one of the most radiation resistant organisms. Cultures of this organism are still viable after exposure to 0.01 MGy (1 Mrad) of $\gamma$-radiation (Battista, 1997).

Ionizing radiation is a penetrating sterilization process that creates free hydrogen and hydroxyl radicals. These are reactive as reducing and oxidizing agents, changing the valence state of $\mathrm{Fe}$ and other transition metals (McNamara et al., 2003) and cleaving C-C bonds (Tuominen et al., 1994), depending on the source of radiation and exposure time. Ultimately, this exposure causes breakdown of macromolecules and less complex organic compounds; it is very damaging to nucleic acids. The survival of small molecules varies, depending on which molecules are present, sample mineralogy, water content, and temperature. Amino acid chirality is expected to be preserved following $\gamma$-irradiation, but significant degradation could still occur. Sample cooling during irradiation and sample dehydration prior to irradiation may slow down the oxidation of organic molecules.

\subsection{Alternative sterilization techniques}

If sterilization of samples by dry heat or $\gamma$-irradiation proves unsuitable or inappropriate, then it might be necessary to consider other sterilization protocols. The Terms of Reference of the COSPAR SSAP Working Group specifically excluded consideration of the sterilization $\operatorname{method}(\mathrm{s})$; the SSAP is only concerned with the sample-safety assessment (Kminek SSAP progress presentation to MSPG2 29 $\mathrm{Jan}$ 2021) and not with how to make the sample safe (in other words, the sterilization method(s), or parameters). With this in mind, the SSAP Working Group briefly discussed the issue of alternative sterilization modes and issued a finding as follows (Kminek, written communication, 26 ${ }^{\text {th }}$ Apr 2021):
"Not all chemical extraction processes for organic analysis are sterilising. Some might be sterilising, but this would need to be assessed on a case-by-case basis and after agreement on proper sterilisation criteria for extraterrestrial samples."

Approved sterilization methods for the MSR samples have yet to be determined. Other than customary sterilization processes might require independent testing to be considered for approval. This will take time, and it is not certain what types of sterilization process(es) would be accepted as sufficient for sterilizing samples from Mars (Kminek, written communication, 26 ${ }^{\text {th }}$ Apr 2021). Bearing this in mind, SE-FG discussions of several potential alternative sterilization methods are summarized below.

One such procedure could be to utilize an analytical technique that would be applied to the sample to obtain scientific data, which then leaves the remaining material sterile. For example, a variety of solvent extraction and acid hydrolysis techniques have been used to investigate the soluble organic composition of meteorites, lunar regolith, and other extraterrestrial materials (Figure 3; see Simkus et al., 2019 for a detailed review). Amino acids and other water-soluble organic molecules are extracted from the sample matrix by first heating powdered samples in ultrapure water at $100^{\circ} \mathrm{C}$ for $24 \mathrm{~h}$ in a sealed test tube. After cooling to room temperature, the tubes are centrifuged or filtered to separate out the water extract from solid particles. The supernatant water is removed, transferred to another test tube, and dried down separately under vacuum. The residue from the water extract is hydrolyzed in $6 \mathrm{M} \mathrm{HCl}$ at $100^{\circ} \mathrm{C}$ for $24 \mathrm{~h}$. Acid hydrolysis breaks peptide bonds releasing free amino acids and inactivating any amino acid biopolymers present in the sample extract (Tsugita and Scheffler, 1982). This technique has been shown to efficiently extract and hydrolyze proteins in $E$. coli cells, marine sediments, and Pleistocene fossil mollusk shells (Glavin and Bada, 1998; Glavin and Bada, 2001). Analysis of amino acid standards taken through the identical extraction procedures show no evidence of significant thermal decomposition, racemization, or isotopic fractionation of the amino acids (Glavin et al., 2010). Formic acid is also commonly used to extract and isolate free purines from bacterial DNA and RNA by breaking the N-glycosidic bonds (May and Hattaman, 1975; Glavin et al., 2002; 2004). Appel et al. (2006) demonstrated in experiments that acid hydrolysis and complete inactivation of prions could be achieved after heating in $1 \mathrm{M} \mathrm{HCl}$ at $\geq 85^{\circ} \mathrm{C}$ for 1 hour. Thus, the proposed sample preparation sequence of solvent extraction followed by acid hydrolysis in $6 \mathrm{M} \mathrm{HCl}$ at $100^{\circ} \mathrm{C}$ for $24 \mathrm{~h}$, which converts bound organic polymers into free organic molecules, could inactivate any biopolymers in the sample extract, rendering it sterile. Further study would be needed to demonstrate the efficacy of alternative sterilization procedures.

Microwave-assisted hot acid extraction in $\mathrm{HCl}$, formic acid, and acetic acid has also been used for spore lysis and extraction of acid-soluble proteins for the sequencing of small peptides using MALDI-MS techniques (Swatkoski et al., 2006; Chen et al., 2019). Although these microwaveassisted acid extraction methods were not designed for complete acid digestion and hydrolysis of spore proteins to free amino acids (heating times were only $\sim 1-15$ minutes), extraction in $6 \mathrm{M} \mathrm{HCl}$ at $100^{\circ} \mathrm{C}$ for $24 \mathrm{~h}$ would lead to complete protein hydrolysis and biopolymer inactivation. 


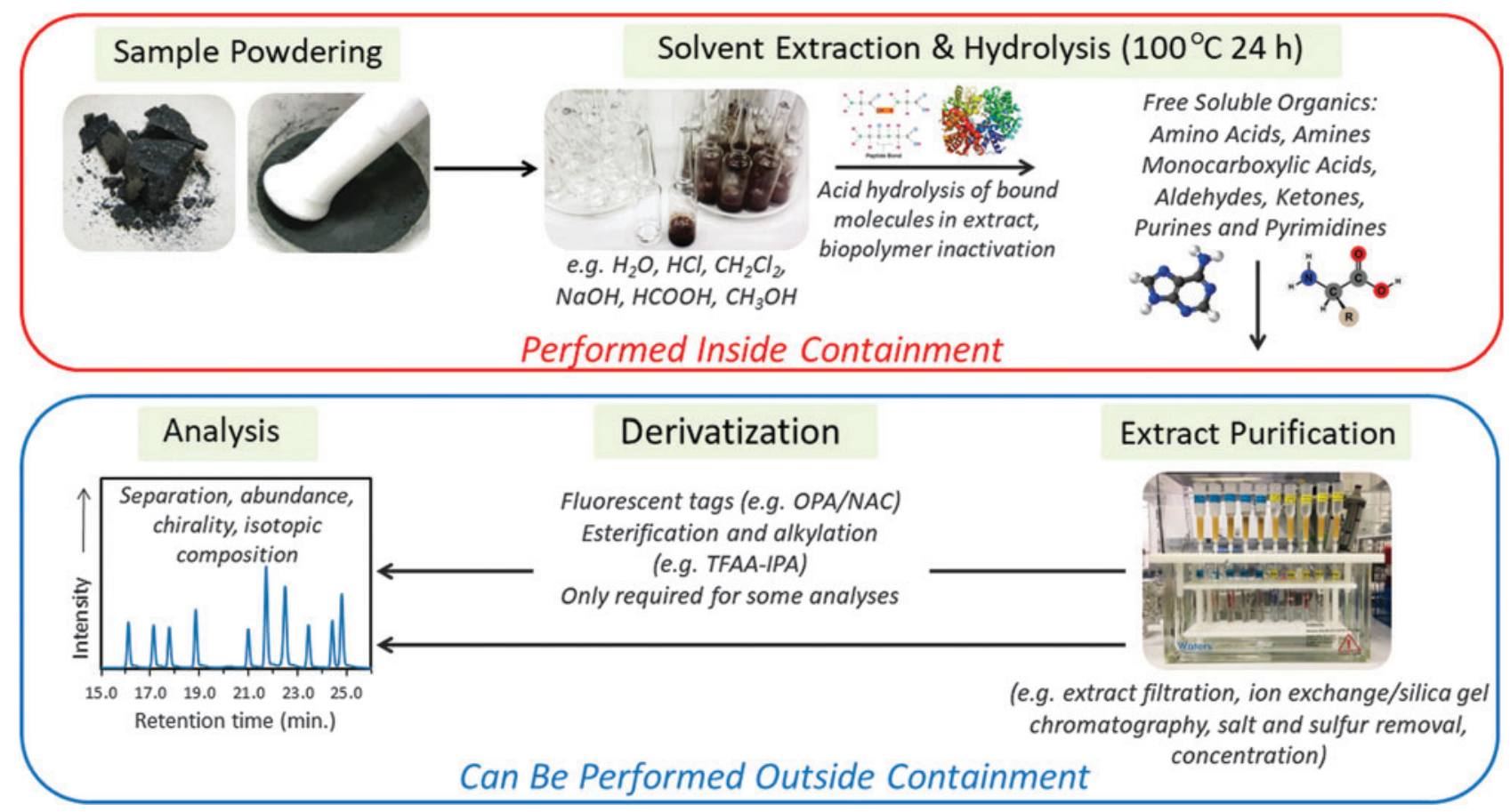

FIG. 3. Schematic illustrating standard protocols used for extracting and analyzing soluble organic compounds in extraterrestrial materials. Hydrolysis of unsterilized sample extracts must be performed inside containment (red box), while additional extract purification and other chemical processing steps required for the analysis of free molecules can be performed outside containment (blue box). Figure modified from Simkus et al. (2019).

Direct heating of bulk samples in acid should be avoided to preserve carbonates, clays, and other minerals that are susceptible to degradation or alteration by acid exposure. Acid hydrolysis should only be performed on water or organic solvent extracts of the bulk sample or mineral separates. Preliminary scanning electron microscope (SEM) and X-ray diffraction (XRD) analyses of a carbonaceous meteorite after exposure to water at $100^{\circ} \mathrm{C}$ for $24 \mathrm{~h}$ have shown no evidence for significant alteration of the minerals during extraction (Burton et al., 2018). Additional experiments to understand the impact of hot water extraction on the sample mineralogy of other meteorites are in progress (A. Burton, personal communication to D. Glavin on 9/29/20). Future work should also be performed to constrain the effects of the water extraction procedure on isotopic exchange with clay minerals.

There are other sterilization modes that are theoretically possible, but do not provide effective sterilization like $\gamma$ irradiation or heat treatment. For example, ultraviolet (UV)$\mathrm{C}$ radiation is routinely used for sterilization of surfaces in the medical and food context (Kowalski, 2009). Although UV-C might be used to sterilize surfaces within the SRF, UV radiation is non-penetrative and therefore ineffective at sterilizing the interior volumes or shaded areas of samples (Kerny and Schuerger, 2011). UV-C radiation could cause the production of oxychlorine species and the subsequent oxidation of amino acids without effectively sterilizing the sample (Liu et al., 2021). Consequently, UV radiation would not be applicable to subsample sterilization.

Other procedures during sample analysis may result in localized sterilization of the sample. For example, FIB (Focused-Ion Beam) retrieval of a subsample would probably sterilize the subsample at the point of interaction of the ion beam, particularly if the ion beam slices cellular material. The disruptive effect of the beam energy is likely to cause loss of integrity of cell membranes and other biomolecules. However, the vacuum within which the subsample FIB procedure takes place is not inherently sterilizing to many organisms, and so the part of the subsample not exposed to the direct effects of the ion beam would not be sterilized.

As discussed in Section 6.4, sterilization of gas evolved from a sample by filtration to remove particles above a specific size range and any biomolecules associated with those particles would also be possible.

\subsection{Lethal processes, collateral damage, and criteria for choosing a sterilization method}

The killing mechanisms apparently shared across different sterilization methods are most generally charactered as deactivating replication-reproduction molecules and disrupting cell membranes (see also Sections 2.1 and 2.2). The WHO characterizes effects of sterilization methods as follows:

Heating in an autoclave (steam sterilization): Exposure of microorganisms to saturated steam under pressure in an autoclave achieves their destruction by the irreversible denaturation of enzymes and structural proteins. (Regarding proteins, see also Leuko et al., 2017, p. 6). However, the efficacy of steam autoclaving in destroying microorganisms is diminished in mixtures with other materials (as in regolith or soil). For example, it is known that certain microorganisms in soil can survive autoclaving (e.g., Nowak and Wronkowska, 1987).

Dry-heat sterilization: In dry-heat processes, the primary lethal process is considered to be oxidation of cell constituents (see also Leuko et al., 2017, p. 7). NASA Planetary 
Protection researchers have been working recently with industry leaders on heat sterilization of various biological indicators in various conditions that include vacuum controlled versus heated ambient chamber atmospheres, and these researchers found no statistical difference at higher temperatures (e.g., Kempf et al., 2008; Schubert and Beaudet, 2011). Oxidation is certainly a factor, but at these long-duration high heat temperatures in vacuum, researchers have observed more of the denaturation of fundamental macromolecules and the breaking of necessary chemical bonds, so the oxygen in ambient atmosphere-although widely used for much DHMR (see Section 2.1) - is not necessary to produce the desired microbial reduction.

Exposure to ionizing radiation: $\gamma$-radiation and electron beams are used to effect ionization of the molecules in organisms. Mutations are thus formed in the DNA, and these reactions disrupt replication.

The common theme appears to be breaking of certain presterilization chemical bonds (including strong C-C, C-O, $\mathrm{C}-\mathrm{N}$, and $\mathrm{C}-\mathrm{H}$ bonds of predominantly covalent character plus weaker hydrogen and van der Waals bonds) and formation of different bonds and compounds, which disable the pre-sterilization biological function of the pre-sterilization chemical compound. In the 2002 Draft Protocol, Rummel et al. stated that " ... bond breakage by heat or $\gamma$-radiation should be similar for Earth and Mars life-forms, and sterilization conditions for Earth microorganisms should eradicate organisms of similar size from Mars." (Rummel et al., 2002, p. 10).

Rummel et al. (2002) went on to state:

\begin{abstract}
"Whether we assume that life on Mars is based on the same building blocks as terrestrial life, or on other covalently bonded complex molecules, only two methods of sterilization are considered viable options at present-dry heat or gamma radiation, either alone or in combination. These methods will penetrate the sample and, therefore, provide the highest level of assurance that putative organisms will be destroyed. It is recognized that the application of heat, and in some cases gamma irradiation, will modify geological properties of the sample. Within reason, every effort should be made to develop and implement a method of sterilization that protects the scientific integrity of the sample." (p. 10-11).
\end{abstract}

More recently, conclusions from NASA's Sterilization Working Group (Craven et al., 2021), with input from sterilization experts across industry, government, and academia, indicated that terrestrial sterilization technologies should be extremely effective at inactivating all martian biology, because they likely share fundamental chemistries of chemical bonds. These proven modalities act by directly impacting chemical bonds in essential structures for life including nucleic acid, proteins, and lipid structures.

The main criteria for selecting between heat and $\gamma$ irradiation for sterilization appear to be the following:

(1) what else (besides the microorganisms) is in the object to be sterilized that is necessary to the intended purpose of the object; for MSR, the object is the sample, and its intended purpose is for one or more of its attributes to be analyzed for science; and

(2) how (for MSR) the sample attribute intended for measurement would be affected by the chosen sterilization method.
For example, the detrimental effects of heat sterilization on some medical instruments and materials of patient care items are well understood. Certain materials used in these instruments and items are heat-tolerant, but many are heatsensitive, requiring use of alternative sterilization methods (e.g., Rutala and Weber, 2016, 2019). Some (categories of) associated materials (that co-occur with the target microorganisms) are heat-sensitive, in the sense that they lose their necessary desired properties when subjected to heat sterilization. For example, Berejka and Kaluska (2008) tabulated the distortion and melt-transition temperatures of numerous plastic polymers used in freshly manufactured disposable medical products or their packaging. All the distortion temperatures and most of the melt transition temperatures fell below the temperature range of steam autoclaving, precluding heat as a sterilization method for these items. $\gamma$-irradiation is a common and widely used method for sterilizing heat-sensitive materials (Berejka and Kaluska, 2008) and pharmaceuticals (Ražem, 2008).

The effects of ionizing radiation for sterilization are likewise well understood in contexts of (1) sterilization of drugs and pharmaceuticals and minimizing collateral damage to their carrier compounds (e.g., Marciniec and Dettlaff, 2008; Ražem, 2008) and (2) radiation effects on containment casks for radioactive waste (e.g., Bouniol and Aspart, 1998; William et al., 2013; Reches, 2019). In the context of sterilization of microorganisms and inactivation of complex biochemical structures, ionizing radiation breaks chemical bonds and, specifically in organic-chemical compounds, damages DNA molecules, thereby interfering with cell replication-reproduction ("direct effect") (USNRC, 2012; Hammad, 2008). Ionizing radiation also induces radiolysis of water - the breaking of $\mathrm{H}-\mathrm{O}$ bonds in the abundant $\mathrm{H}_{2} \mathrm{O}$ of cells-yielding free radicals $\mathrm{H} \bullet$ and $\bullet \mathrm{OH}$ and, upon their recombination, $\mathrm{H}_{2} \mathrm{O}_{2}$ molecules, initiating oxidation reactions (UNNRC, 2012; Hammad, 2008; Marciniec and Dettlaff, 2008). "Ionizing radiation initiates ... radiolytic dissociation leading to the breaking up of different types of bonds, hydrolysis, deamination, deacetylation, decarboxylation, polymerization and isomerization" (Marciniec and Dettlaff, 2008, p. 201). Directly formed molecular, ionic, and free-radical products of radiolysis of unbound, physically bound, or chemically bound water, and products of their subsequent reactions and side reactions, include $\mathrm{H}_{2}, \mathrm{H}_{2} \mathrm{O}_{2}, \mathrm{H}^{+}$aq, $\mathrm{OH}_{\mathrm{aq}}^{-}, \mathrm{e}^{-}{ }_{\mathrm{aq}}, \mathrm{H}^{*}, \mathrm{OH}^{*}, \mathrm{O}^{2}, \mathrm{O}^{-}, \mathrm{O}^{2-}, \mathrm{HO}^{2}, \mathrm{HO}^{2-}$, and $\mathrm{O}_{2}$ (Bouniol and Aspart, 1998). Radiolysis of water-including structural molecular $\mathrm{H}_{2} \mathrm{O}$ and $\mathrm{OH}$ in minerals - creates many more opportunities for oxidation-reduction of coexisting mineralforming and life-supporting elements than the same radiation produces in anhydrous or otherwise volatile-poor materials.

\subsection{Refinement of investigation strategies by sterilization sensitivity}

The measurement types described for iMOST investigation strategies (Beaty et al., 2019) are useful as a broad, curated compilation of community perspective on Mars sample science. One of the outputs of the first MSPG was a report, Science in Containment (MSPG, 2019), which designated the $\sim 200$ iMOST Measurements associated with 57 Investigation Strategies as either sterilization-tolerant or sterilization-sensitive (Appendix D, MSPG 2019) with respect to sterilization by temperature and/or irradiation. The 
classification led to MSPG (2019) Finding \#4, that most of the measurements (>90\%) described by iMOST for MSRrelated science investigations "could probably be acceptably performed on sterilized samples." However, this Finding was not informed by either identification of specific sterilization-sensitive phases (e.g., minerals and noncrystalline solids) or specified sterilization parameters.

An important first stage of this work has been to look again at the designations given by MSPG to the $\sim 200$ iMOST Measurements (Beaty et al., 2019). This re-analysis was undertaken to support our efforts to define the minimum set of analytical needs for sterilization-sensitive measurements that the SRF should support. We have refined the designations on the basis of the following parameters and considerations:

- The occurrence of specific keywords in iMOST investigation strategies and their supporting measurements that implied sensitivity to sterilization in the attributes of the desired samples for each investigation strategy (e.g., alteration; carbonate; clay; evaporite; hydrated; hydrothermal; hydrous; phyllosilicate etc.)

- The specific sterilization parameters provided to MSPG2 by the NASA and ESA PPOs-the application of dry heat under two temperature-time regimes $\left(180^{\circ} \mathrm{C}\right.$ for 3 hours; $250^{\circ} \mathrm{C}$ for $30 \mathrm{~min}$ ) and $\gamma$-irradiation (at 100 Mrad; 1 MGy).

- iMOST Objective 1-Interpret the primary geologic processes and history that formed the martian geologic record, with an emphasis on the role of water-is subdivided by geological environments. The five (5) geological environment categories are sedimentary, hydrothermal, deep subsurface groundwater, subaerial, and igneous. For each, multiple investigation strategies, sample types, and measurement types are identified. Sixty-eight (68) distinct unique desired measurement types are identified for investigation strategies of paleoenvironments, paleohabitability, and potential biosignature preservation under iMOST Objective 1 (sub-objectives 1.1, 1.2, 1.3, and 1.4; nearly one-third of the total of 202 for the entire iMOST report; Beaty et al., 2019; Table 2). All 42 Objective 2 (Assess and interpret the potential biological history of Mars, including assaying returned samples for the evidence of life) measurement types seek the organic matter (OM)bearing subsets of the Objective 1 samples. A subset of Objective 3 about quantitative determination of the timeline of Mars surface-hydrosphere evolution constitutes another eight (8) Mars surface/near-surface measurement types (Table 2). Thus, more than half $(118 / 202$; Table 2$)$ of all iMOST measurements are in the areas of life history and paleoenvironment, paleohabitability, and potential biosignature preservation. Other objectives (1.5; the rest of 3 ; and 4, 5, 6, and 7) involve volatiles, igneous phenomena, Mars' interior, and preparation for future human exploration (Beaty et al., 2019).

Jezero Crater is the operating area for the primary mission of Mars 2020 rover Perseverance. The iMOST report with its wide-ranging list of scientific-community goals and objectives was completed months before the Jezero Crater landing site was recommended at the last M2020 landing- site selection workshop. Jezero Crater was selected soon thereafter. Herd et al. (2021) reported that the only iMOST objective Perseverance cannot achieve during its primary mission is sub-objective 1.3 (Understand the rocks and minerals representative of a deep subsurface groundwater environment), which must await access to deeply altered Noachian basement rock during Perseverance's extended mission. Consequently, the entire catalog of iMOST investigation strategies, sample types, and measurement types (Beaty et al., 2019) needs to be, and is, considered here.

- Many individual iMOST measurement types refer to and require measurements of multiple different sample attributes of a given sample, each by a different instrumental measurement type. Some sample attributes may be affected by sterilization and others not, even in the same subsample. Some attributes may be affected in some minerals but not in others in the same sample. Thus, there is no easy 1:1 mapping of a unique iMOST measurement to a single analytical instrument type for all attributes that need to be measured, and there is no easy 1:1 mapping for sterilization sensitivity of a given specimen attribute. In the updated sterilization sensitivity assessment of iMOST measurement types here, an iMOST measurement type was classified as sterilization sensitive if either PPO-provided sterilization method would affect at least one of the subsample attributes that needs to be measured for the corresponding iMOST investigation strategy.

The outcome of the re-assessment is shown in Table 2.

Table 2 results are the basis for significant findings for the analysis of samples returned from Mars:

FINDING SS-1: More than half of the measurements described by iMOST for investigation into the presence of (mostly molecular) biosignatures (iMOST Objectives 2.1, 2.2 and 2.3) in returned martian samples are sterilizationsensitive and therefore cannot be performed with acceptable analytical precision or sensitivity on subsamples sterilized either by heat or by $\gamma$-irradiation at the sterilization parameters supplied to MSPG2. That proportion rises to $86 \%$ of the measurements specific to the investigation of extant or recent life (iMOST Objective 2.3).*

A corollary of Finding SS-1 is that the other (up to almost) half of the measurements described by iMOST for investigation into the presence of (mainly molecular) biosignatures of ancient life (Objective 2.2) in returned martian samples are sterilization-tolerant.

*Note: The COSPAR-convened Working Group (Sample Safety Assessment Protocol WG; SSAP), working in parallel with MSPG2, is refining the protocols and processes necessary to satisfy planetary protection requirements. The scope of SSAP is broader than, but overlaps considerably with, the search for extant life, such that many of the observations and measurements made for SSAP will be the same as observations and measurements that would be made in a search for extant life. Tautologically, observations and measurements supporting detection and characterization of extant life (if any) and similar measurements of ancient biomolecules are all sterilization sensitive. 
Table 2. Classification of iMOST Investigation Strategies into Sterilization Categories.

\begin{tabular}{|c|c|c|c|c|c|}
\hline \multirow[t]{2}{*}{ Measurement Target } & \multirow[t]{2}{*}{$\begin{array}{c}\text { iMOST } \\
\text { Objective }\end{array}$} & \multirow[t]{2}{*}{$\begin{array}{c}\text { No. of } \\
\text { Measurements }^{\ddagger}\end{array}$} & \multicolumn{2}{|c|}{$\begin{array}{c}\text { No. of } \\
\text { Sterilization- } \\
\text { Sensitive } \\
\text { Measurements } \\
\end{array}$} & \multirow[t]{2}{*}{$\begin{array}{c}\text { Finding } \\
\text { Number (This } \\
\text { Study) }\end{array}$} \\
\hline & & & \# & $\%$ & \\
\hline \multicolumn{6}{|l|}{ Assessment by MSPG: ${ }^{*}$} \\
\hline & All & 202 & 65 & $32 \%$ & \\
\hline \multicolumn{6}{|l|}{ Refinement by SE-FG: ${ }^{\ddagger}$} \\
\hline Overarching & All & 202 & & & $1,2,15,16,17$ \\
\hline $\begin{array}{l}\text { Extant or recent life (mainly } \\
\text { molecular biosignatures) }\end{array}$ & 2.3 & 7 & 6 & $86 \%$ & $3,4,7$ \\
\hline $\begin{array}{l}\text { Carbon chemistry and ancient } \\
\text { life (mainly molecular } \\
\text { biosignatures) }\end{array}$ & 2.1 & 10 & 7 & $70 \%$ & $3,4,5,6,7,8$ \\
\hline $\begin{array}{l}\text { Ancient life (mainly } \\
\text { molecular biosignatures) }\end{array}$ & 2.2 & 25 & 12 & $48 \%$ & $5,6,7,8$ \\
\hline $\begin{array}{l}\text { Geological materials: } \\
\text { Habitability related: } \\
\text { (including physical, chemical, } \\
\text { isotopic, mineral potential } \\
\text { biosignatures) }\end{array}$ & $1.1-1.4$ & 68 & 28 & $41 \%$ & $9,10,11,13$ \\
\hline $\begin{array}{l}\text { Geological materials: } \\
\text { Quantitative timeline of Mars } \\
\text { including surface- } \\
\text { hydrosphere evolution }\end{array}$ & $\begin{array}{c}3 \mathrm{D}, 3 \mathrm{~F}, \\
3 \mathrm{G}\end{array}$ & 8 & 1 & $13 \%$ & 9,13 \\
\hline Geological materials: Igneous & 1.5 & 5 & 0 & $0 \%$ & 12 \\
\hline Gases (volatiles) & 4 & 19 & 9 & $47 \%$ & 14 \\
\hline $\begin{array}{l}\text { Geological materials: } \\
\text { Quantitative timeline of } \\
\text { geophysical evolution }\end{array}$ & $\begin{array}{l}3 \mathrm{~A}, 3 \mathrm{~B} \\
3 \mathrm{C}, 3 \mathrm{E}\end{array}$ & 7 & 0 & $0 \%$ & 12 \\
\hline $\begin{array}{l}\text { Planet-scale: Crust, mantle \& } \\
\text { core }\end{array}$ & 5 & 17 & 1 & $6 \%$ & 12 \\
\hline $\begin{array}{l}\text { Prepare for human } \\
\text { exploration: ISRU; } \\
\text { Environmental hazards }\end{array}$ & 6,7 & 36 & 6 & $17 \%$ & $3-11,13$ \\
\hline Search for life & 2 & 42 & 25 & $60 \%$ & \\
\hline Total excluding Biology & $1,3-7$ & 160 & 45 & $28 \%$ & \\
\hline Total including Biology & All & 202 & 70 & $35 \%$ & \\
\hline
\end{tabular}

${ }^{*}$ Tabulated as sensitive to either heat or $\gamma$-irradiation. *Includes both temperature and $\gamma$-irradiation.

From the "Total excluding biology" line of Table 2:

FINDING SS-2: Almost three quarters (115 out of 160; $72 \%$ ) of the measurements described by iMOST for science investigations not associated with Objective 2 but associated with Objectives concerning geological phenomena that include past interactions with the hydrosphere (Objectives 1 and 3) and the atmosphere (Objective 4) are sterilization-tolerant and therefore can (generally) be performed with acceptable analytical precision or sensitivity on subsamples sterilized either by heat or by $\gamma$-irradiation at the sterilization parameters supplied to MSPG2.

The assessment leading to Finding SS-2 and the corollary to Finding SS- 1 suggests that, for many ( $\sim 72 \%$ of) iMOST measurement types not associated with life-sciences $\mathrm{Ob}-$ jective 2, analyses of sterilized MSR samples may be performed in uncontained laboratories without a dependency on the results from SSAP testing for potential biohazards.
Combining these sterilization-tolerant ancient-life measurements with the many measurements supporting many other investigation strategies that are also sterilizationtolerant indicates that (100 total minus 35\% sterilization sensitive $=) 65 \%$ of the sum of all investigations including biology (last row of Table 2) can (probably) be performed with acceptable analytical precision or sensitivity on sterilized subsamples (i.e., are sterilization tolerant).

In this way, the $65 \%$ proportion in the last row of Table 2 combines Findings SS-1 and SS-2 to (1) supersede the ">90\%" estimate in Finding \#4 of the MSPG Science in Containment report (MSPG, 2019) and (2) support Finding \#6 of the MSPG Science in Containment report (MSPG, 2019). However, sterilization sensitivity dominates the measurements for potential biosignature preservation, the life sciences, and the geologic paleoenvironmental and habitability context of life-science observations.

\footnotetext{
MSPG2 endorses the previously proposed strategy of conducting as many measurements as possible outside the SRF, where the option exists.
} 
Sterilization sensitivity analysis as a contingency plan for SRF capabilities. An ideal situation for the MSR Campaign and the scientific community would be if returned samples are determined by SSAP to be safe, and no sample sterilization takes place - then all scientific researchers could work on unsterilized material in their own laboratories. However, the MSR Campaign must anticipate other possibilities, including a situation in which SSAP determines samples are not safe for release in an unsterilized condition. The Sterilization Effects analysis reported here is part of a technical framework for a plan that answers the question

"If any specific sample cannot be declared safe by means of the SSAP tests, and sample sterilization is the only way to enable scientific measurements outside the SRF, then how are sterilization-sensitive scientific measurements made?"

The answer to this question is important to the entire MSR Campaign. "The Mars Perseverance mission addresses highpriority science goals for Mars exploration, including key questions about the potential for life on Mars. The mission takes the next step by, not only seeking signs of habitable conditions on Mars in the ancient past, but also searching for signs of past microbial life itself" (https://www.nasa.gov/ perseverance/overview). This report shows that most of the sterilization-sensitive iMOST measurement types are among either the iMOST objectives for life detection and life characterization (half or more of the measurements for life-science sub-objectives are critically sterilization sensitive) or the iMOST objectives for inferring paleoenvironments, habitability, preservation of potential biosignatures, and the geologic context of life-science observations (nearly half of the measurements for sub-objectives involving geological environments, habitability, potential biosignature preservation, and gases/volatiles are critically sterilization sensitive) (Table 2; see Beaty et al., 2019 for the full lists of iMOST objectives, goals, investigations, and sample measurement types). Sterilization-sensitive science about ancient life on Mars and its relationship to its ancient environment will be severely impaired or lost if the samples collected by Perseverance cannot be analyzed in an unsterilized condition.

The following three Sections (3, 4, and 5) of the report describe in greater detail how sterilization affects the solid subsamples rendering them unsuitable for specific investigations (sterilization sensitive). A subsequent section (6) discusses gases and evolved volatiles. Implications for the SRF are then discussed (Section 7). One answer to the question posed above is explored in Section 7-to add contingency instruments to contained laboratories to the SRF specifically for sterilizationsensitive science that is not enabled by instruments present in the SRF to support Curation, SSAP, and time-sensitive science (Carrier et al., 2022; Tait et al., 2022; Tosca et al., 2022).

\section{Sterilization-Sensitive Science I: Extant or Recent Life}

\subsection{Background}

A high priority of the Mars Sample Return program is to establish whether life on Mars exists or existed where and when allowed by paleoenvironmental conditions. One of the main problems that immediately arises is that it is difficult to find a completely encompassing definition for life on Earth, let alone for life on Mars. The features that we currently use to recognize a living system on Earth are that it: (i) formed mainly from carbon, hydrogen, nitrogen, oxygen, phosphorus, and sulfur (CHNOPS elements); (ii) requires liquid water; (iii) uses, transports or stores energy; (iv) has the ability to create and maintain a cellular system; (v) regulates and repairs its systems and (vi) undergoes adaptive evolution (National Research Council, 2007; Popa, 2014). But putative martian life need not have some of these characteristics manifested in the same way as Earth life. This is a serious issue for the investigations that would be undertaken to determine the presence, or otherwise, of life-forms in returned martian samples.

Since the characteristics of martian life are unknown, it is likely that several different sets of investigations would be required to recognize and validate its presence. As noted in the iMOST report (Beaty et al., 2019), some of the life detection analyses proposed for returned martian samples could be modeled on terrestrial methods for detecting and characterizing life in extreme environments on Earth (Figure 4). As Figure 4 indicates, many of the investigations are based on analysis of organic compounds, only some of which might be appropriate for identification of a martian organism. In the following sections, we consider whether, and how, these investigations would be affected if the returned samples were sterilized (either by dry heat or irradiation) prior to analysis.

\subsection{Sterilization by dry heat}

The effectiveness of dry heat sterilization on terrestrial soil samples has been studied for many years. Exposure at $160^{\circ} \mathrm{C}$ for three hours was insufficient to sterilize some soils (Labeda et al., 1975; Trevors, 1996) as was a longer heating time at lower temperature $\left(90^{\circ} \mathrm{C}\right.$ for $24 \mathrm{hrs}$; Wolf et al., 1989). Only temperatures greater than $200^{\circ} \mathrm{C}$ for a minimum of $24 \mathrm{~h}$ (Alef and Nannipleri, 1995) were proven effective. Based on these data, sterilization of martian soils under the given conditions $\left(180^{\circ} \mathrm{C}\right.$ for 3 hours; $250^{\circ} \mathrm{C}$ for $30 \mathrm{~min}$ ) may be unsuccessful, especially if any putative martian life were resistant to heat while desiccating. Terrestrial organisms that are resistant to desiccation are sometimes resistant to radiation damage; the resistance mechanisms, which include DNA repair, quenching of reactive oxygen states, etc. are thought to be effective to both desiccation and radiation (Mattimore and Battista, 1996; Daly et al., 2004). Dry heat sterilization at $180^{\circ} \mathrm{C}$ for 3 hours would probably leave many organic molecules intact for additional analysis; however, sterilization at $250^{\circ} \mathrm{C}$ for $30 \mathrm{~min}-$ utes would almost certainly result in significant destruction of macromolecules. Some monomers (e.g., amino acids) may survive, and amino acid chirality is likely to be preserved (Glavin and Bada, 2001). Dry heat degrades DNA (and accompanying secondary heat shock degrades proteins) at temperatures around $95^{\circ} \mathrm{C}$ (Mackey et al., 1991), a process that may be accelerated at higher temperature.

Notwithstanding the failure of dry heat to sterilize terrestrial soil samples, heating microorganisms can still cause considerable damage. Temperature can have profound effects on cellular physiology and morphology. As a sample is exposed to high temperatures, biological information is inevitably lost when the organisms cannot repair biomolecules or reproduce. High temperatures have been shown to cause severe damage to microbial structures (vegetative and sporulating), which could lead to cell death.

Most authors consider that microbial inactivation by heat is a multi-target phenomenon. For example, when Escherichia coli 


\section{Methods for detecting and differentiating between live, dead and dormant cells}

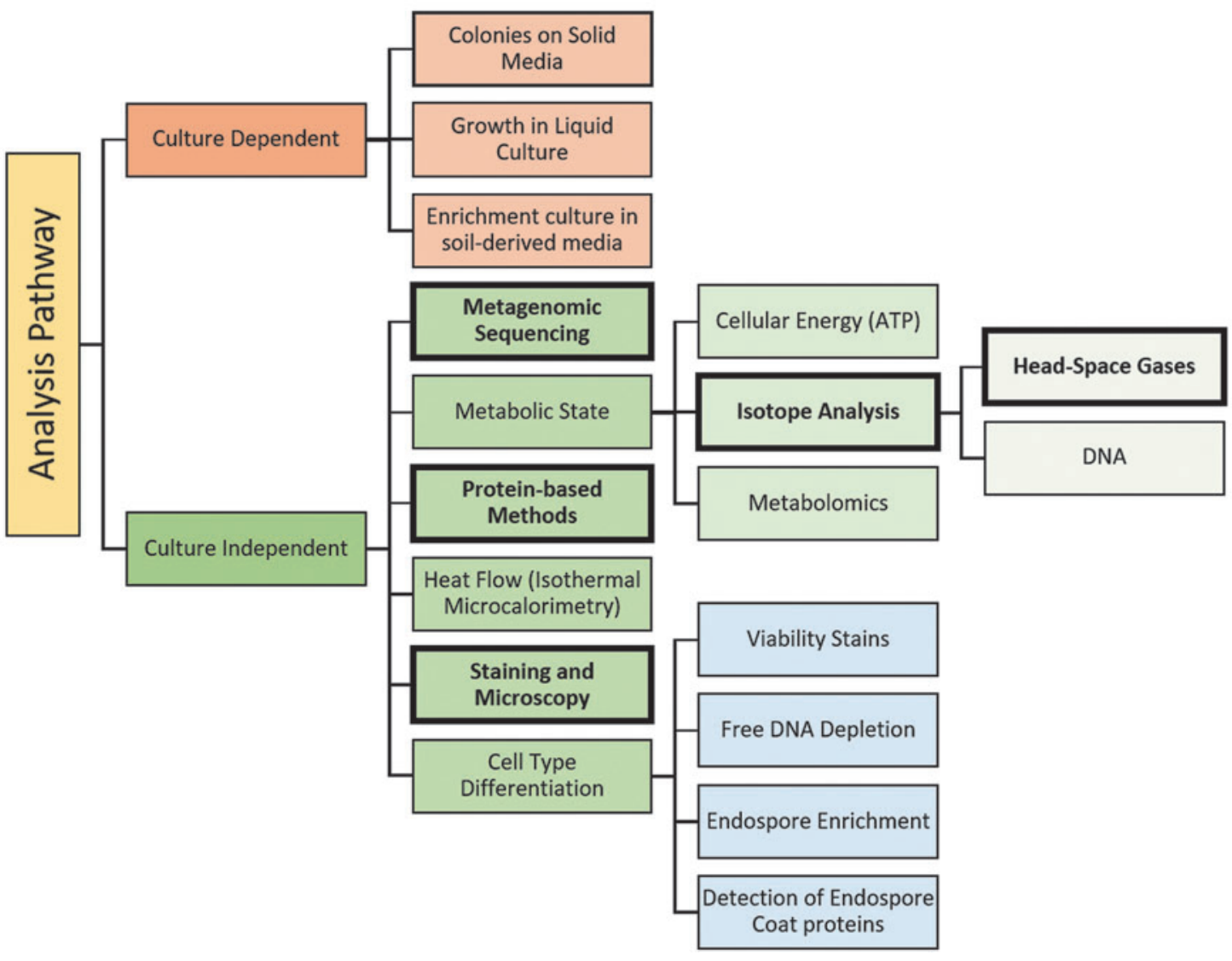

FIG. 4. Common methods for detecting and differentiating between live, dead, and dormant cells in terrestrial samples. The subset of methods outlined in bold are those which might be suitable for detection of putative martian life, assuming it has some of the characteristics of terrestrial life. Figure adapted from Beaty et al. (2019) and Emerson et al. (2017).

is exposed to $80^{\circ} \mathrm{C}$ for $15 \mathrm{~min}$, it experiences damage to cell walls and outer membranes, ribosome degradation, RNA and DNA damage, protein denaturation (possible coagulation of proteins), and enzyme inactivation (Russell, 2003). Although this organism is not an extremophile, it serves to illustrate the general point that, in the absence of microbial activity and repair, a range of generic biomolecules is destroyed.

Even the environmentally resistant spores of Bacillus species, when exposed to $160^{\circ} \mathrm{C}$ for $1-5 \mathrm{~min}$, exhibit deterioration of the spore coat, proteins and enzymes, cell membrane (leakage of dipicolinic acid; DPA), as well as DNA strand breakage and damage (Russell, 2003). It is also understood that heat inactivation is related to oxidative killing, which results from the formation of free radicals that are able to react with, and produce, irreversible damage to the spore polymers such as proteins and DNA (Marquis et al., 1994). Cellular damage to critical components (Cebrián et al., 2017) would lead to cell death if the component is indispensable for the self-maintenance and replication of the cell (Mackey and Mañas, 2008).

Early work by Rosenburg et al. (1971) suggests that there is a numerical temperature correlation between the thermodynamic parameters of protein denaturation and the observed death rates of various organisms, which explains the probable cause of cell death in mesophilic bacteria. A classic paper in this regard is that by White (1984). Although the paper was a refutation of the potential for the reproduction of life at $250^{\circ} \mathrm{C}$, it provides one of the few assessments and quantifications of half-lives of key biological molecules at this temperature. Peptide bonds were found to have half-lives of minutes (some such as the Glu-Ala bond less than a minute). Carbon-nitrogen bonds, for example in nucleic acid nucleobases, have half-lives up to $57 \mathrm{~min}$ (in thymine). These data show that at this temperature sterilization is effective because of the rapid degradation of all types of biological molecules.

FINDING SS-3: Suggested strategies for investigating the potential for extant life in returned martian samples lie in understanding biosignatures and, more importantly, the presence of nucleic acid structures (DNA/ RNA) and possible agnostic functionally similar information-bearing polymers. A crucial observation is that exposure of microorganisms to temperatures associated with sterilization above those typical of a habitable surface or subsurface environment results in a loss of biological information. If extant life is a target for subsample analysis, sterilization of material via dry heat would likely compromise any such analysis. 
There is an important fundamental problem regarding the loss of biological information through sterilization. Any presumed martian life may have a different biochemistry, or may utilize biomolecules with different physical and chemical properties. This would make it difficult to predict with confidence a priori how sterilization might degrade martian biomolecules. The rates and nature of degradation pathways could only be predicted once we understand martian biochemistry. This circular problem suggests that molecular degradation of any putative life must be avoided, at least in the first samples returned from Mars.

\subsection{Sterilization by gamma $(\gamma)$ irradiation}

The most common source of sterilizing radiation is $\gamma$ radiation from cobalt-60 $\left({ }^{60} \mathrm{Co}\right)$, which can damage DNA or other complex molecules critical for microbial reproduction. The 100 Mrad (1 MGy) dosage suggested for martian samples is an order of magnitude higher than $10 \mathrm{Mrad}(0.1$ MGy) values reported to kill many environmental microbes and fungi (Allen et al., 1999; McNamara et al., 2003) and even higher than the $2.5 \mathrm{Mrad}(25 \mathrm{kGy})$ suggested for sterilization of medical instruments (Simmons, 2012).

As with heat sterilization, there is a wide range of literature that documents substantial damage to important biological molecules, even in radiation-resistant cells. For example, Bacillus pumilus cells exposed to $1.3 \mathrm{Mrad}$ (13 kGy) show an impact on the spore coat, DNA strand breakage and damage (Borick and Fogarty, 1967), data that have been corroborated in more recent cellular studies (McNamara et al., 2003; Setlow, 2005). The radiation resistant organism Deinococcus radiodurans showed DNA and RNA damage at 9 Mrad (90 kGy) (Richmond et al., 1999).

However, molecular structure and even enzyme activity can be retained at radiation doses higher than those required to kill microorganisms. For example, Shih and Souza (1978) showed how urease and other enzymatic activity could be retained, although at a reduced level, after $\gamma$-radiation sterilization sufficient to kill cells in native Californian soils. UV and fluorescence spectroscopy have been used to show the change in structural characteristics of autoclaved $\left(121^{\circ} \mathrm{C}\right)$ and $\gamma$-sterilized soils (Berns et al., 2008). These studies show that, although biological information is retained after cell destruction, the reduction in enzymatic activity after sterilization supports the principle that radiation sterilization destroys biological information. Unfortunately, it is not clear how much information is lost-and this probably depends on assumptions about "martian" biology. Additional studies are required to determine how much biological information can be retained following different exposures to $\gamma$-irradiation.

FINDING SS-4: Suggested strategies for investigating the potential for extant life in returned martian samples lie in understanding biosignatures, including the presence of nucleic acid structures (DNA/RNA) and possible agnostic functionally similar information-bearing polymers. A crucial observation is that exposure of microorganisms to $\gamma$-radiation results in a loss of biological information through molecular damage and/or destruction. If extant life is a target for subsample analysis, sterilization of material via $\gamma$ - irradiation would likely compromise any such analysis.

\subsection{Conclusions}

The study of extant life requires the analysis of a variety of complex molecules such as proteins, lipids, and nucleic acids and the structures that they form. Some of the molecules are labile and almost all are prone to degradation by heat and/or irradiation, and hence, analyses must be undertaken on subsamples that have not been exposed to such conditions. The core rationale for this conclusion is simple: sterilization, by definition, is designed to destroy the viability of cells. No sterilization process could destroy the viability of cells while still retaining molecular structures completely intact. As a matter of biological principle, any sterilization process would result in the loss of biological information. Only one iMOST extant-life science measurement is $\gamma$-tolerant-microscopy of morphological biosignatures.

On the matter of alien biochemistries, we observe that the sterilization effects we discuss here are likely applicable to all complex chained biological macromolecules. These same principles would apply to an alien biochemistry constructed from organic molecules but with a completely novel architecture. This alien chemistry would still contain a range of carbon-carbon and carbon-heteroatom bonds, which we would expect to degrade under these sterilization conditions. (see also Section 4.1 and 7.4) We cannot speculate about the effects of sterilization on biochemistries that use entirely different elements but would note that the conditions we choose for sterilization and the energies associated with them are likely destructive to a variety of highly complex chained molecules. Nevertheless, it is the case that further work on the rate of degradation of a range of molecules and molecular structures in Mars-analog regolith and rocks under the proposed sterilizing conditions would be of value.

Unnecessary loss of information should be avoided. For amino acids, acid hydrolysis is a perfectly sound approach that has been used for decades to determine the total abundances, distribution, and enantiomeric ratios which are all preserved and can be used to establish their origin (abiotic or biotic). However, solvent extraction and acid hydrolysis can lead to degradation and loss of information for some organic compound classes. For example, recent studies have shown ancient terrestrial lipids isolated from clay pottery from the Late Pleistocene epoch, when using $\mathrm{HCl}$ extraction techniques, retained information on $\mathrm{C}$ and $\mathrm{N}$ content (Lucquin et al., 2016); however, the extraction technique still caused loss of biological information about molecules relative to analysis in their native state. Because of the overall value of the samples returned from Mars, it is critical not to lose any information during manipulation or aggressive sterilization and/or extraction methods; therefore, the entire sample extract may not be subjected to full acid hydrolysis, and a portion of the unhydrolyzed solvent extract can, and should, be retained inside containment for further analysis.

We note that the proposed capabilities for analysis that result from this conclusion (Section 7) focus on the detection of life, the priority of SSAP. We have also considered that if life is found, the SRF should have the capability to use or extend the suggested capabilities into detailed characterization of that life. 


\section{Sterilization-Sensitive Science II: Organic Molecular Biosignatures}

\subsection{Background}

The following definition of a biosignature is taken from the iMOST report (Beaty et al., 2019, p. S56-S57):

A biosignature (a definitive biosignature) is an object, substance and/or pattern whose origin specifically requires a biological agent (Des Marais, 2008; Mustard et al., 2013). One key example is complex organic molecules and/or structures whose formation and abundances relative to other compounds are virtually unachievable in the absence of life (e.g., Cronin and Walker, 2016). A potential biosignature is an object, substance and/or pattern that might have a biological origin and therefore compels investigators to gather more data before reaching a conclusion as to the presence or absence of life. The usefulness of a potential biosignature is therefore determined not only by the probability that life created it but also by the improbability that nonbiological processes produced it.

Figure 5 (taken from the iMOST report) illustrates the types of biosignatures that might be recognized in returned martian samples (see also sections 3.4 and 5.6). If hypothetical martian life was constructed differently from terrestrial life (i.e., based on chemistry different from terrestrial life- "agnostic" chemistry), we would still expect it to be made of carbon-based macromolecules enclosed within an organic membrane. Such molecular structures could be detected by the proposed mass spectrometry methods that have been identified for SSAP and the SRF
(Table 4). Thus, existing molecular analytical methods allow for an agnostic view on the details of molecular structure. In terms of entirely alien chemistries based on different elements (e.g., silicon), even here we would expect large molecular aggregates and chains that are characteristic of biological molecular complexity, and they could be seen by mass spectrometry methods. Furthermore, organic molecular biosignatures are only one of the six categories of potentially diagnostic biosignatures (Figure 5) for extant life, and five of the six (all except metabolic biochemical activity) apply to detection of past and ancient life. Consideration of agnostic biosignatures emphasizes four areas (https://www.agnosticbiosignatures.org/about)

(1) Molecular complexity-distributions and patterns of molecules and defines criteria for patterns that are unlikely to form abiotically;

(2) Molecular Complementarity—sequencing to explore sample complexity, specifically oligonucleotides;

(3) Chemical Fractionation-elemental and isotopic accumulation in compartments isolated from the surrounding environment as a potential biosignature; and

(4) Disequilibrium and Energy Transfer-disequilibrium redox (oxidation-reduction) chemistries that are inconsistent with abiotic redox reactions as an indicator of active metabolism.

Most of these are closely related to established categories of potential biosignatures (Figure 5). Data in many of these

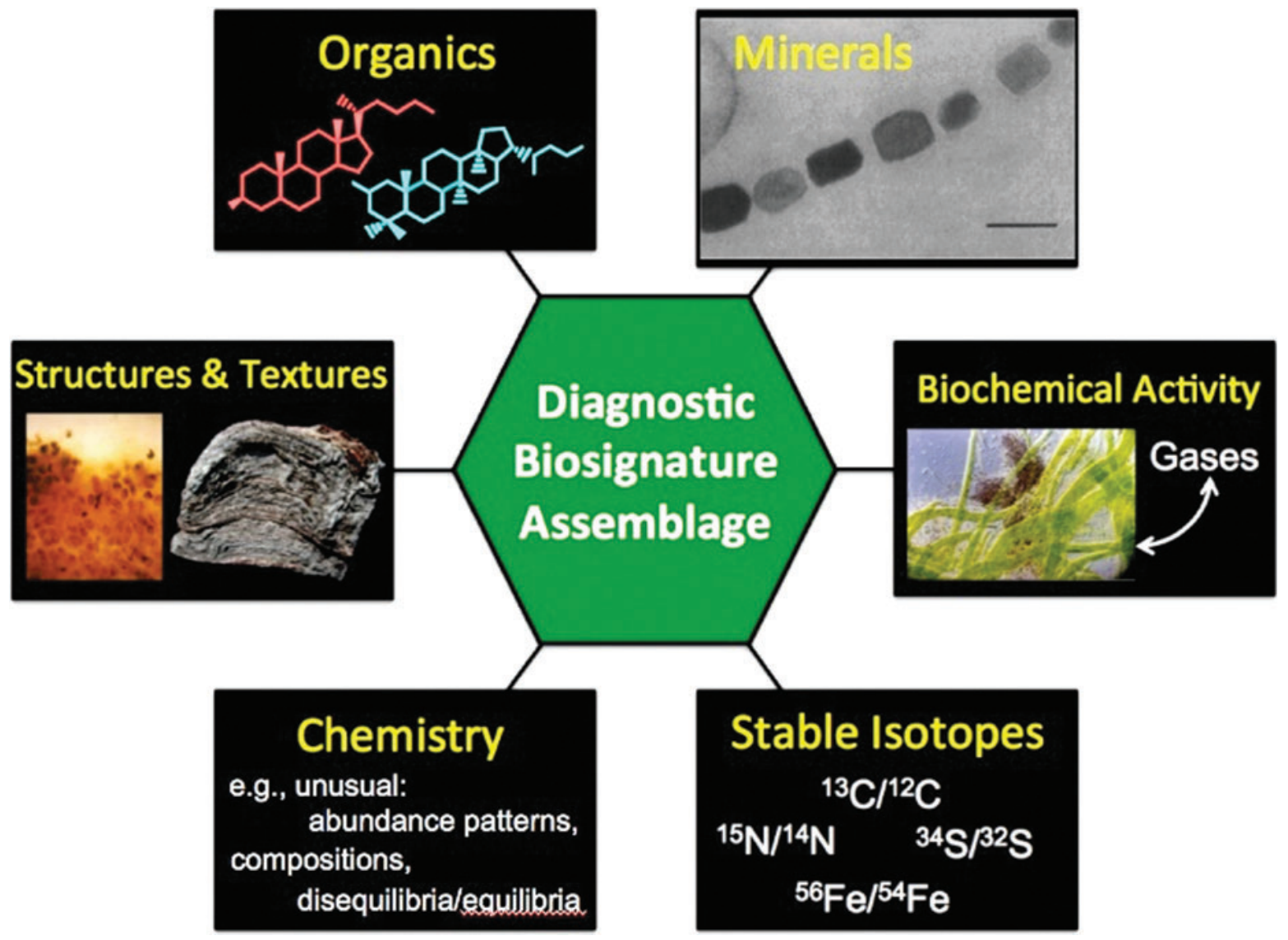

FIG. 5. Categories of biosignatures to be sought in suites of samples returned from Mars. This is Figure 2.5 from the iMOST report (Beaty et al., 2019). 
categories will be acquired by instruments that will be in the SRF to support SSAP and sample processing during curation (Tait et al., 2022). Some patterns and outliers in these measurements and observations will identify potential biosignatures for further investigation even if these potential biosignatures are based on different carbon chemistry than terrestrial life, or on other functionally similar informationbearing polymers (Rummel et al., 2002). In summary, all measurements we will be making as part of the martian organic molecular biosignature/life detection search and the criteria implemented are based on the characteristics of life as we know it on Earth and our current understanding of abiotic chemistry, but most would also detect "an object, substance, and/or pattern that might have a biological origin" (Beaty et al., 2019, p. S56-S57) even if based on a different chemistry of functionally similar information-bearing polymers.

The possibility that sterilization might affect a geological biosignature, manifest as a structure or a texture in a rock or as a specific mineral, is considered in the next section. Here, we consider the potential effects of sterilization on molecular biosignatures, and how sterilization might change organic compounds, their relative abundance patterns, and isotopic compositions. Many of the effects noted are consistent with the findings from the previous section; this should be expected because extant and extinct organisms are merely complex arrangements of biomolecules.

Organic biosignatures are carbon bearing compounds that can plausibly be linked to the presence of living or extinct organisms. These compounds can be relatively small, simple molecules (e.g., amino acids and short chain alkanes) that may be produced abiotically as well as biologically. Larger, more complex molecules, for example, peptides, proteins, DNA (deoxyribonucleic acid) and RNA (ribonucleic acid) are also biosignatures. On Earth, compounds associated with cell membranes such as lipids, sterols, and fatty acids, and their geologically stable reaction products (hopanes, steranes, etc.) are preserved in the geologic record for hundreds of millions of years (Peters et al., 2007). All these compounds are susceptible to alteration and/or destruction by elevated temperatures and/or $\gamma$-radiation.

The samples to be collected by Perseverance from Jezero Crater will be acquired from the surface with a Regolith Bit or taken as a core drilled from a rocky outcrop with a Coring Bit (Moeller et al., 2021). The cores will be a maximum length of around $6 \mathrm{~cm}$, with a design margin up to $7.6 \mathrm{~cm}$ (Moeller et al., 2021). The lack of a magnetic field on Mars means that samples in the martian near-surface are exposed to intense ionizing radiation from solar and galactic cosmic radiation that can penetrate up to $\sim 2$ meters depth and degrade organic matter over time (Figure 6). Galactic cosmic radiation (GCR) consists primarily of high energy protons and $\alpha$-particles and secondary neutrons produced in planetary atmospheres; however, $\gamma$-rays are produced as secondaries in the near-surface and $\gamma$-radiation is a significant contributor to the total accumulated radiation dose from GCRs (Hassler et al., 2014; Pavlov et al., 2012). The Mars Science Laboratory (MSL) Sample Analysis at Mars (SAM) measurements of the cosmic ray produced noble gases ${ }^{36} \mathrm{Ar}$,

${ }^{21} \mathrm{Ne}$, and ${ }^{3} \mathrm{He}$ released from the Cumberland mudstone samples collected from the upper $5 \mathrm{~cm}$ in Gale Crater yielded a surface exposure age of $78 \pm 30$ Ma (Ma stands for mega-anna, million years) (Farley et al., 2014). Similar measurements of the Mojave mudstone in Gale Crater yielded a cosmic ray exposure age range of $300 \mathrm{Ma}$ to $>1 \mathrm{Ga}$ (Martin et al., 2017; Cohen et al., 2019). Based on a

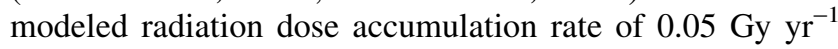

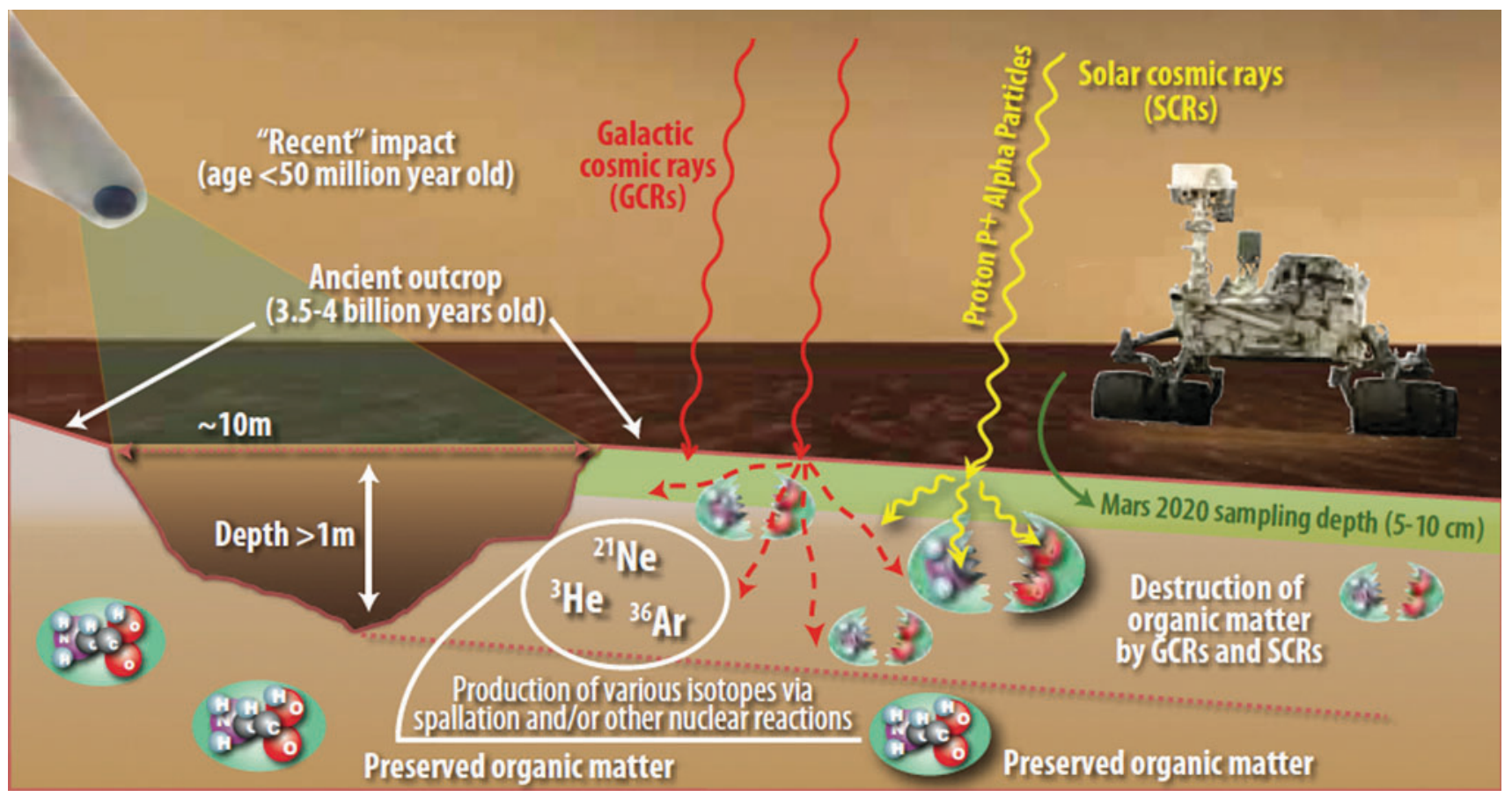

FIG. 6. Degradation of organic matter within the upper 1-2 meters on the martian surface will occur because of exposure to ionizing radiation from solar and galactic cosmic rays. The degradation of organics is strongly a function of time of exposure (see text) as well as depth. Differential erosion is a function of time, as shown in the figure by the ages of several surface features and the modern surface. Image credit: Jay Friedlander, NASA Goddard Space Flight Center. 
(Pavlov et al., 2012), a surface exposure age of $80 \mathrm{Ma}$ would correspond to a total $\gamma$-radiation exposure of $4 \mathrm{MGy}$. This is a higher radiation dose than the 1 MGy suggested as a sterilization protocol for the returned samples, and it should be noted that the radiation dosage would be minimally attenuated at the depths below the surface from which the core samples will be drilled.

Given the radiation exposure history of the martian nearsurface, it is possible that reduced organic molecules are present at trace abundances. Concentrations of reduced organics ranging from tens to hundreds of parts per billion ( $\mathrm{ppb}$ ) of chlorobenzene, thiophenes, and other volatile aliphatic and aromatic hydrocarbons of martian origin were measured by the SAM instrument after pyrolysis heating of several ancient mudstones in Gale Crater (Freissinet et al., 2015; Eigenbrode et al., 2018). Amino acids have not yet been identified in Sample Analysis at Mars (SAM) wet chemistry analyses of either scooped aeolian dune material or a drilled mudstone in Gale Crater (Millan et al., 2020); however, a few amino acids of possible martian origin (including glycine, $\beta$-alanine and $\gamma$ amino- $n$-butyric acid, with concentrations ranging from $\sim 7$ to $130 \mathrm{ppb}$ ) have been identified in acid-hydrolyzed, hot water extracts of the martian meteorite RBT 04262 (Callahan et al., 2013). The presence of these achiral, straight-chained, $n$ - $\omega$ amino acids may be due to high temperature Fischer-Tropschtype synthesis during igneous processing on Mars or during impact ejection from Mars. Higher abundances (ppm levels) of amino acids have been identified in the martian meteorites Allan Hills (ALH) 84001 and Nakhla (Bada et al., 1998; Glavin et al., 1999); however, their amino acid distributions and enantiomeric ratios closely matched those found in their landing site environments (Antarctica and Egypt, respectively) indicating significant terrestrial amino acid contamination. Callahan et al. (2013) were unable to identify any nucleobases in formic acid extracts of five different martian meteorites above the $1 \mathrm{ppb}$ analytical detection limit of the liquid chromatography-mass spectrometry instrument used. If any reduced organic molecules of biological interest such as amino acids, carboxylic acids, or nucleobases do occur in the returned samples, they could be present at very trace concentrations ( $\mathrm{ppb}$ levels or lower) and exposure to heat or $\gamma$-radiation could reduce their concentrations to undetectable levels.

\subsection{Sterilization by dry heat}

Exposing organic molecules to elevated temperatures for an extended period of time will cause the carbon bonds in the molecule to break and new, smaller molecules to be produced. This process is commonly called cracking, and the result is a set of molecules, such as $\mathrm{CO}_{2}$ and $\mathrm{O}_{2}$, that are no longer identifiable as biosignatures. The cracking process is kinetically controlled and dependent not only on the temperature the molecule experiences, but also on the length of time the molecule is exposed to this temperature. In general, larger molecules will decompose faster and at lower temperature than smaller molecules. Isolated RNA molecules can denature at temperatures as low as $20^{\circ} \mathrm{C}$, and free DNA can denature at $90^{\circ} \mathrm{C}$ (Wang et al., 2014). Individual nucleobases may be able to survive to temperatures as high as $200^{\circ} \mathrm{C}$ (Wang and You, 2015). However, neither DNA nor RNA is likely to survive dry heat sterilization intact. Similarly, although peptide bond stability can be enhanced in high temperature aqueous solutions (Shock, 1992), dry heat sterilization causes denaturation and oxidative damage to macromolecules. Some biomolecules may require increased temperatures or dwell times for inactivation through denaturation and bond cleavage. Ongoing MSR planetary protection efforts are investigating these effects.

Pyrolysis is the analytical process of heating a sample to a specific temperature for a specified amount of time to drive off volatiles, after which chemical and isotopic properties of both the (thermally altered) remaining sample and the evolved volatiles can be measured separately. Geologically stable molecules, such as hopanes and steranes, are stable in laboratory pyrolysis experiments to temperatures around $400^{\circ} \mathrm{C}$ (Wu and Geng, 2016) and would probably survive dry heat sterilization if analysis involving pyrolysis were regarded as equivalent to dry-heat sterilization for the same temperature and time. Likewise, amino acids are generally stable below $150^{\circ} \mathrm{C}$, and some may even survive at $250^{\circ} \mathrm{C}$ (Rodante et al., 1992). Laboratory experiments suggest that amino acids that survive dry heat sterilization will not undergo any further racemization (Glavin and Bada, 2001). The presence of oxidants (e.g., perchlorate, known to occur at the surface of Mars) in a sample can catalyze the destruction of organic compounds and effectively lower their temperature stability even further (Sutter et al., 2017).

Thermal models indicate that the near-surface materials in Jezero Crater did not experience temperatures significantly higher than $-20^{\circ} \mathrm{C}$ for outcrops and $+10^{\circ} \mathrm{C}$ for regolith in recent geological history (Beaty et al., 2016), although higher natural temperatures may have existed in past epochs. Heating of the sample tubes above these temperatures during, and after, collection could result in unavoidable chemical changes to the samples; MSR Campaign-Level Science Requirements for temperature are that sample temperature is not to exceed $60^{\circ} \mathrm{C}$ (Beaty et al., 2019), and the SRF temperature will easily satisfy this requirement (Tait et al., 2022). Detailed characterization of any organic matter in the returned samples, along with knowledge of their temperature history, will be critical to the search for, and identification of, biosignatures. The preservation of volatiles and organic matter in the sample will be strongly influenced by the temperature and duration of heat sterilization. At elevated temperatures, oxidation and degradation of labile organic compounds will increase with chemical reaction rates that roughly double for every $10^{\circ} \mathrm{C}$ increase in temperature (e.g., Korcek et al., 1972). Therefore, to minimize chemical alteration of the returned samples and maximize their scientific integrity, the temperature and duration of heating of the samples post-collection on Mars should be kept as low as possible. Refrigeration of subsamples in the SRF is recommended for samples with attributes (including extant or recently deceased microorganisms) that would deteriorate on short (minutes to months) timescales if maintained at laboratory ambient temperature (Tosca et al., 2022).

Evolved gas measurements (made by the Sample Analysis at Mars (SAM) instrument on the Curiosity rover) of scooped aeolian drift and drilled from near-surface sedimentary rocks collected in Gale Crater show evidence for the release of both $\mathrm{CO}_{2}$ and $\mathrm{CO}$ at temperatures above $150^{\circ} \mathrm{C}$ (Figure 7 , from Sutter et al., 2019). Many perchlorate and chlorate salts in the samples also readily decomposed at these temperatures (Sutter et al., 2017). These results suggest significant degradation of labile organic matter in the samples either by thermal 


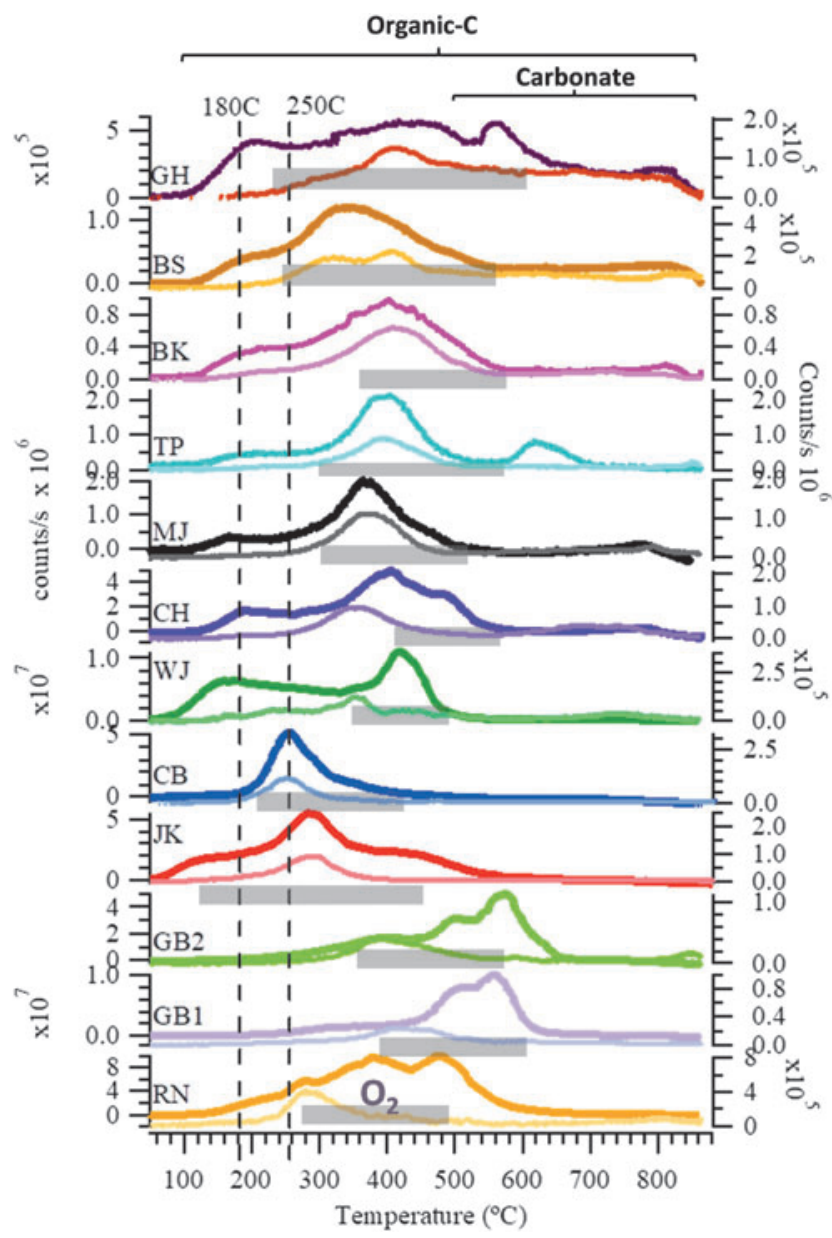

FIG. 7. Evolved gas profiles from the Sample Analysis at Mars (SAM) instrument, showing $\mathrm{CO}_{2}(\mathrm{~m} / z$ 44, top curves) and $\mathrm{CO}(\mathrm{m} / \mathrm{z}, 28$, bottom curves $)$ that result from the decomposition of organic matter and carbonate minerals during heating of scooped aeolian materials (Rocknest, RN and Gobabeb, GB) and several drilled sedimentary rocks (John Klein, JK; Cumberland, CB; Winjana, WJ; Confidence Hills, CH, Mojave, MJ; Telegraph Peak; TP, Buckskin, BK; Big Sky, BK; and Greenhorn, GH). The gray bars indicate the range of temperatures of $\mathrm{O}_{2}$ release from the decomposition of oxychlorine compounds. The dashed lines indicate the proposed dry heat sterilization temperatures. Figure modified from data from Sutter et al. (2017).

decarboxylation and decarbonylation or by combustion in the presence of $\mathrm{O}_{2}$ released from perchlorate decomposition (Sutter et al., 2017). $\mathrm{HCl}$ and $\mathrm{Cl}_{2}$ derived from perchlorate decomposition at temperatures above $150^{\circ} \mathrm{C}$ will also react with organics and produce chlorinated hydrocarbons such as chloroalkanes and chlorobenzene; these compounds have also been detected by SAM (Glavin et al., 2013; Ming et al., 2014; Freissinet et al., 2015). Therefore, alteration of the original chemical composition of the returned samples and associated volatile loss will occur during heat sterilization at $180^{\circ} \mathrm{C}$ or $250^{\circ} \mathrm{C}$ and should be avoided on samples to be used for any quantitative measurements of organics, oxychlorine compounds, or any other volatile species that could decompose or be released from the sample at these temperatures.

Oxalate and other oxidized organic salts have been predicted as common components of martian sedimentary rocks because of the highly oxidizing conditions of the martian surface (Benner et al., 2000). These oxidized organics could account for a significant fraction of the $\sim 250$ to $2,400 \mathrm{ppm} \mathrm{C}$ measured in sedimentary rocks at Gale Crater (Sutter et al., 2017). Fe(III) oxalate will decompose to $\mathrm{Fe}(\mathrm{II})$ oxalate releasing $\mathrm{CO}_{2}$ at temperatures above $\sim 200^{\circ} \mathrm{C}$ (Hermankova et al., 2010), and $\mathrm{Fe}(\mathrm{III})$ oxalate decomposition at temperatures as low as $160^{\circ} \mathrm{C}$ is possible if perchlorates are also present in the sample ( $\mathrm{J}$. Lewis, pers. comm. to D. Glavin on 7/15/20). Refractory organic matter, such as the kerogen-like macromolecular material in ancient Gale Crater lake sediments that evolved S-bearing organics and aromatic and aliphatic hydrocarbons at temperatures above $500^{\circ} \mathrm{C}$ (Eigenbrode et al., 2018), would probably be largely unaffected by dry heat sterilization at $180^{\circ} \mathrm{C}$ for $3 \mathrm{~h}$ or $250^{\circ} \mathrm{C}$ for $30 \mathrm{~min}$.

Organic compound classes of both prebiotic and biotic interest, including amino acids, purines and pyrimidines, sugars and carboxylic acids, are also very sensitive to alteration by heating. Amino acids will start to decompose by thermal decarboxylation in the solid state at temperatures above $150^{\circ} \mathrm{C}$ (Rodante, 1992). N-glycosidic bond fracture and amine group oxidation of purine nucleosides occur at temperatures $>200^{\circ} \mathrm{C}$ (Wang and You, 2015), and rapid $\lambda$-DNA strand breakage was observed at a temperature of $250^{\circ} \mathrm{C}$ (Glavin et al., 2002). Analysis of amino acids extracted from a Murchison meteorite residue after heating the meteorite in a tube furnace to a peak temperature of $220^{\circ} \mathrm{C}$ for $\sim 1$ minute showed that over $50 \%$ of the amino acids were destroyed during heating (Glavin and Bada, 2001). Although a previous Murchison heating experiment reported some amino acid racemization at temperatures above $150^{\circ} \mathrm{C}$ (Hochstein et al., 1974), no significant racemization of aspartic acid and alanine in the Murchison meteorite sample that had been heated to $220^{\circ} \mathrm{C}$ occurred (Glavin and Bada, 2001).

FINDING SS-5: Suggested strategies for investigating biomolecules in returned martian samples lie in detection of a variety of complex molecules, including peptides, proteins, DNA (deoxyribonucleic acid) and RNA (ribonucleic acid), as well as compounds associated with cell membranes such as lipids, sterols and fatty acids and their geologically stable reaction products (hopanes, steranes, etc.) and possible agnostic functionally similar information-bearing polymers. Exposure to temperatures above MSR Campaign-Level Requirements for sample temperature, up to and including sterilization temperatures, results in a loss of biological information. If the presence of biosignatures is a target for subsample analysis, sterilization of material via dry heat would likely compromise any such analysis.

\subsection{Sterilization by gamma $(\gamma)$ irradiation}

The effect of $\gamma$-irradiation on organic biosignatures is as destructive as heat. As described in Section 3.3, radiation will break molecular bonds and destroy biosignatures. Small molecules, such as amino acids, may survive $\gamma$ irradiation, but their survival will be dependent on the mineralogy and water content of the bulk sample in which they are hosted (see Figure 8 below and discussion thereof). More complex organic molecules will undergo a 


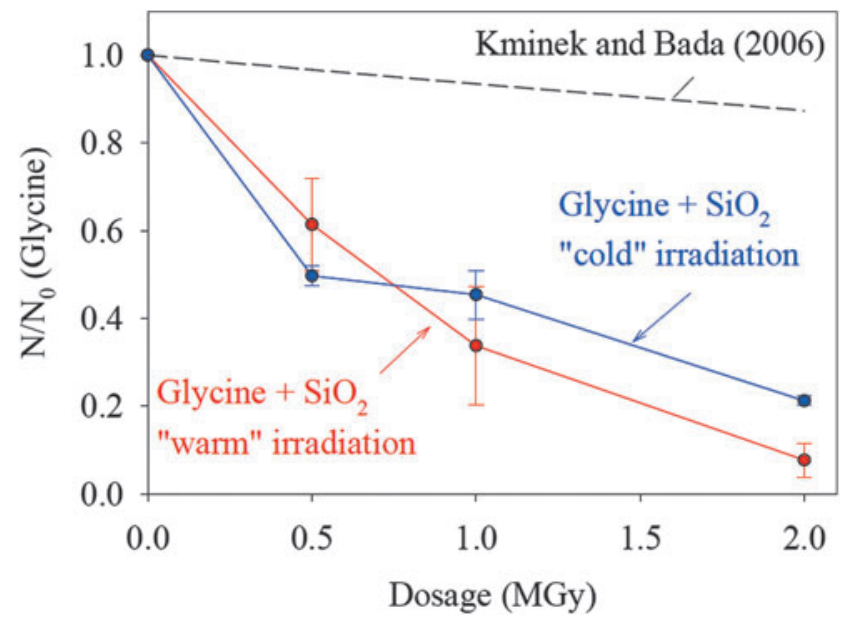

FIG. 8. Degradation of glycine by irradiation. The fraction of pure glycine standard remaining $\left(\mathrm{N} / \mathrm{N}_{\mathrm{o}}\right)$ decreases by $\sim 10 \%$ with increasing exposure to $\gamma$-radiation (up to $2 \mathrm{MGy}$ ) at room temperature (dashed line). In contrast, when mixed with fused silica, the fraction of glycine remaining drops to $\sim 40 \%$ after exposure to 1 MGy and $\sim 20 \%$ after 2 MGy radiation at both room temperature ("warm" irradiation; red line) and when cooled to $-55^{\circ} \mathrm{C}$ ("cold" irradiation; blue line) (Kminek and Bada, 2006). Figure modified from Kminek and Bada (2006) and Pavlov et al., (2014).

variety of dealkylation, cross-linking, and aromatization reactions, which would hinder scientists' abilities to detect biosignatures. In natural analogs on Earth, higher molecular weight organic molecules are degraded faster than lower molecular weight compounds (Wang et al., 2014). Enzymes, proteins, and peptides can survive $\gamma$-radiation doses as large as 0.5 MGy, but they experience significant amounts of alteration with increased radiation doses (Blanco et al., 2018). Exposure to radiation can also produce organic acids such as formate and oxalate from more complex organic material if clay minerals are present to act as catalysis sites (Fox et al., 2019).

Although the surface exposure ages of samples collected by Perseverance in Jezero Crater will not be known until the samples are returned to Earth for more detailed laboratory analyses, it is reasonable to assume that the samples will have already experienced tens of millions of years of cosmic radiation exposure prior to their collection (Section 4.1). Based on the radiolysis constants of pure amino acids from the work of Kminek and Bada (2006), Pavlov and colleagues (2012) suggested that organic molecules with masses $>300$ amu would be effectively destroyed in less than 300 million years in the top $5 \mathrm{~cm}$ of the martian surface, but smaller molecules with masses $<100$ amu could survive up to a billion years. However, to provide more accurate survival time estimates, additional experiments were conducted to determine the radiolysis constants of amino acids and other organic compounds mixed in Mars analog materials.

Gamma irradiation experiments conducted by using the ${ }^{60} \mathrm{Co}$ source at the NASA Goddard Space Flight Center (GSFC) to determine the radiolysis rates of amino acid mixtures in Mars analog materials and meteorites have shown that significant decomposition for some amino acids can occur after 1 MGy exposures (Pavlov et al., 2014). Although previous $\gamma$-radiation experiments have shown that less than $10 \%$ of dry solid glycine is destroyed after a 1 MGy exposure (Kminek and Bada, 2006), the radiolysis constants of pure glycine and other amino acids, when mixed with fused silica, are significantly larger with more than $60 \%$ of the amino acids destroyed after 1 MGy exposure (Figure 8). A similarly rapid decomposition of carboxylic acids in fused silica was also observed after exposure to $1 \mathrm{MGy} \gamma$-radiation (Pavlov et al., 2014). Complete destruction of all amino acids in the fused silica mixture after 1 MGy exposure was observed when $1 \mathrm{wt}$. $\%$ magnesium perchlorate or $10 \mathrm{wt}$. \% liquid water was added to the samples (A. Pavlov, pers. comm. to D. Glavin on 7/14/ 20); similar quantities of water could be evolved from hydrous minerals in the sample during sterilization (see below).

Gamma radiation exposure experiments conducted at $-50^{\circ} \mathrm{C}$ showed a slight reduction in the amino acid degradation rates at doses $>1$ MGy compared with the experiment at room temperature (Figure 8). The amino acid results from the $\gamma$-radiation experiments of the Murchison meteorite were much more complex than the experiments with pure amino acids (Kminek and Bada, 2006). After 1 MGy exposure, there was no significant decomposition observed for the lower molecular weight amino acids glycine and alanine, while more than $60 \%$ of the heavier amino acid isovaline was destroyed during the experiment. There was no evidence of significant racemization or carbon isotope fractionation of any of the amino acids in the Murchison meteorite after 1 MGy exposure. Similar $\gamma$-radiation experiments of the amino acid leucine that was spiked in pure clay mineral mixtures showed $\sim 50-80 \%$ degradation and only a few percent racemization after 1 MGy exposure (Bonner et al., 1985). Analysis of purine and uracil mixed with calcium carbonate showed a $10 \%$ loss of these organic compounds after a total $\gamma$-radiation dose of only 3 Gy (Ertem et al., 2017).

Ionizing radiation exposure can also degrade macromolecular organic matter. Laboratory studies found that irradiation of macromolecular organic material in natural samples led to dealkylation, cross-linking, radiolytic cleavage and oxidation, processes that result in an increase in aromaticity and oxygen containing compounds and enrichments in ${ }^{13} \mathrm{C}$ in the remaining organic material (Court et al., 2006; Schäfer et al., 2009; Yang et al., 2020). Another laboratory investigation showed that exposure of Archean kerogen to proton irradiation doses up to $0.5 \mathrm{MGy}$ (equivalent to $\sim 7 \mathrm{Ma}$ of cosmic ray exposure in the upper $5 \mathrm{~cm}$ of the martian surface) resulted in the generation of organic acid-radiolysis products, including acetate and oxalate (Fox et al., 2019).

Only a few iMOST life-science measurements are $\gamma$ tolerant - those of morphological biosignatures.

FINDING SS-6: Suggested strategies for investigating biomolecules in returned martian samples lie in detection of a variety of complex molecules, including peptides, proteins, DNA (deoxyribonucleic acid) and RNA (ribonucleic acid) as well as compounds associated with cell membranes such as lipids, sterols, and fatty acids and their geologically stable reaction products (hopanes, steranes, etc.) and possible agnostic functionally similar information-bearing polymers. Exposure to radiation results in a loss of biological information. If the presence of biosignatures is a target for subsample analysis, sterilization of material via $\gamma$-irradiation would likely compromise any such analysis. 


\subsection{Conclusions}

In summary, heat sterilization of returned martian samples at temperatures above $150^{\circ} \mathrm{C}$ will cause irreversible chemical reactions in the subsamples (as will any processes involving heating samples to temperatures far above levels they have previously experienced) that will lead to significant decomposition of labile organic matter and volatile loss. Although any organic matter present in the samples may have already experienced alteration from ionizing radiation when exposed on the surface of Mars, $\gamma$-radiation sterilization at 1 MGy doses will lead to additional degradation and oxidation of any labile or refractory organic matter present in the returned samples. Some studies have directly compared the effects of heat and $\gamma$-irradiation. Both ${ }^{60} \mathrm{Co}$ irradiation (35-36 kGy at two different combinations of dose rate and time) and repeated steam autoclaving $\left(121^{\circ} \mathrm{C}\right)$ significantly increased the quantity of dissolved organic matter (DOM) in aqueous phase extracts relative to untreated soil (Berns et al., 2008). Sterilization of returned samples by either dry heat or $\gamma$-irradiation would cause irretrievable loss of information about potential biomolecules. Both PPO-provided sterilization methods considered by MSPG2 will alter or destroy organic biosignatures in returned martian samples. In situ measurements on Mars suggest that organic biosignatures are likely to be present at very low concentrations. Any alteration or destruction of these compounds during sterilization may reduce the effective concentration below detectable levels. Therefore, we recommend that characterization and quantification of organic biosignatures take place on unsterilized subsamples.

This and the previous section have individually considered sterilization sensitivity of organic molecular biosignatures of both extant and extinct life to heat and $\gamma$ irradiation sterilization. Taken together (Table 2), the preceding Findings combine into one Major Finding about organic molecular biosignatures:

MAJOR FINDING SS-7: The use of heat or $\gamma$ irradiation sterilization should be avoided for subsamples intended to be used for organic biosignature investigations (for extinct or extant life). Studies of organic molecules from extinct or extant life (either indigenous or contaminants, viable or dead cells) or even some organic molecules derived from abiotic chemistry cannot credibly be done on subsamples that have been sterilized by any means. The concentrations of amino acids and other reduced organic biosignatures in the returned martian samples may also be so low that additional heat and/or $\gamma$-irradiation sterilization would reduce their concentrations to undetectable levels. It is a very high priority that these experiments be done on unsterilized subsamples inside containment.

Potential biosignatures of ancient life other than organic molecular biosignatures (Figure 5) are also damaged by both PPO-provided proposed sterilization methods in certain important sample types (Section 5.6).

A possible alternative to performing all the organic analyses inside the SRF would be to use sample preparation techniques that would render the subsamples sterile, allowing for some investigations to take place outside containment. For example, solvent extraction and acid hydrolysis techniques have been employed on a variety of natural and extraterrestrial samples, including martian meteorites (Glavin and Bada, 1998; Bada et al., 1998; Simkus et al., 2019 and references therein). Acid hydrolysis has been shown to be highly effective at converting polymers or other acid-labile bound compounds into free organic molecules (May and Hattaman, 1975; Tsugita and Scheffler, 1982; Glavin et al., 2001). If it can be confirmed that any biopolymers in the solvent extract would be inactivated by the acid hydrolysis procedure (Appel et al., 2006), additional processing and purification of the sterile extract and detailed compositional analyses of free soluble organic molecules using state of the art analytical instrumentation could then be performed outside of containment. Importantly, acid hydrolyzed solvent extracts are homogenous with respect to their soluble organic compositions and can therefore be split and sent to multiple outside laboratories for independent analyses. The analysis of the abundances, relative distributions, enantiomeric and isotopic compositions of organic compounds in the extracts would provide valuable information to help inform the biohazard assessments. Measurements of free organic molecules in the hydrolyzed extracts outside of containment could be part of the sample safety analysis protocol and would be complementary to the microbiological studies of biopolymers or other potential signatures of extant life in unsterilized samples that must be performed in containment. We recognize that the use of acid hydrolysis for the analysis of sample extracts outside of containment is contingent on regulatory approval of this type of sterilization method. $100^{\circ} \mathrm{C}$ for $24 \mathrm{~h}$ is the standard/traditional temperature used for solvent extraction and acid hydrolysis of soluble organic compounds from a variety of extraterrestrial and terrestrial samples, including martian meteorites (e.g., Bada et al., 1998; Glavin and Bada, 1998; Glavin et al., 1999; Callahan et al., 2013; Simkus et al., 2019). Higher extraction temperatures and/or longer heating durations can lead to additional undesirable decomposition or racemization of amino acids and other chiral compounds (e.g., Kaiser and Benner, 2005). Although other conditions could be used, it would be important to use similar extraction conditions that have been used previously to analyze soluble organics in meteorites and other extraterrestrial samples to enable direct comparison to published results. A temperature of $100^{\circ} \mathrm{C}$ for $24 \mathrm{~h}$ acid hydrolysis is also harsher than acid treatments previously used to inactivate prion peptides (Appel et al., 2006, see below), so the proposed hydrolysis conditions provide additional margin on sterilization of this potential biohazard. Future analysis should be done to investigate this extraction and acid hydrolysis approach in SRF containment.

FINDING SS-8: Solvent extraction and acid hydrolysis at $\sim 100^{\circ} \mathrm{C}$ of unsterilized martian samples will inactivate any biopolymers in the extract and would not require additional heat or radiation treatment for the subsamples to be rendered sterile. Hydrolyzed extracts should be safe for analysis of soluble free organic molecules outside containment and may provide useful information about their origin for biohazard assessments; this type of approach, if approved, is strongly preferred and endorsed. 
It should be noted that extraction procedures are most likely destructive for spatially resolved investigations (in situ spot analyses) of the organic material in the samples including the relationship of organic molecules to different specific minerals. Even if the organic molecules themself survive a particular sterilization method, bulk methods will generally not preserve the spatial distribution of the organic molecules within the sample.

The proposed use of solvents to extract organic molecules (as in Finding SS-8) does not contradict the conclusions reached in the justification for Finding SS-7. Ancient lipids and other refractory organics that are generally more robust to manipulation than molecules such as nucleic acids and proteins can be extracted by using solvent extraction methods (Finding SS-8) with minimum loss of information, which would allow for these approaches to be used to recover information during a process that would also sterilize part of the sample. Of course, there is no categorical distinction between a labile molecule and one that is not-there is a continuum. The point is that any form of sterilization is likely to result in a very great loss of biological information among the vast number of small and labile molecules that make up an extant cell (Finding SS-7), but solvent extraction can achieve the recovery of relatively refractory molecules with their important information on long extinct organisms (Finding SS-8). This leads to a conclusion that the study of extant or recently dead organisms should be carried out on unsterilized subsamples, but part of the subsample could be processed by solvent extraction in containment for analysis outside the SRF to obtain information on molecules such as geologically relatively stable lipids.

\section{Sterilization-Sensitive Science III: Geological Materials}

\subsection{Background}

Geological materials (minerals and rocks) contain and preserve evidence of paleoenvironments, habitability, and the geologic context of life-science observations, and are the host materials for the preservation of potential biosignatures. Solid planetary materials (rocks and regolith) throughout the Solar System consist mainly of silicate minerals and various ices. Minerals are identified by their properties, which are consequences of their chemical composition and crystallographic structure. The spatial distribution of minerals and their textures and association with other minerals reflect the processes and conditions by which the minerals were formed and modified. A rock is an assemblage of minerals; different types of rocks form and are modified at temperatures from as low as ambient surface temperatures up to $1400-1500^{\circ} \mathrm{C}$.

Primary rock-forming minerals are produced by igneous processes (magma genesis, migration, and solidification) and may be metamorphosed (recrystallized without melting) by heat and/or pressure. The primary minerals might react chemically with any fluid present in a hydrosphere and/or an atmosphere; the fluid might be liquid (with or without solutes) or gas. As the reactions proceed, some of the primary mineral species become depleted or even totally destroyed and new (secondary) minerals are produced. The composition of the fluid also changes as the original solutes are consumed and replaced by species dissolved from the minerals during the chemical reactions.
Mineral-fluid reactions follow the natural laws of thermodynamics (equilibrium, disequilibrium) and kinetics (metastable persistence and rates and mechanisms of reactions). The reactions, and the products they form, are controlled by the local conditions (temperature, pressure, and the composition of the solvent and solutes). Solutes may be transported away from the reaction site, but the secondary minerals and often some residual primary minerals persist. The local conditions at the time of the reaction can be inferred by thermodynamic and kinetic modeling of the mineral compositions, especially the secondary minerals. For the purposes of this report, we consider that the fluid that causes alteration on Mars is water.

If the mineral-fluid reactions occur at, or very near, the surface where the three reservoirs-rock, atmosphere and hydrosphere-interact directly, the phenomenon is referred to as weathering. The residual primary minerals and secondary minerals present in the solid residue (e.g., "soil") after weathering might be physically redistributed as grains by flow of water (including ice) and wind. As such grains are transported, and when they settle out from the fluid to form surficial deposits, they are referred to as sediment. Solutes that were added to the water by the weathering reactions may precipitate from the solution, forming chemical sediments (i.e., carbonate, sulfate, chloride minerals, etc.). Burial of physical and chemical sediments by additional sediment, compaction, and chemical reactions with fluids in the pores between the sediment grains result in lithification of unconsolidated sediment to produce a sedimentary rock. Diagenesis is the process of change of sediments to sedimentary rock that occurs at lower temperature and pressure than metamorphism. Mineral-water reactions that occur at any depth but under the influence of hot water (e.g., water heated by impact or nearby magma) result in hydrothermal alteration.

Life is known to exist on Earth over a range of temperature and pressure conditions; all life as we know it requires liquid water, so temperature and pressure conditions conducive to life are defined by the thermodynamic stability range of liquid water. There is ample evidence from orbiters, landers, and rovers that abundant sediments on Mars were deposited from flowing water (river, delta) and standing water (lake) that was present at the surface of Mars in previous eras. Ancient deposition of sediment by moving ice (glaciers) and wind (aeolian sediments) is also recognized. After deposition, sediments were buried, and chemical reactions between pore fluids and detrital minerals (chemical diagenesis) transformed unconsolidated sediment (sands, muds) into sedimentary rocks (sandstone, mudstone). After burial and lithification, these ancient sedimentary rocks on Mars were exhumed by erosion, enabling deposits from ancient sedimentary and diagenetic environments to be examined and sampled from the current surface of Mars.

A very wide range of secondary minerals may be produced by alteration; many of them contain $\mathrm{H}_{2} \mathrm{O}$ or $\mathrm{OH}$ in their crystal structures. Clay, sulfate, carbonate, and chloride minerals are products of weathering, chemical sedimentation, and diagenesis. There is abundant evidence from orbital remote sensing that clay minerals (most of which are phyllosilicates), the common products of rock-water reactions during igneous rock weathering, are widespread in ancient sedimentary rocks currently exposed on Mars' surface (Poulet et al., 2005; Bibring et al., 2005; Mustard et al., 


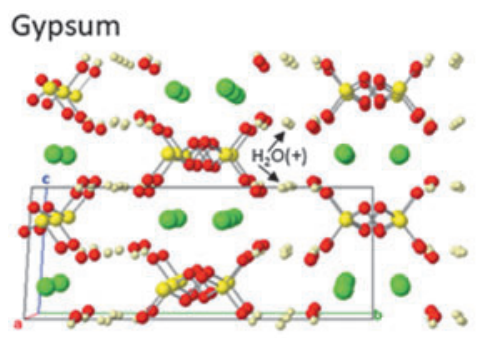

Anhydrite

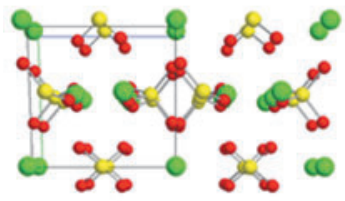

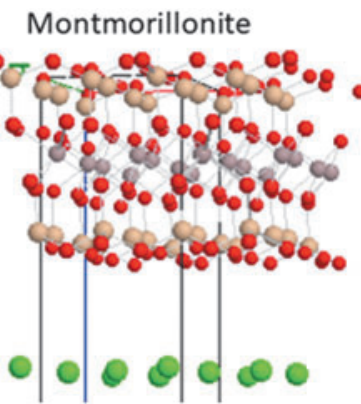

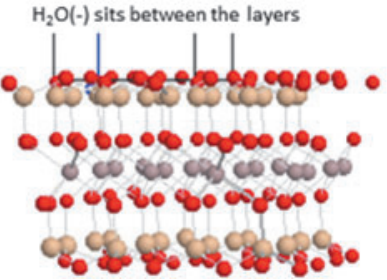

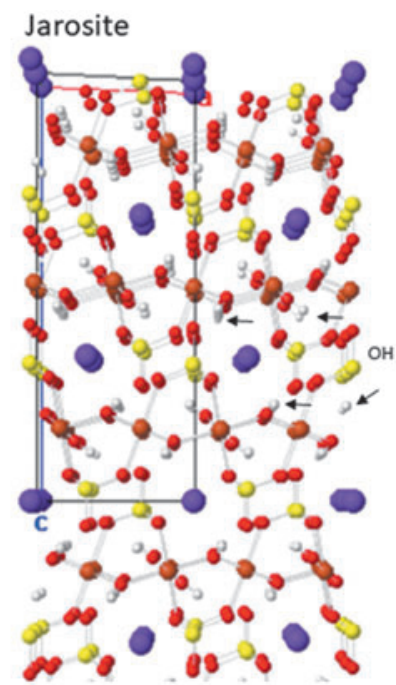

Calcium

- Sulfur

- Oxygen

Silicon (+ Al)

- Aluminium (+ Fe)

Potassium

- Iron

- Hydrogen

FIG. 9. Crystal structure diagrams of minerals that contain scientifically important oxidation-reduction (redox)-sensitive volatile elements $(\mathrm{O}, \mathrm{H}, \mathrm{S}, \mathrm{Fe})$ : gypsum $\left(\mathrm{CaSO}_{4} \cdot 2 \mathrm{H}_{2} \mathrm{O}\right)$, anhydrite $\left(\mathrm{CaSO}_{4}\right)$, the smectite-group clay mineral, montmorillonite $\left(\sim \mathrm{Ca}_{0.25}\left(\mathrm{Al}(\mathrm{Mg}, \mathrm{Fe}(\mathrm{II}))_{2}(\mathrm{Si}, \mathrm{Al})_{4} \mathrm{O}_{10}(\mathrm{OH})_{2} \cdot \mathrm{nH}_{2} \mathrm{O}\right)\right.$, and the alunite-group sulfate, jarosite $\left(\mathrm{KFe}(\mathrm{III})_{3}(\mathrm{SO})_{2}(\mathrm{OH})_{6}\right)$. Solid lines are the edges of the unit cell. The structures are adapted from the minerals database MinDat (https:// www.mindat.org), which uses data from the American Mineralogist Crystal Structure Database (http://rruff.geo.arizona.edu/ AMS/amcsd.php).

2005, 2008; Bishop et al., 2008, 2018; Ehlmann et al., 2008a, 2011; Ehlmann and Mustard, 2012). Recent modeling (Sheller et al., 2021) suggests that much of the $\mathrm{H}$ and $\mathrm{O}$ of ancient liquid $\mathrm{H}_{2} \mathrm{O}$ was incorporated into the $\mathrm{OH}$ groups of the abundant clay minerals of Mars (see formula for montmorillonite in the caption for Figure 9). Smectite-group clay minerals are known to occur on Mars at Gale Crater from X-ray diffraction (XRD) data acquired using MSL Curiosity's CheMin instrument (Bish et al., 2013; Vaniman et al., 2014, Rampe et al., 2017, 2020; Hurowitz et al., 2017; Yen et al., 2017; Bristow et al., 2018) and smectites have been spectroscopically detected at Jezero Crater (Ehlmann et al., 2008a; Goudge et al., 2015; Horgan et al., 2020). Clay minerals are also common host minerals for adsorbed organic molecules (Grim, 1953; Velde, 1992; Ehlmann et al., 2008a), including prospective molecular biosignatures.

Sulfate minerals (structures and formulae for three known to occur on Mars are shown in Figure 9), most of which are also hydrous and commonly evaporites (formed by evaporation), are widespread on Mars and have been spectroscopically detected from orbit, particularly in the Gale Crater operation area of MSL rover Curiosity (Milliken et al., 2010). They have also been confirmed by X-ray diffraction data from Curiosity's CheMin instrument (Vaniman et al., 2014, Rampe et al., 2017, 2020; Hurowitz et al., 2017; Yen et al., 2017; Bristow et al., 2018). All of the first 15 bedrock borehole samples analyzed by CheMin contain at least one sulfate mineral (Figure 9), 13 out of 15 contain at least one hydrous sulfate mineral (gypsum, bassanite, or jarosite), $80 \%$ contain one or more Ca-sulfates (gypsum, anhydrite, bassanite), and only two (2) contain only the anhydrous Casulfate mineral anhydrite (Rampe et al., 2020). Abundances and isotopes of $\mathrm{H}, \mathrm{O}$, and $\mathrm{S}$ in such minerals and mineral assemblages would be very informative of paleofluids and paleoenvironmental conditions. Sulfates are abundant in some rocks of potentially habitable paleoenvironments that were considered as landing sites for recent Mars missions, but sulfate minerals were not detected from orbit at Jezero Crater (Ehlmann et al., 2008a; Goudge et al., 2015; Horgan et al., 2020) or mentioned specifically by advocates for Jezero Crater (Golombek et al., 2012; Grant et al., 2018). Jarosite has recently been reported in Jezero Crater from orbital spectroscopic data (Dundar et al., in review).

Carbonate minerals have been detected spectroscopically from orbit at several localities on Mars (Ehlmann et al., 2008b), and specifically at Jezero Crater (Ehlmann et al., 2008b; Horgan et al., 2020). Carbonate minerals and rocks could be, or contain, important biosignatures. Likely ancient lake-margin carbonates in Jezero Crater (Horgan et al., 2020; a.k.a. its "bathtub ring') are of great interest to MSR because, on Earth, many macro-, micro-, and molecularfossils consist of, or are hosted in, carbonate rocks (limestones consisting almost entirely of calcite $\mathrm{CaCO}_{3}$ ).

All indications to date of carbonate minerals on Mars from orbital spectroscopy correspond to $\mathrm{Mg}$-carbonate. Magnesite $\left(\mathrm{MgCO}_{3}\right)$ is anhydrous; however, the orbital spectra are also consistent with magnesite + hydromagnesite (Calvin et al., 1994; Ehlmann et al., 2008b; Horgan et al., 2020). Hydromagnesite is one of many hydrous Mgcarbonate minerals. Hydrous $\mathrm{Mg}$-carbonates are sparsely distributed on Earth and occur naturally in cold climates in which dehydration kinetics are slow (Jull et al., 1988; Velbel et al., 1991; El-Shenawy et al., 2020) and in evaporitic lakes (Coshell et al., 1998; Russell et al., 1999). Hydrous Ca- carbonates (ikaite is calcium carbonate hexahydrate; glendonite, and jarrowite are calcite pseudomorphs after ikaite) have not yet been reported from Mars but are well known from Earth. They occur in modern and ancient cold ocean-, estuary-, and lake-bottom environments on Earth, and the presence of glendonite and jarrowite after ikaite is widely regarded as a paleothermometer of the water body from which the ikaite precipitated (e.g., Suess et al., 
1982; Shearman and Smith, 1985; Council and Bennett, 1993; James et al., 2005; Huggett et al., 2005; Selleck et al., 2007; Shulz et al., 2020).

The observed assemblages of secondary minerals, which are part of the ensemble of evidence for habitable conditions that were extant when sediments were deposited, contributed to the selection of the Mars 2020 landing site (Grant et al., 2018).

The Curiosity rover has been exploring Gale Crater since landing there in 2012. It has traversed a range of sedimentary rocks formed by ancient (paleo-)weathering at Mars' surface and diagenesis in the ancient subsurface. Weathering of rocks would have been followed by erosion, transport, deposition, and lithification of grains to form the sequences of sandstones, mudstones, and siltstones of the ancient streams, deltas, and lakes present in the crater 3.6 to 3.2 billion years ago (Grotzinger et al., 2015). The paleotemperatures at which the sediments were produced were likely above those at which liquid water is thermodynamically stable or metastable for sufficiently long intervals of time for the full range of sedimentary cycle processes to operate.

Mineralogical analysis by Curiosity has confirmed the specific characteristics and variety of clay minerals, silicarich X-ray amorphous (non-crystalline) materials, and sulfate minerals in the Gale Crater sediments (Bish et al., 2013; Vaniman et al., 2014, Rampe et al., 2017, 2020; Hurowitz et al., 2017; Yen et al., 2017; Bristow et al., 2018). Carbonate minerals are present in Gale Crater as confirmed by MSL SAM measurements but are below the $\sim 1 \%$ detection limit of CheMin (Rampe et al., 2020). Sediments deposited as smectite-group clay minerals and calcium sulfates in the ancient lake in Gale Crater and observed now as outcrops of layered and veined sedimentary rocks may indicate that habitable conditions existed when the sediments were laid down (Grotzinger et al., 2014; 2015).

Jezero Crater was selected as the landing site for the Mars 2020 rover Perseverance (Grant et al., 2018) because, like Gale Crater, it is characterized by the clay-rich sediments of an ancient river delta and associated lake deposits that also deposited carbonate minerals (Ehlmann et al., 2008b; Goudge et al., 2015; Horgan et al., 2020). Preliminary identification of these minerals is the basis for the anticipation that samples returned from Jezero Crater would show the existence of habitable conditions and, possibly, signs of past or present life.

There is an array of crystalline and non-crystalline (amorphous) materials in geological samples. Within the array, hydrous minerals and amorphous materials are most able to preserve physicochemical evidence of past habitable conditions and conditions necessary for biosignature preservation. They are also able to maintain their textural-contextual relationships with one another and with other adjacent minerals.

Minerals are characterized and identified from their crystallographic properties (symmetry, lattice dimensions) and elemental compositions (the major "rock-forming" elements include $\mathrm{Si}, \mathrm{O}, \mathrm{Fe}, \mathrm{Mg}, \mathrm{Ca}$ and $\mathrm{Al}$; minor elements include $\mathrm{Mn}, \mathrm{Cr}, \mathrm{Ni}$ and $\mathrm{P}$ ). Knowing the crystal structure and elemental composition of a mineral allows determination of stoichiometric and structural formulae of the individual mineral species. The samples returned from Mars will include rocks - assemblages of minerals - and one of the main stages in study of the samples will be determina- tion of their petrology. This is determination of the arrangement of minerals (and any non-crystalline phases) in the sample, their spatial distribution, texture, diversity of mineral species, and compositions.

Once identified, the mineralogy, mineral chemistry, and petrology of a sample can be used to infer the processes that the specimen has experienced. For example, evidence of past mineral-water interactions comes from the presence of hydrated or hydrous minerals, salts, etc. The solution chemistry of the fluid that caused the alteration may be modeled from combinations of chemical thermodynamics and the rates for kinetically controlled reactions together with knowledge of the mobility of major, minor, and trace elements. Adding in the geologic, stratigraphic, and geomorphic context of a sample (gained from knowing its collection locale on Mars) enables consideration of the spatial evolution of the solute hydro-geochemistry of the waters that formed the alteration-mineral assemblages.

Measuring the hydration states of hydrous minerals and amorphous materials constrains the thermodynamic activity of water $\left(a_{\mathrm{H} 2 \mathrm{O}}\right)$ and implications for habitability. Measuring the hydrogen and oxygen stable isotopic composition in minerals and amorphous phases formed by aqueous alteration constrains the nature of the fluid-whether it was fresh, brackish, marine, or a hypersaline brine. Knowing this, the environment of formation may be inferred: was it in groundwater or porewater, an ancient lake, or an ocean or from circulating hydrothermal or metasomatic fluids. It is also possible to model the isotopic composition of the associated paleo-atmosphere, invoking mass-dependent and mass-independent fractionation, with concomitant implications for the chemical evolution of the atmosphere and of ancient surface-, ground-, and pore-waters. Measuring the stable isotopic composition of carbon in carbonates and sulfur in sulfates constrains mass-dependent fractionation by physical or metabolic processes.

The preservation of sample properties is essential to the science outcomes of the Mars Sample Return Campaign. Acquiring data about Mars (rather than about sterilization) in containment when necessary-from returned samples supports interpretation of the geologic processes, environments, and history preserved in Mars' geologic record, with an emphasis on the role of water (iMOST Objective 1; Beaty et al., 2019). Preserving the scientifically important measurable properties in these samples also establishes the knowledge context for (paleo)environmentally correct interpretation of life science data (iMOST Objective 2, also almost entirely in containment) and geochronology (for which most science data can be acquired outside containment).

\section{2. "Water" and its constituents in minerals and amorphous solids}

Before discussing the effects of dry heat and $\gamma$-irradiation on geological materials, it is appropriate to define the meaning of specific terms as they are applied to minerals (adapted from Velbel and Zolensky, 2021).

Hydrous or hydrated (sensu lato): contains $\mathrm{H}_{2} \mathrm{O}$ in its crystal structure and loses molecular water $\left(\mathrm{H}_{2} \mathrm{O}\right)$ on heating. There are two sites within a mineral where molecular water may reside; each is designated with its own symbol. $\mathrm{H}_{2} \mathrm{O}(-)$ is adsorbed water rather than a fixed part of the 
crystal structure; it can be driven off by heating. An example is the interlayer water in smectite-group clay minerals (see Figure 9 middle). In contrast, $\mathrm{H}_{2} \mathrm{O}(+)$ is water bound within the crystal structure. It is lost on heating when the nonvolatile constituents of a mineral recrystallize into a different mineral; for example, gypsum $\left(\mathrm{CaSO}_{4} \cdot 2 \mathrm{H}_{2} \mathrm{O}\right.$; Figure 9 top left) decomposing to anhydrite $\left(\mathrm{CaSO}_{4}\right.$; Figure 9 lower left) plus water; this reaction is written:

$$
\mathrm{CaSO}_{4} \cdot 2 \mathrm{H}_{2} \mathrm{O} \rightarrow \mathrm{CaSO}_{4}+2 \mathrm{H}_{2} \mathrm{O}(+)
$$

Hydrous or hydrated (sensu stricto) refers only to $\mathrm{H}_{2} \mathrm{O}(+)$. The temperature at which water is lost varies with mineral species, and $\mathrm{H}_{2} \mathrm{O}(-)$ is driven off at lower temperatures than $\mathrm{H}_{2} \mathrm{O}(+)$ in a given mineral if both exist in the same mineral.

Hydroxylated: contains $\mathrm{OH}$ in its crystal structure (e.g., formula for montmorillonite in caption for Figure 9) and loses molecular water $\left(\mathrm{H}_{2} \mathrm{O}\right)$ on heating. It is lost on heating when the non-volatile constituents of a mineral recrystallize into a different mineral; for example, serpentine $\left(\mathrm{Mg}_{3} \mathrm{Si}_{2} \mathrm{O}_{5}(\mathrm{OH})_{4}\right)$ decomposing to $\mathrm{Mg}$-rich olivine $\left(\mathrm{Mg}_{2} \mathrm{SiO}_{4}\right)$ and $\mathrm{Mg}$-rich pyroxene $\left(\mathrm{MgSiO}_{3}\right)$ and water; this reaction is written:

$$
\mathrm{Mg}_{3} \mathrm{Si}_{2} \mathrm{O}_{5}(\mathrm{OH})_{4} \rightarrow \mathrm{Mg}_{2} \mathrm{SiO}_{4}+\mathrm{MgSiO}_{3}+2 \mathrm{H}_{2} \mathrm{O}
$$

Regrettably, this species ( $\mathrm{OH}$ in a mineral structure) is also widely colloquially referred to as "structural water."

\subsection{Sterilization by dry heat}

MSR Campaign-Level Science Requirements for sample temperature are that sample temperatures will not exceed $60^{\circ} \mathrm{C}$ (required) or $40^{\circ} \mathrm{C}$ (desired) (Beaty et al., 2019, their Table A3.1). The proposed temperature of the SRF BSL-4 space satisfies the requirement (Tait et al., 2022). Heat sterilization at the temperatures considered here, by defini- tion, does not satisfy the requirement. The heat sterilization temperatures considered here exceed the MSR CampaignLevel temperatures requirement by $120-190^{\circ} \mathrm{C}$, and the desired temperature by $140-210^{\circ} \mathrm{C}$. Numerous phenomena associated with habitability, life, and biosignature preservation occur within this temperature range, and a variety of sample attributes constitute the evidence of these phenomena. This section discusses how heat sterilization would modify or destroy a subsample's preserved natural inventory of measurable habitability- and biosignature-related attributes that formed below the sterilization temperature. Sterilization temperature $\left(T_{S}\right)$, dehydration temperature $\left(T_{D}\right)$, and the maximum temperature experienced by a mineral on Mars $\left(T_{M}\right)$ are considered in this following section.

There is an abundance of heat-sensitive minerals identified on Mars, including iron oxides, clay minerals, sulfates, and carbonates (Section 5.1). These minerals generally formed at low temperatures on or near the surface of Mars, that is, in high-priority, potentially habitable geological environments. Identification and characterization of hydrous minerals and measurements of abundances and isotopes of $\mathrm{H}$ and $\mathrm{O}$ and other redox-(oxidation-reduction)-sensitive elements in these minerals reveal fundamental scientific information about the conditions under which these minerals formed. They also yield information on how paleoenvironments and habitability changed over time from ancient to modern-day Mars.

Sheet silicates such as the phyllosilicate groups of clay minerals are hydrous/hydrated by virtue of containing structural $\mathrm{OH}$, adsorbed molecular water, or both (Figure 9 center). Loss of $\mathrm{OH}$ from phyllosilicates is not expected at proposed sterilization temperatures (Figure 10a), and CheMin XRD data from Gale crater suggest little molecular water associated with interlayer cations (e.g., Vaniman et al., 2014), but such minor interlayer water that may persist in martian clay minerals might be lost during heat sterilization. Mars-relevant smectite group minerals that
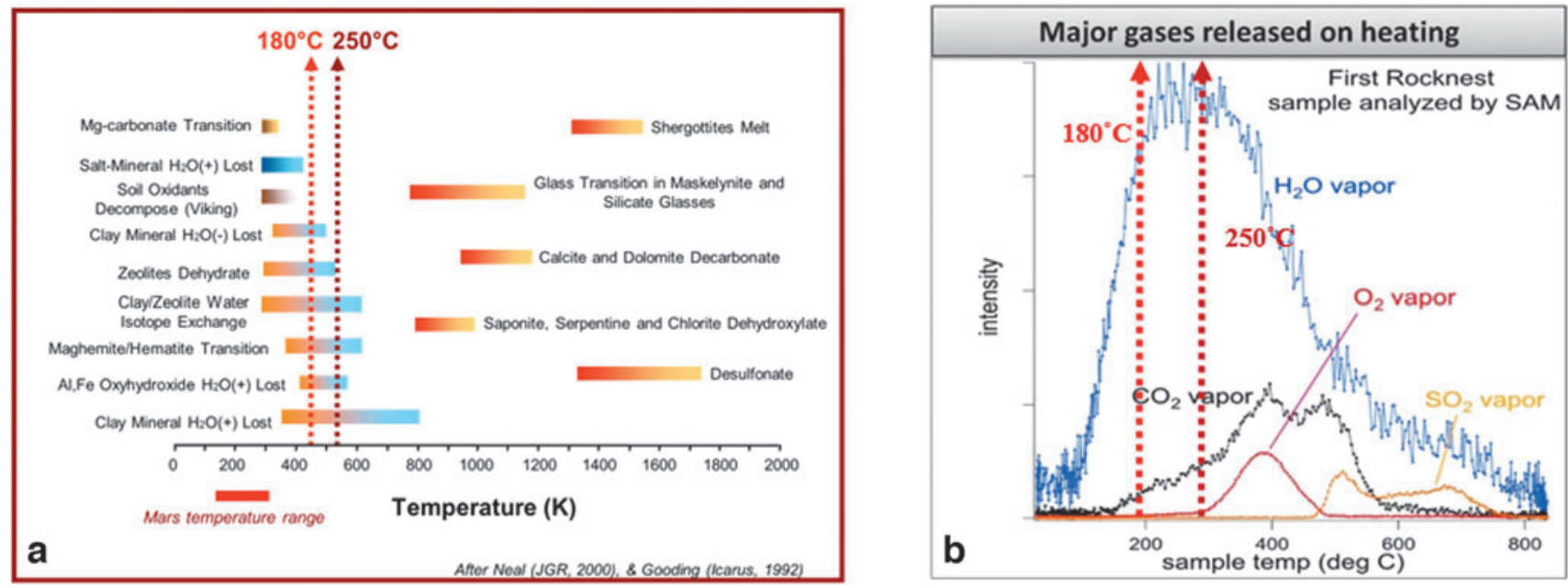

FIG. 10. (a) Phase transition temperatures for campaign-relevant minerals and amorphous materials. The dashed lines indicate the proposed dry heat sterilization temperatures. Modified after Gooding (1992) and Neal (2000); (b) MSL SAM analysis showing losses of $\mathrm{H}_{2} \mathrm{O}$ from solid (mineral plus amorphous material) sample material at the Rocknest site in Gale Crater, Mars, on heating to the proposed sterilization temperatures for MSR. The dashed lines indicate the proposed dry heat sterilization temperatures. SAM data from Leshin et al. (2013). Figure modified from NASA Planetary Photojournal image PIA16573; Image Credit: NASA/JPL-Caltech/GSFC. 
lose most or all of their molecular interlayer water below the proposed sterilization temperatures include saponite (Kawano and Tomita 1991, Che et al., 2011), montmorillonite (Huang et al., 1994), and nontronite and Fe-smectite (Frost et al., 2000).

The sulfate mineral group alunite, which includes jarosite, a scientifically and paleo-environmentally important mineral on Mars, is hydroxylated with $\mathrm{OH}$ bound in its crystal structure (Figure 9 right). Jarosite loses much of its $\mathrm{OH}$ at the proposed sterilization temperatures (Frost et al., 2005). Both anhydrous (anhydrite; Figure 9 upper left) and hydrous sulfate minerals (e.g., gypsum; Figure 9 lower left) occur on Mars; the hydrous sulfates contain molecular water bound into their crystal structures. Gypsum loses all its molecular water by thermal dehydration (sensu stricto) over the temperature range between the MSR Campaign required maximum $\mathrm{T}$ of sample exposure $\left(60^{\circ} \mathrm{C}\right)$ and the sterilization temperatures $\left(180^{\circ} \mathrm{C}\right.$ and $250^{\circ} \mathrm{C}$; Figure $\left.10 \mathrm{a}\right)$ being considered for MSR heat sterilization (Bish and Duffy 1990); the same is true for most hydrous Mg-sulfates (Vaniman et al., 2004; Vaniman and Chipera 2006). All scientific information about molecular water abundance and the $\mathrm{O}$ and $\mathrm{H}$ isotopes of the molecular water would be completely lost if returned gypsum-bearing or hydrous $\mathrm{Mg}$-sulfate-bearing samples are heat sterilized ("Salt-mineral $\mathrm{H}_{2} \mathrm{O}(+)$ ") in Figure 10a).

Anhydrous carbonate minerals themselves are not expected to be significantly impacted by heat sterilization since their decomposition temperatures are much higher than the sterilization temperatures we are considering (Velbel and Zolensky, 2021). However, their carbon and oxygen stable isotope ratios, which are scientifically very important as indicators of the ancient aqueous geochemical environments in which they form (O'Neil and Barnes, 1971; Grady et al., 1989; Walter and Des Marais, 1993), could be compromised by sterilization-induced redox phenomena in the same manner as described elsewhere in this section, as would any organic molecular fossils. Furthermore, as noted above, all indications to date of carbonate minerals on Mars from orbital spectroscopy correspond to Mg-carbonate; the orbital spectra are consistent with the presence of the hydrous Mg-carbonate hydromagnesite (Calvin et al., 1994; Ehlmann et al., 2008b; Horgan et al., 2020). Hydrous carbonates contain $\mathrm{H}$ and $\mathrm{O}$ as molecular water, and some also contain hydroxyl (Jull et al., 1988; Velbel et al., 1991; ElShenawy et al., 2020; Tosca et al., 2022). Water from these minerals is evolved (these minerals are "dehydrated") at temperatures $\left(\mathrm{T}_{\mathrm{D}}\right)$ less than proposed sterilization temperatures $\left(T_{S}\right)$. When $T_{S}>T_{D}$ of a mineral, then water would be expelled from the mineral on sterilization ("Mg-carbonate transition" in Figure 10a). No matter whether this is absorbed or structural water $\left(\mathrm{H}_{2} \mathrm{O}(-)\right.$ or $\left.\mathrm{H}_{2} \mathrm{O}(+)\right)$ or the hydroxyl group $(\mathrm{OH})$, the original mineral has been changed. Tosca et al. (2022) provide additional examples of devolatilization of $\mathrm{H}$ and $\mathrm{O}$ from these minerals. All hydrated (or hydrous) and hydroxylated minerals are sensitive to sterilization by dry heat if they lose water at temperatures below the proposed $\mathrm{T}_{\mathrm{S}}$ (Figure 10a).

When heated, minerals that form at low temperatures can be altered by different mechanisms, depending on their structure and composition. Decarbonation of carbonates and desulfurization of sulfates occur as well as dehydration and dehydroxylation. Figure 10a shows the range of transition temperatures for minerals commonly formed at low temperature, several of which have been identified on Mars (Figure 10b). Also shown is the temperature range proposed for dry heat sterilization. It is clear from Figure 10 that heating to either of the $T_{S}$ considered in this study would drive kinetically influenced thermodynamic reactions, including oxidation-reduction of co-existing redox-sensitive mineral-forming elements (e.g., Fe in montmorillonite and jarosite). It would also cause loss of volatiles from CHNOPS-bearing host phases, potentially resulting in isotopic re-equilibration and/or catalytic alteration of organic molecules.

An additional outcome of heating to temperatures even below $\mathrm{T}_{\mathrm{S}}$ could be recrystallization of new minerals from $\mathrm{X}$-ray amorphous phases, which are known from CheMin to be abundant in sedimentary rock at Gale Crater (Rampe et al., 2020). The subset of amorphous materials that consists of volcanic glass is not expected to be devitrified at any appreciable rate at sterilization temperatures (Friedman and Long, 1984); even highly hydrated volcanic glass (perlite) does not thermally decompose until reaching temperatures higher than the proposed sterilization temperatures (Thomas et al., 2015). Several varieties of amorphous silica are known. Hydrothermal silica is known to preserve morphological and organic molecular biosignatures on Earth (e.g., Westall et al., 2015), and similar hydrothermal silica may occur on Mars (Ruff et al., 2011); anhydrous amorphous silica is not expected to be affected by heat sterilization. Hydrothermal hydrated amorphous (opaline) silica is also known to preserve morphological and organic molecular biosignatures in terrestrial hot spring deposits (Cady and Farmer, 1996). However, unlike anhydrous amorphous silica, if amorphous hydrated (opaline) silica occurs on Mars as one of the candidate phases for the X-ray amorphous material detected by MSL's CheMin, then sterilization of samples containing such material at the sterilization temperatures considered here will dehydrate it (Thomas et al., 2015) and recrystallize it to anhydrous silica, with loss of textural and likely organic molecular biosignatures. Similarly, various smectite-group clay minerals (e.g., saponite, nontronite) crystallize rapidly from hydrous amorphous silicate gel at temperatures of $\sim 60-70^{\circ} \mathrm{C}$ (Decarreau and Bonnin, 1986; Schumann et al., 2012). Heat sterilization at either temperature considered would far exceed the recrystallization temperatures of such amorphous precursors, destroying them. Measurements and investigations of such geological materials are critically heat sterilization sensitive.

Based on current understanding as informed by MSL data from Gale Crater, the overall temperature range of processes that relate to retrieving Mars paleoenvironmental information (i.e., the origin and chemical evolution of (paleo) surface water, groundwater, and/or porewater; potential (paleo)habitability and biosignature preservation) from returned sedimentary rock samples is between Mars ancient surface ambient and $\sim 150^{\circ} \mathrm{C}$ (Borlina et al., 2015). After deposition from flowing (river, delta) and standing (lake) water, sediments at Gale Crater were buried to depths at which maximum burial temperatures are estimated to have ranged from $\sim 80-120^{\circ} \mathrm{C}$ and not exceeded $150^{\circ} \mathrm{C}$ (Borlina et al., 2015), probably for tens to hundreds of millions of years (Farley et al., 2014). Chemical reactions (diagenesis) 
between pore fluids and detrital minerals are likely to have altered many detrital minerals and may have produced much of the clay-mineral content of the sedimentary rocks (Vaniman et al., 2014; Fraeman et al., 2016; Rampe et al., 2017, 2020; Bristow et al., 2018). If the fluviodeltaic and lacustrine sedimentary rocks of Jezero Crater experienced burial histories similar to those of strata at Gale Crater, the entire relevant record of habitability-related conditions and processes would be at risk of being overprinted and reset by sterilization at either of the proposed sterilization temperatures $\left(180^{\circ} \mathrm{C}\right.$ and $\left.250^{\circ} \mathrm{C}\right)$ and thereby lost.

The abundances, structural sites, oxidation states, and isotopic composition of CHNOPS elements and co-existing redox-sensitive elements (e.g., $\mathrm{Fe}$ as in montmorillonite) are evidence for the nature of ancient, potentially habitable surface and near-surface environments on Mars. Their mineral hosts form in nature at low temperatures and would decompose if heated to the proposed sterilization temperatures for MSR. Measurements and investigations of the listed properties of such geological materials are sterilization sensitive. The effects of heating would result in irreversible loss of fundamentally important scientific information on mineral composition and structure and, hence, on the martian paleoenvironments in which they were deposited.

Among the many types of scientifically important measurements that would be adversely affected by heat sterilization are K-Ar and especially Ar-Ar geochronology of the mineral jarosite. Jarosite (Figure 9) occurs in more than half of the first 15 bedrock boreholes examined by the CheMin XRD on Curiosity in Gale Crater (Rampe et al., 2020); it forms by weathering and diagenesis and is therefore a promising and powerful tool for determining when it formed, constraining the age of its host rock and the paleoenvironmental conditions it represents. Most noble gas laboratories intentionally heat terrestrial and meteoritic samples overnight at around $100-200^{\circ} \mathrm{C}$ to drive off adsorbed terrestrial (contaminant) atmospheric gases. However, the adsorbed gases on returned Mars samples would be martian, not terrestrial contaminants, so heating during sterilization would remove or redistribute the low-temperature $\left(<T_{\mathrm{s}}\right)$ fraction of this component. The noble gas record would be compromised, and the derived Ar-Ar chronology for processes that occurred at low temperatures on Mars would be incorrect. This is one geochronometer that cannot be examined by using heat sterilized subsamples.

Apart from dry heat sterilization, there is a further issue related to the temperatures experienced by the returned samples. Figure 10a shows the approximate range of temperatures for Mars' surface today. It is important to recognize that any temperature experienced by the samples that are higher than the maximum to which they were naturally exposed on Mars will modify the lower-temperature phenomena present in the subsamples and thereby render them sterilization sensitive. Heating to $150^{\circ} \mathrm{C}$ to $200^{\circ} \mathrm{C}$ for earth-exposed samples (terrestrial materials incl. rock and soils; meteorites) removes terrestrial atmospheric contaminants (adventitious $\mathrm{C}$, water, etc.). However, exposure to the same temperatures during sample sterilization or preparation for analysis would remove from returned Mars samples scientifically crucial atoms and molecules from Mars, leaving behind in the sample only a partial and compromised record of Mars.
Therefore, even if such temperature is routinely used during sample preparation for those measurements on terrestrial samples, it would not be appropriate for Mars samples. The temperature limits for the samples from their acquisition on Mars to arrival at the SRF are already constrained by M2020 design requirements (see Beaty et al., 2019). It is expected that the temperatures experienced by the returned samples during processing (Basic Characterization and Preliminary Examination phases), curation, and preparation are carefully controlled and monitored (Tait et al., 2022). Every effort should be made to maintain the samples at temperatures below which mineral transitions occur.

FINDING SS-9: Minerals and amorphous materials formed by low temperature processes on Mars are highly sensitive to thermal alteration, which leads to irreversible changes in composition and/or structure when heated. Exposure to temperatures above MSR CampaignLevel Requirements for sample temperature, up to and including sterilization temperatures, has the potential to alter them from their as-received state. Sterilization by dry heat at the proposed sterilization temperatures would lead to changes in many of the minerals that are most significant for the study of paleoenvironments, habitability, and potential biosignatures or biosignature hosts. It is crucial that the returned samples are not heated to temperatures above which mineral transitions occur.

\subsection{Sterilization by gamma $(\gamma)$ irradiation}

It has long been known that ionizing radiation can effect changes in minerals. For example, fluorite, halite, and most varieties of quartz (except amethyst) change color upon $\gamma$ irradiation (Bass, 1957), which indicates that local imperfections (color centers, Frenkel defects in fluorite, impurity defects in quartz) in the crystal structures and crystal chemistries of those minerals were locally re-organized (Klein, 2002). There have also been reports that, when exposed to ionizing radiation, "glassware and other materials tend (sic) to become brownish, [exhibit] loss of tensile strength in fabric and some plastics" (Leuko et al., 2017, p. 8). Few studies have comprehensively documented the effects of $\gamma$-irradiation on rocks and minerals; Allen et al. (1999) remains one of the most systematic studies to date of the mineralogical and chemical changes in response to high doses of $\gamma$-radiation. Allen et al. (1999) $\gamma$-irradiated three basalt samples, one each at three different doses between 3 and $300 \mathrm{kGy}$. They then investigated the samples' responses to irradiation by measuring twenty-eight major, minor, and trace elements in each irradiated sample and a control basalt. Water samples irradiated at the same time showed no evidence of boiling, which indicated that sample temperature remained below $100^{\circ} \mathrm{C}$. The basalts' anhydrous rockforming minerals showed no change in composition: among the few cosmochemically volatile elements analyzed, abundances of most ( $\mathrm{Na}, \mathrm{As}, \mathrm{Sb}, \mathrm{Zn}$, and $\mathrm{Cs}$ ) are identical within large measurement error across the full range of radiation doses and the control; only the concentration of $\mathrm{Au}$ falls by half in the two most irradiated basalt samples relative to the control basalt and the least irradiated basalt. 
Allen et al. (1999) also investigated low-temperature minerals, including Na-montmorillonite (Clay Minerals Society Source Clay SWy-1), halite, aragonite, gypsum, and JSC Mars-1 simulant. This last mentioned is a material dominated by palagonite, containing poorly crystalline $\mathrm{Fe}$ oxides and phyllosilicates formed through the hydration of volcanic glass (Allen et al., 1998). Using a variety of analytical methods to examine bulk chemistry, structure, and other physical and spectroscopic properties, Allen et al. (1999) concluded that $\gamma$-irradiation resulted in no detectable changes in bulk chemical composition, crystallographic structure, $\mathrm{Sr}$ and $\mathrm{Nd}$ isotopic composition, or surface area. Comparable results were found by other studies, such that there is widespread agreement that the overall crystal structure of clay minerals (001 interlayer (d)-spacing, all other interplanar spacings, and unit cell parameters of axial dimensions, interaxial angles and crystallographic symmetry) is retained after $\gamma$-irradiation at 1 MGy (Gournis et al., 2000; Plötze et al., 2003; Bank et al., 2008). Similarly, major and minor rock-forming element abundances in clay minerals and clay-bearing altered materials are sterilization-tolerant. Note that only anhydrous components were measured-hydrous components, for example, $\mathrm{H}_{2} \mathrm{O}(-)$ were not measured. Allen et al. (1999) did not record any evidence for the dehydration of gypsum or montmorillonite, but they did observe increases in the thermoluminescence of quartz and plagioclase.

Allen et al. (1999) concluded that "large" doses of $\gamma$ irradiation (i.e., in the context of their study, $>50 \mathrm{kGy}$ ) appeared to have little impact on bulk physical and chemical properties of anhydrous components of rocks and minerals. However, their analytical techniques (INAA, ICP-ES) were insensitive to the valence state of Fe. Other studies used analytical techniques sensitive to the nuclear or electronic environment of $\mathrm{Fe}$ (i.e., Mössbauer spectroscopy and electron paramagnetic resonance (EPR) spectroscopy) to investigate any changes in $\mathrm{Fe}$ redox state brought about by $\gamma$-irradiation of soils (containing phyllosilicates and Fe-(oxy)hydroxides).

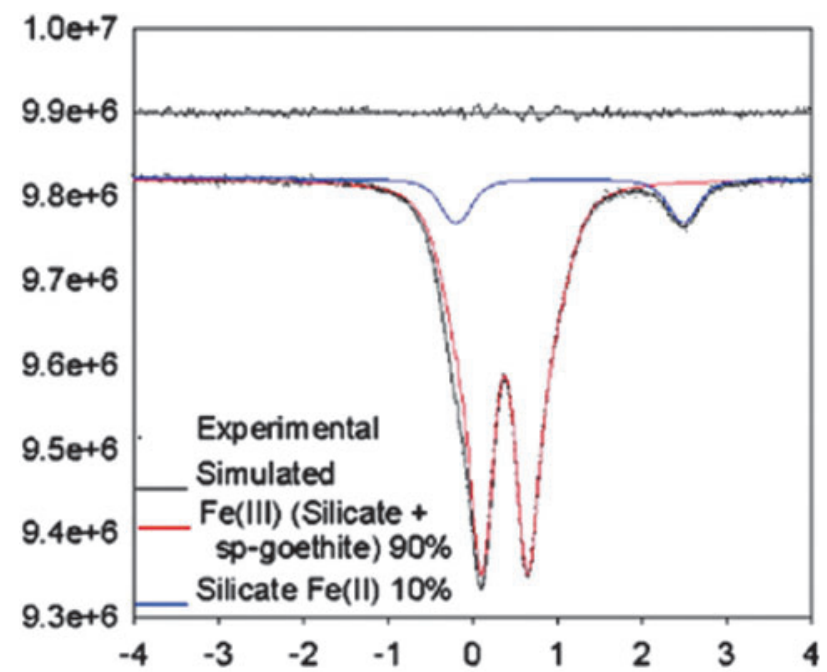

Using Mössbauer spectroscopy, Gournis et al. (2000) found an increase of the ferrous (Fe(II)) component in clay minerals after a total $\gamma$-irradiation dose of $84.24 \mathrm{kGy}$. The authors inferred the cause of the increase to be from radiolysis of interlayer water and subsequent reduction of $\mathrm{Fe}$ (III) by an atomic hydrogen free radical; that is, $\mathrm{Fe}(\mathrm{III})$ was reduced to $\mathrm{Fe}(\mathrm{II})$ as $\mathrm{H} \bullet$ (a radiolysis product) was oxidized to $\mathrm{H}^{+}$. Note that the production of $\mathrm{H}^{+}$would lower the $\mathrm{pH}$ of an aqueous solution, that is, the solution would become more acidic, potentially leading to further destruction of the mineral. Indeed, a companion EPR study of the same clay mineral demonstrated production of additional defects in the mineral's structure that could have resulted directly from irradiation or from acid dissolution (Gournis et al., 2001).

Pushkareva et al. (2002) investigated several clay minerals, several closely related minerals, and some hydroxides by Electron Spin Resonance (ESR) spectroscopy and found that production of radiation-induced defects at $\gamma$-irradiation doses from 0.1-30 MGy enhanced $\mathrm{H}$-isotope exchange with hydroxyl (OH) hydrogen. Plötze et al. (2003) examined SWy-1, four other montmorillonites, and twelve other clay minerals (illites, kaolinites, dickites, halloysites, and nacrite) $\gamma$ irradiated at $1.1 \mathrm{MGy}$, by several methods including EPR. Their study also observed reduction of iron in clay lattices from $\mathrm{Fe}(\mathrm{III})$ to $\mathrm{Fe}(\mathrm{II})$, along with decrease of smectite (montmorillonite) cation exchange capacities (CECs) and layer charge.

Very similar results regarding $\mathrm{Fe}(\mathrm{III})$ reduction to $\mathrm{Fe}(\mathrm{II})$, $\mathrm{pH}$ decrease, and decrease of CEC relative to non-sterilized soil and autoclaved soil, were observed in $\gamma$-irradiated (20 kGy) natural soil-sediment samples, although the presence of the Fe-hydroxide mineral goethite and organic matter complicated interpretation (Bank et al., 2008). The authors documented an increase in silicate-bound $\mathrm{Fe}(\mathrm{II}) / \mathrm{Fe}_{\text {Total }}$ from $10 \%$ to $16-18 \%$ and a concomitant decrease in goethitebound $\mathrm{Fe}(\mathrm{III}) / \mathrm{Fe}_{\text {Total }}$ from $90 \%$ to $\sim 84 \%$ (Figure 11). No major mineralogical changes were detected by X-ray diffraction. The results from these studies indicate that the extent of physical and chemical change in response to $\gamma$-irradiation

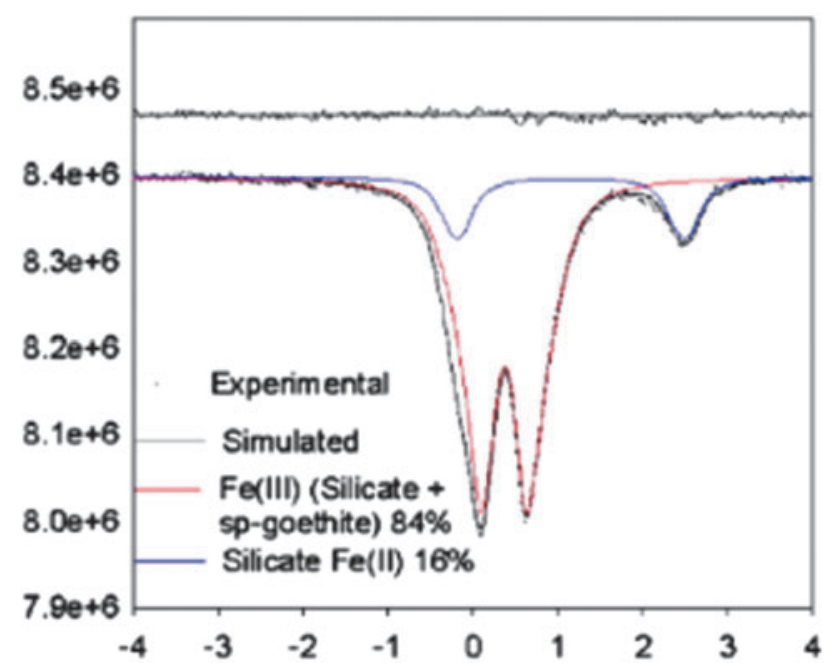

FIG. 11. Mössbauer spectra of soil untreated (left) and irradiated at 0.02 MGy (right; Bank et al., 2008). Relative changes in the total concentration of Fe(III) bound in silicate minerals and goethite are shown by the intensity of the red doublet, whereas those reflecting changes to silicate-bound Fe(II) are shown by the blue doublet. Percentages correspond to relative percent of total Fe. 
may also depend on other species present in the overall mineral assemblage (e.g., Bank et al., 2008). Consensus is lacking on the mechanisms through which $\gamma$-irradiation influences these specific properties. Present understanding of clay mineralogy and crystal chemistry indicates that several of these changes probably reflect the chemical consequences of a change in redox state of lattice-bound iron, which is accompanied by changes in crystal structure and layer charge, the latter of which in turn influences interlayer cation occupancy and hydration, and cation exchange capacity (e.g., Neumann et al., 2001; Stucki, 2011; Gorski et al., 2013). Possible pathways for the reactions could include solid-state migration of trapped electrons, direct electron transfer to lattice bound $\mathrm{Fe}(\mathrm{III})$, or reduction by $\mathrm{H}$-radicals generated from the radiolysis of mineral surface-bound or lattice-bound $\mathrm{H}_{2} \mathrm{O}$ (e.g., Gournis et al., 2001). Irradiation of poorly crystalline glasses and iron oxides, hydroxides, or oxyhydroxides can produce peroxides, superoxides, and/or molecular hydrogen (Weber et al., 1997; Reiff and Laverne, 2015). These compounds could react with surrounding minerals in unpredictable and irreversible ways.

Studies of synthetic counterparts of hydrous silicate minerals in concrete have been undertaken mainly for the nuclear industry. Concrete contains a category of hydrous silicate phases-calcium-silicate hydrates, synthetic analogs of the tobermorite family (William et al., 2003; Marty et al., 2015). The structural formula for several members of the family is $\mathrm{Ca}_{4} \mathrm{Si}_{6} \mathrm{O}_{15}(\mathrm{OH})_{2} \cdot \mathrm{nH}_{2} \mathrm{O}$. In tobermorite $9 \AA$ $(0.9 \mathrm{~nm}) \mathrm{n}=2$, and in tobermorite $11 \AA(1.1 \mathrm{~nm}) \mathrm{n}=5$ (Merlino et al., 1999); a $14 \AA$ (1.4 nm) variety is also known (Merlino et al., 1999, 2001; William et al., 2013), as is clinotobermorite (Merlino et al., 1999, 2001). On heating, tobermorite $14 \AA$ dehydrates and shrinks to tobermorite 11 $\AA$. The behavior on heating of tobermorite $11 \AA$ is more complex: "normal" tobermorite $11 \AA$ specimens dehydrate and shrink further to tobermorite $9 \AA$, whereas "anomalous" tobermorite $11 \AA$ does not shrink upon heating (Merlino et al., 1999). The different thermal dehydration behaviors result from the occurrence of tobermorite $11 \AA$ in two polytypes (monoclinic and orthorhombic) with different site occupancies (Merlino et al., 2001). Hydroxyl water is driven off above $400^{\circ} \mathrm{C}$, but molecular water is driven off between 50-250 ${ }^{\circ} \mathrm{C}$ (Ramachandran et al., 1964; Shaw et al., 2000; Marty et al., 2015; Rodriguez et al., 2017; Maddalena et al., 2019).

Shrinking of the synthetic analogs of tobermorite in concrete by radiation-induced heating is a major contributor to radiation damage (fracturing) of concrete reactor vessels (William et al., 2013) and the concrete used for dry cask nuclear storage, where MGy doses are common (Reches, 2019). Modification processes that affect the microstructure of the cement hydrates includes breaking of covalent bonds (including production of crystal-structural defects); production of molecular, ionic, or radical species of $\mathrm{H}$ and $\mathrm{O}$; and dehydration (Reches, 2019). "The impact of gamma rays on chemically-bound water may directly impart sufficient energy in order to dehydrate phases such as $\mathrm{C}-\mathrm{S}-\mathrm{H}$ or $\mathrm{Ca}(\mathrm{OH})_{2}$. The multi-scale effects of such dehydration are similar to those of dehydration by heating but have been observed even without a rise in the bulk temperature of the product." (emphasis added; Reches, 2019, p. 5, cites Kelly et al., 1969 and Gray, 1972, for these observations.).
The reaction of sulfates to $\gamma$-irradiation has also been explored. In their analysis of gypsum $\left(\mathrm{CaSO}_{4} \cdot 2 \mathrm{H}_{2} \mathrm{O}\right)$, Allen et al. (1999) did not measure $\mathrm{O}, \mathrm{S}$, or $\mathrm{H}$, but did measure $\mathrm{Ca}$ and four trace elements. Because $\mathrm{Ca}$ in gypsum $\left(\mathrm{CaSO}_{4} \cdot 2 \mathrm{H}_{2} \mathrm{O}\right)$ is "diluted" by the structural water relative to anhydrite $\left(\mathrm{CaSO}_{4}\right), \mathrm{Ca}$ abundance should have increased as a proportion (ppm) of the total sample mass if sample mass was lost by dehydration. Allen et al. (1999) found no difference in the abundance of $\mathrm{Ca}$ in irradiated gypsum relative to the control. From this, and strikingly similar XRD patterns of gypsum before and after $\gamma$-irradiation, Allen et al. (1999) concluded that 0.3 MGy $\gamma$-irradiation induced no mass loss (dehydration) of gypsum. In contrast, a study of a variety of hydrated sulfates in pure cement pastes and cement-based composites irradiated at six doses between 68 and 1188 MGy showed that gypsum (Figure 9), ettringite $\left(\mathrm{Ca}_{6} \mathrm{Al}_{2}\left(\mathrm{SO}_{4}\right)_{3}(\mathrm{OH})_{12} \cdot 26 \mathrm{H}_{2} \mathrm{O}\right)$, monosulfate $\left(3 \mathrm{CaSO}_{4} \cdot 32 \mathrm{H}_{2} \mathrm{O}\right)$, and tobermorite (all present in the initial and control samples) were extensively or completely decomposed at 130 MGy (Łowińska-Kluge and Piszora, 2008). The observed changes among samples were not consequences of radiative heating - the temperature of the radiation chamber was maintained at $20 \pm 2^{\circ} \mathrm{C}$ (LowińskaKluge and Piszora, 2008). The dose increments of this study do not permit assessment of whether these effects are similarly expressed at $1 \mathrm{MGy}$. Additional knowledge is required about the fate of structural $\mathrm{H}_{2} \mathrm{O}$ in gypsum between 0.3 MGy (highest dose considered by Allen et al., 1999) and 130 MGy (lowest dose for which data are reported by Łowińska-Kluge and Piszora, 2008).

If any hydrous $\mathrm{Ca}$ - or $\mathrm{Mg}$-carbonates occur in MSR samples, they will, like hydrous sulfates, be highly vulnerable to dehydration or radiolysis during sterilization.

Table 3 summarizes the $\gamma$-irradiation doses, dose rates, and effects on the minerals and artificial materials discussed above.

There have been a few studies that directly compare the effects of heat and $\gamma$-irradiation on samples. For example, both ${ }^{60} \mathrm{Co}$ irradiation $(60 \mathrm{kGy})$ and dry heat $\left(90^{\circ} \mathrm{C}\right.$ for $\left.48 \mathrm{hr}\right)$ significantly increased extractable $\mathrm{Mn}$ abundances in three soils (Wolf et al., 1989). Chikkamath et al. (2021) found complex but similar oxidation of interlayer $\mathrm{Fe}^{2+}$ in montmorillonite followed by reduction with increased duration of ${ }^{60} \mathrm{Co}$ irradiation at a dose rate of $0.6 \mathrm{kGy} / \mathrm{h}$ for $18 \mathrm{~h}$ and with increased temperature from 50 to $300^{\circ} \mathrm{C}$, and demonstrated that redox reactions involving interlayer $\mathrm{Fe}$ could reduce aqueous $\mathrm{Cr}(\mathrm{VI})$.

\subsection{Fluid inclusions}

Evaporitic calcium sulfates of diverse hydration states are ubiquitous, and halite occurs locally, in the fluviolacustrine sedimentary rocks at Gale crater examined by the CheMin XRD (Rampe et al., 2020). Some crystals of evaporitic minerals-especially halite (Knauth and Beeunas, 1986; Ayora et al., 1994, 2001; Lowenstein et al., 2001; Benison, 2013) and gypsum (Ayllón-Quevedo et al., 2007; Benison, 2013; Evans et al., 2015)—naturally encapsulate microscopic quantities of the aqueous solution from which they precipitated. These fluid inclusions are direct samples of ancient, usually briny (Roedder, 1990), fluid from ancient terrestrial oceans (Knauth and Beeunas, 
TABle 3. Effects of $\gamma$-IrRadiation on Minerals.

\begin{tabular}{|c|c|c|c|c|c|c|}
\hline $\begin{array}{c}\text { Mineral / } \\
\text { material } \\
\end{array}$ & $\begin{array}{c}\text { Dose rate } \\
\mathrm{kGy} / \mathrm{t}\end{array}$ & $\begin{array}{c}\text { Irrad. } \\
\mathbf{t}\end{array}$ & $\begin{array}{c}\text { Dose } \\
\text { MGy* }\end{array}$ & Effect & Method & Reference \\
\hline \multirow[t]{5}{*}{$\begin{array}{l}\text { Wyoming } \mathrm{Na} \text { - } \\
\text { montmorillonite } \\
\text { (CMS SC SWy- } \\
\text { 1) }\end{array}$} & $\begin{array}{l}18.9 \mathrm{kGy} \mathrm{h}^{-1} \\
3.15 \times 10^{2} \mathrm{~Gy} \\
\min ^{-1}\end{array}$ & $\begin{array}{l}15.8 \mathrm{~h} \\
950 \\
\min \end{array}$ & 0.3 & $\begin{array}{l}\text { No change to crystal } \\
\text { structure }\end{array}$ & XRD & $\begin{array}{l}\text { Allen et } \\
\text { al., } 1999\end{array}$ \\
\hline & $\begin{array}{l}3.51 \mathrm{kGy} \mathrm{h}^{-1} \\
58.5 \mathrm{~Gy} \mathrm{~min}^{-1}\end{array}$ & & 0.08424 & $\begin{array}{l}\text { Increase of the } \\
\text { ferrous }(\mathrm{Fe}(\mathrm{II}) \text { ) } \\
\text { component, } \\
\text { interpreted as } \mathrm{Fe}(\mathrm{III}) \\
\text { reduction to } \mathrm{Fe}(\mathrm{II}) \text { as } \\
\mathrm{H}^{\cdot} \text { - a radiolysis } \\
\text { product - was } \\
\text { oxidized to } \mathrm{H}^{+}\end{array}$ & $\begin{array}{l}{ }^{57} \mathrm{Fe} \\
\text { Mössbauer } \\
\text { spectra }\end{array}$ & $\begin{array}{l}\text { Gournis et } \\
\text { al., } 2000\end{array}$ \\
\hline & $\begin{array}{l}3.51 \mathrm{kGy} \mathrm{h}^{-1} \\
58.5 \mathrm{~Gy} \mathrm{~min}^{-1}\end{array}$ & & 0.08424 & $\begin{array}{l}\text { Structural } \\
\text { paramagnetic defects }\end{array}$ & EPR & $\begin{array}{l}\text { Gournis et } \\
\text { al., } 2001\end{array}$ \\
\hline & $2.548 \mathrm{kGy} \mathrm{h}^{-1}$ & & 1.1 & $\begin{array}{l}\text { Reduction of iron in } \\
\text { clay lattices from } \\
\mathrm{Fe}(\mathrm{III}) \text { to } \mathrm{Fe}(\mathrm{II}) \text {, } \\
\text { along with decrease } \\
\text { of cation exchange } \\
\text { capacity (CEC) and } \\
\text { layer charge. }\end{array}$ & EPR & $\begin{array}{l}\text { Plötze } \text { et } \\
\text { al., } 2003\end{array}$ \\
\hline & $2.548 \mathrm{kGy} \mathrm{h}^{-1}$ & & 1.1 & $\begin{array}{l}\text { No change to crystal } \\
\text { structure }\end{array}$ & XRD & $\begin{array}{l}\text { Plötze } \text { et } \\
\text { al., } 2003\end{array}$ \\
\hline \multicolumn{7}{|l|}{$\begin{array}{l}\text { Other clay } \\
\text { minerals }\end{array}$} \\
\hline $\begin{array}{l}\text { several clay } \\
\text { minerals, several } \\
\text { closely related } \\
\text { minerals, and } \\
\text { some hydroxides }\end{array}$ & Not specified & & $0.1-30$ & 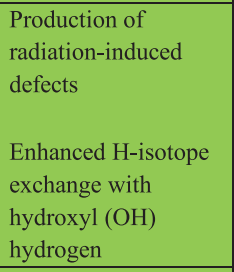 & ESR & $\begin{array}{l}\text { Pushkareva } \\
\text { et al., } 2002\end{array}$ \\
\hline $\begin{array}{l}4 \text { other } \\
\text { montmorillonites } \\
\text { (incl. STx-1, } \\
\text { MX80), } 12 \text { other } \\
\text { clay minerals } \\
\text { (illites, } \\
\text { kaolinites, } \\
\text { dickites, } \\
\text { halloysites, and } \\
\text { nacrite) }\end{array}$ & $2.548 \mathrm{kGy} \mathrm{h}^{-1}$ & & 1.1 & $\begin{array}{l}\text { Reduction of iron in } \\
\text { clay lattices from } \\
\text { Fe(III) to } \mathrm{Fe} \text { (II), } \\
\text { along with decrease } \\
\text { of cation exchange } \\
\text { capacity (CEC) and } \\
\text { layer charge. } \\
\text { No change to crystal } \\
\text { structure }\end{array}$ & EPR & $\begin{array}{l}\text { Plötze et } \\
\text { al., } 2003\end{array}$ \\
\hline \multicolumn{7}{|l|}{ Tobermorite } \\
\hline tobermorite & $38-40 \mathrm{kGy} \mathrm{h}^{-1}$ & & 130 & $\begin{array}{l}\text { Extensively or } \\
\text { completely destroyed }\end{array}$ & XRD & $\begin{array}{l}\text { Łowińska- } \\
\text { Kluge and } \\
\text { Piszora } \\
2008\end{array}$ \\
\hline \multicolumn{7}{|l|}{$\begin{array}{l}\text { Natural soil- } \\
\text { sediment }\end{array}$} \\
\hline & $\begin{array}{l}0.5 \mathrm{kGy} \mathrm{h}^{-1} \\
50 \mathrm{krad} \mathrm{h}^{-1}\end{array}$ & $40 \mathrm{~h}$ & 0.02 & $\begin{array}{l}\mathrm{Fe}(\mathrm{III}) \text { reduction to } \\
\mathrm{Fe}(\mathrm{II}), \mathrm{pH} \text { decrease, } \\
\text { and decrease of } \mathrm{CEC}\end{array}$ & & $\begin{array}{l}\text { Bank et al., } \\
2008\end{array}$ \\
\hline \multirow[t]{2}{*}{$\begin{array}{l}\text { Synthetic Fe- } \\
\text { oxides }\end{array}$} & & & & & & \\
\hline & & & 1 & $\begin{array}{l}\text { did not reduce } \\
\mathrm{Fe}(\mathrm{III}) \text { but enhanced } \\
\text { bioavailability and } \\
\text { thereby facilitated } \\
\text { microbial reduction } \\
\text { of } \mathrm{Fe} \text { (III) to } \mathrm{Fe} \text { (II) }\end{array}$ & & $\begin{array}{l}\text { Brown et } \\
\text { al., } 2014\end{array}$ \\
\hline \multicolumn{7}{|l|}{ Sulfates } \\
\hline gypsum & $\begin{array}{l}18.9 \mathrm{kGy} \mathrm{h}^{-1} \\
3.15 \times 10^{2} \mathrm{~Gy} \\
\min ^{-1}\end{array}$ & $\begin{array}{l}15.8 \mathrm{~h} \\
950 \\
\min \\
\end{array}$ & 0.3 & None & XRD & $\begin{array}{l}\text { Allen } e t \\
\text { al., } 1999\end{array}$ \\
\hline $\begin{array}{l}\text { gypsum } \\
\text { ettringite }\end{array}$ & $38-40 \mathrm{kGy} \mathrm{h}^{-1}$ & & 130 & $\begin{array}{l}\text { Extensively or } \\
\text { completely destroyed }\end{array}$ & XRD & $\begin{array}{l}\text { Łowińska- } \\
\text { Kluge and } \\
\text { Piszora } \\
2008\end{array}$ \\
\hline
\end{tabular}

* If multiple doses were administered, the one closest to the PPO-designated 1 MGy is shown. 
1986; Ayora et al., 1994. 2001; Lowenstein et al., 2001; Evans et al., 2015), ancient continental saline lakes (Ayllón-Quevedo et al., 2007; Benison, 2013) and modern counterparts (Benison, 2013), groundwaters (Benison, 2013), and deep formation waters (Knauth and Beeunas, 1986), and-in some primitive meteorites - from extraterrestrial rock-water systems (Zolensky et al., 1999, 2017; Rubin et al., 2002; Yurimoto et al., 2014). Temperatures at which a sedimentary evaporite mineral grew can be determined from the fluid inclusions containing vapor bubbles (e.g., Roedder, 1990; Zolensky et al., 1999; Rubin et al., 2002; Kesler et al., 2013; Benison, 2013; Evans et al., 2015). Specific analytes can include $\mathrm{pH}$ (Roedder, 1990; Benison, 2013), the $\mathrm{H}$ and $\mathrm{O}$ isotopes of the ancient solvent (Knauth and Beeunas, 1986; Yurimoto et al., 2014; Evans et al., 2015), salinity (e.g., Ayllón-Quevedo et al., 2007; Benison, 2013), specific ionic solutes (Roedder, 1990; Ayora et al., 1994, 2001; Zolensky et al., 1999, 2017; Benison, 2013) and their isotopes (e.g., S and O of the sulfate anion, and isotopes of trace $\mathrm{Sr}$, in sulfate minerals, Evans et al., 2015; Rb/Sr, I/Xe, and ${ }^{40} \mathrm{Ar} /{ }^{39} \mathrm{Ar}$ and other geochronology of halite, Zolensky et al., 1999, 2017; Rubin et al., 2002), precipitated mineral solids (Roedder, 1990; Zolensky et al., 1999; Rubin et al., 2002; AyllónQuevedo et al., 2007), dissolved gases (Roedder, 1990; Zolensky et al., 1999), dissolved organic molecules (Roedder, 1990; Benison, 2013; Zolensky et al., 2017) and microorganisms (Benison, 2013). These fluid inclusions are highly promising analytical targets but are exceptionally sensitive to temperature changes, depending on their contents. Heat sterilization would be especially deleterious (Benison, 2013); differential thermal expansion of the fluid inclusion and its host mineral could fracture the mineral, resulting in loss of the liquid (Roedder, 1990). Radiolysis of the water by $\gamma$-irradiation sterilization would destroy the hitherto preserved redox state of numerous elements and damage organic carbon compounds, as described in Sections 3 and 4.

FINDING SS-10: Crystal structure, major and nonvolatile minor element abundances, and stoichiometric compositions of minerals are unaffected by $\gamma$-irradiation of up to $0.3-1 \mathrm{MGy}$, but crystal structures are completely destroyed at 130 MGy. Measurements of these specific properties cannot be acquired from subsamples $\gamma$-irradiated at the notional 1 MGy dose-they are sterilization-sensitive.

FINDING SS-11: Sterilization by $\gamma$-irradiation (even at sub-MGy doses) results in significant changes to the redox state of elements bound within a mineral lattice. Redox-sensitive elements include $\mathrm{Fe}$ and other first-row transition elements (FRTE) as well as C, H, N, O, P and $\mathrm{S}$. Almost all minerals and naturally occurring amorphous materials that formed under habitable conditions, including the ambient temperatures of Mars' surface or shallow subsurface, contain at least one of these redoxsensitive elements. Therefore, measurements and investigations of the listed properties of such geological materials are sterilization sensitive and should not be performed on $\gamma$-irradiated subsamples.

\subsection{Physical, inorganic chemical, isotopic, and mineral biosignatures}

In addition to organic molecular biosignatures (Sections 3 and 4), ancient life can also leave morphological, chemicalpattern, isotopic, and mineralogical biosignatures (Figure 5). As discussed in Sections 5.2 and 5.3, some rock textures, chemical patterns, isotopes, minerals, etc. in subsamples containing volatile elements and compounds and redoxsensitive elements are adversely affected by devolatilization and oxidation-reduction that are caused by exposure to sterilization conditions. Rock fabrics are distorted by volume change upon hydration and dehydration. Chemical abundance patterns, including the different proportions of elements in different oxidation-reduction state and proportions of volatile elements, are changed. Sterilization stimulates artificial isotope exchange. Hydrous minerals lose structural molecular $\mathrm{H}_{2} \mathrm{O}$ and become different (less-hydrous or anhydrous) minerals. These signatures are, in general, less sensitive to sterilization than organics. However, if the chemical or isotopic signature is preserved in redox sensitive elements, or in sedimentary or secondary alteration-product minerals, and subsequently subjected to degradation under sterilization conditions, then this information could be lost. Given that we do not know what isotopic systems or minerals may preserve evidence of life should it have existed (or exist) on Mars, and because we could lose that information during sterilization without knowing, we should assume that these signatures of life are also sterilization sensitive.

\subsection{Igneous and metamorphic rocks and minerals}

Igneous and impact metamorphosed rocks formed at $\mathrm{T}>$ Ts and cooled over thousand to millions of years. All nowexposed rocks containing igneous and impact metamorphic features cooled from their high temperatures of formation, through the temperatures proposed for sterilization, to the present-day low surface temperature from which Perseverance will sample them, and thus already (naturally) experienced the temperatures associated with sterilization. Most of the primary (formed at the rock's time of formation) measurable compositional attributes of such rocks are sterilization-tolerant-they will not be compromised by brief exposure to the proposed dry heat-sterilization regimen. (Exceptions include life-detection measurements and measurements of weathered rinds, all of which are referred to in iMOST sub-objectives other than iMOST SubObjective 1.5-the "igneous rocks and processes" subobjective (Beaty et al., 2019), and all of which are identified elsewhere in this report as sterilization sensitive.) While it is possible that some small subset of other geochemical or isotopic characteristics in particular types of samples (such as $\mathrm{He}$ and other light noble gases in glassy or fine-grained samples) could be affected to some degree by heatsterilization, most investigations of high-temperature processes are expected to be sterilization-tolerant, including radiometric age-dating of igneous and shock metamorphosed minerals. Noble gas analyses and cosmogenic radionuclide analyses are deemed sterilization tolerant of $\gamma$ irradiation and can be done outside the SRF on sterilized samples. Measurements of noble gases as paleo-atmosphere tracers, as discussed in the following section (Section 6), are also expected to be sterilization tolerant (Table 2). 
FINDING SS-12: A significant fraction of investigations that focus on high-temperature magmatic and impact-related processes, their chronology, and the chronology of Mars' geophysical evolution are sterilization-tolerant. While there may be a few analyses involved in such investigations that could be affected to some degree by heat sterilization, most of these analyses would not be affected by sterilization involving $\gamma$ irradiation.

\subsection{Conclusions}

Heating geological materials above their formation temperatures would cause changes to some, or all, of the following sample attributes in many Mars paleoenvironmentrelevant minerals: crystallographic structure, stoichiometry, elemental and isotopic composition, and oxidation-reduction state. Irradiation at kGy-MGy levels (doses less than those considered for MSR sterilization protocols) induces significant changes in the valence state of the lattice-bound Fe present in many minerals. By inference, similar effects on other lattice-bound redox-sensitive elements cannot currently be excluded. Elements at risk include additional firstrow transition elements (e.g., $\mathrm{Cr}$ and $\mathrm{Mn}$ ) as well as $\mathrm{C}, \mathrm{H}, \mathrm{N}$, O, P, S and Ce (McNamara et al., 2003). The redox state of $\mathrm{C}$ in organic molecules may also be affected by $\gamma$ irradiation, through the effect of irradiation on redoxsensitive elements in the minerals with which the organic matter is intimately associated. Net redox changes in latticebound components are also known to influence the stable isotope signatures of lattice-bound transition metals and might also impact on stable isotope signatures of associated elements $(\mathrm{C}, \mathrm{H}, \mathrm{N}, \mathrm{O}, \mathrm{S})$ in the same mineral (Johnson et al., 2008; Neumann et al., 2011; Bauer and Vennemann, 2014). Redox phenomena (production of free radicals by radiolysis of water) in particular are more severely affected by irradiation than heating.

Many of the samples likely to be collected from Jezero Crater will have formed at low temperatures; many will contain hydrated and/or hydroxylated minerals and/or host other CHNOPS-containing volatile compounds (especially organic matter). Formation or secondary modification of these minerals and compounds would almost certainly have occurred at temperatures below those proposed for dry heat sterilization. Although the effects on elements such as $\mathrm{H}$ and $\mathrm{O}$ are slightly different, $\gamma$-irradiation at kGy-MGy doses affects the same CHNOPS elements and compounds (esp. water) and redox phenomena in volatile-hosting minerals and compounds as heat, and redox phenomena in particular more severely (production of free radicals by radiolysis of water). Sterilization by either dry heat or $\gamma$ irradiation would cause irreversible damage to the materials; consequently, analytical investigations of such materials are critically sterilization-sensitive and must be performed on unsterilized subsamples. MSPG2 is unable to identify with confidence any measurement of abundances or oxidationreduction states of CHNOPS elements, other redox-sensitive elements (e.g., Fe and other FRTE; Ce) or their isotopes that would be affected by only one, but not both, of the PPOprovided sterilization methods.
Furthermore, sterilization of subsamples with volatile-rich minerals or amorphous material has the potential to yield products that could react with minerals assumed to be sterilization insensitive. For example, releasing peroxide or molecular hydrogen has the potential to alter the redox states of adjacent minerals, amorphous materials, and organic molecules.

Sterilization by either heat or $\gamma$-irradiation will irreversibly damage samples produced by low-temperature surface and near-surface processes on Mars and render them unsuitable for the required analytical investigations. Hence for investigations of habitability-related (low temperature of formation/modification, surface/near-surface) geological materials, both dry heat sterilization and $\gamma$-irradiation should be avoided.

MAJOR FINDING SS-13: Scientific investigations of materials containing hydrous or otherwise volatilerich minerals and/or $\mathrm{X}$-ray amorphous materials that formed or were naturally modified at low (Mars surface-/near-surface) temperature are sterilizationsensitive in that they would be compromised by changes in the abundances, redox states, and isotopes of CHNOPS and other volatiles (e.g., noble gases for chronometry), FRTE, and $\mathrm{Ce}$, and cannot be performed on subsamples that have been sterilized by either dry heat or $\gamma$-irradiation.

\section{Analysis of Gas Samples}

\subsection{Background}

Mars' atmosphere is very thin, with a pressure of $\sim 600$ $\mathrm{Pa}$ at the surface. It is approximately $95 \% \mathrm{CO}_{2}$, with most of the remainder being $\mathrm{N}_{2}$ plus trace amounts of noble gases (Ar, $\mathrm{Ne}, \mathrm{Kr}$ and $\mathrm{Xe}$ ), $\mathrm{CO}$, and halogens. Measurement of the chemical and isotopic composition of Mars' atmosphere is a high priority, covered by Objective 4 in the iMOST Report (Beaty et al., 2019). It is important to assess the effects (if any) of sterilization on the gas samples.

Samples of Mars' atmosphere will be returned alongside solid materials. The latter will be collected as either cores drilled from rocks or granular material scooped from the surface. There are plans to bring back a dedicated atmospheric sample; atmospheric gas will also be present in the core tubes as head-space gas. It is also likely that the cores themselves will contain trapped volatiles, including hydrogen and associated oxygen that was incorporated into the solids by chemical reactions that consumed water $\left(\mathrm{H}_{2} \mathrm{O}\right)$.

6.1.1. Gases that exist in sample tubes: Two such sample types are expected. 6.1.1.1. Gases that are returned in a dedicated atmospheric sample: The dedicated atmospheric sample will be received in a dedicated, flight witness, or drillable blank tube, and the martian gas will be transferred to a gas storage and transport vessel likely made of metal for distribution to analytical instruments.

6.1.1.2. Gases that co-exist with solid samples in the sample tubes (headspace gas): It is anticipated that removing the headspace gas and storing it into sub-vessel(s) will be the first step in the eventual opening of each sample tube. The headspace gas and its dedicated martian sample 
vessel will be independent from the solid samples for further subdivision and sterilization in the vessels (if required) for external analysis.

We assume that the headspace gas will be separated promptly from the core tubes and therefore will be available in customized glass or metal gas storage and transport vessels independent from the core tubes.

6.1.2 Gases evolved or chemically extracted from sample solids during sample processing and sterilization: Some of a sample's inventory of volatile elements and their isotopes may be hosted in a mineral, amorphous, or organic host; and some of these hosts will decompose upon warming of the tubes to the SRF's room temperature (Tait et al., 2022; Carrier et al., 2022) and upon heating for sterilization, sterilization by $\gamma$-irradiation (see Sections 3, 4, and 5), and some sample preparation steps. The gases evolved from the solid samples must be captured for analysis.

Some of the martian gas analyses can be done in containment: These are the chemical composition and the stable isotope composition of $\mathrm{C}$ and $\mathrm{N}$ in $\mathrm{CO}_{2}$ and $\mathrm{N}_{2}$. Other measurements such as, for example, noble gas relative abundances and isotopic ratios, $\mathrm{C}$ and $\mathrm{N}$ isotopologs, and triple oxygen isotopes will require detection, precision, and accuracy unlikely to be met in containment and therefore will have to be carried out in external laboratories. Therefore, gas samples that require external analysis will have to be sterilized. Sterilization may not be the same for all gas species and atoms, depending on their potential reactivity. Noble gases will not be affected by $\gamma$-irradiation; H, O, C, $\mathrm{N}$, and $\mathrm{S}$ will likely be affected by radiolytic decomposition of their host molecules upon $\gamma$-irradiation.

\subsection{Sterilization by dry heat}

6.2.1 Gases that exist in the sample tubes: For sterilization of the gas samples contained in glass or metal vessels, the vessels will need to be heated externally to temperatures up to $180-250^{\circ} \mathrm{C}$ for various durations. Heating the samples will inevitably increase the temperature of the host vessel(s), with the potential risk of degassing terrestrial atmospheric contaminants (especially for the noble gases) or triggering chemical reactions (e.g., redox changes for redox-sensitive gaseous species like $\mathrm{CO}_{2}, \mathrm{CO} \ldots$ ) between walls and gaseous molecules. Therefore, it is recommended to design and carry out heating experiments in conditions similar to the glass or metal gas storage and transport vessels actually used (martian gas composition and amount, sample gas pressure, vessel composition). Once the gases are in vessels external to the core tubes, interactions between wall and gas could be minimized upon heat sterilization if the containers would have been baked and degassed sufficiently, at least in the case of noble gases.

6.2.2 Gases evolved from sample solids during sample processing and sterilization: We discussed, in Section 5, the issue of hydrated and hydroxylated minerals as species present within the samples; it is also likely that species from the atmosphere are either trapped or loosely bound within the rocks. As shown in Figure 10a, mineral transformations occur at temperatures lower than the proposed temperature of dry heat sterilization. Figure 10b illustrates how much gas can be liberated on heating; the species analyzed by SAM will partly have been trapped atmosphere (Atreya et al., 2013; Conrad et al., 2016), the remainder coming from breakdown of volatile species and release of structural water (Leshin et al., 2013).

As concluded in Section 5 and encapsulated in Finding SS13, sterilization by dry heating has the potential to degrade the structure of the samples and induce gas release from low temperature phases. It should be avoided for active species $\left(\mathrm{CO}_{2}, \mathrm{H}_{2} \mathrm{O}\right.$, etc. $)$ because they have the potential to be isotopically fractionated if their release is incomplete. It is not clear whether the same caveat applies to noble gases; they are generally released from igneous rocks at temperatures above that of dry heat sterilization, but for sedimentary rocks partial release may liberate some low temperature radiogenic isotopes and fractionate abundances (e.g., changes in the $\mathrm{Ar} / \mathrm{Kr}$ / $\mathrm{Xe}$ ratios). Evolved gases will have to be isolated from solids for analysis, and then, if necessary for external analysis, the gas samples have to be sterilized in vessels independent from the rock samples. To avoid doubt prior to the return and analysis of the atmospheric samples from Mars, it would be prudent to test the effects of heating at sterilization temperatures on gas mixtures encapsulated in gas transfer vessels.

\subsection{Sterilization by gamma $(\gamma)$ irradiation}

We are not aware of any study on the impact of $\gamma$-ray sterilization on noble gases. Given the inertness of these elements and their high ionization potential, it is anticipated that the effects of $\gamma$-ray irradiation should be minimal. For the other volatile species, effects from $\gamma$-ray irradiation are probably variable, depending on their reactivity. The triple bond of $\mathrm{N}_{2}$ ensures that the molecule is very stable, which may prevent its degradation by $\gamma$-ray irradiation; this needs to be verified. The attenuation of $\gamma$-rays through the vessel walls will need to be assessed depending on the material (metal or glass, thickness). Further experimental studies are necessary to assess the effects of $\gamma$-ray irradiation on gaseous molecules.

\subsection{Sterilization by filtration}

Filtration could be another way to remove potential biomolecules from a gas evolved from a sample (e.g., head space gas from the sample tubes or gas released from samples at room temperature). Filtration could be achieved by passing the gas through grids made of an inert material with a low degassing rate (e.g., stainless steel). Prior to filtration, the grid should be thoroughly degassed by vacuum heating. Both the size of the filtration pores and the potential adsorption of different gases onto the grid, as well as possible contamination from the filtration system, should be investigated. The filter size should be consistent with planetary protection requirements. Filtered gas could then be distributed outside the BSL-4 facility. Filtration tests in conditions akin to the expected martian gas samples (pressure, composition, amount of gas) should be designed and carried out to investigate possible adsorption/desorption effects that could compromise the samples' composition (desorption of terrestrial gases, adsorption and fractionation of martian gas, kinetics of filtering).

\subsection{Conclusions}

It is anticipated that a dedicated sample of Mars' atmosphere would be returned in one of the sample tubes or (decision not yet made) in a dedicated gas storage and 
transport vessel to be carried on the SRL or SFR. There will also be other opportunities to analyze gas samples from Mars: from a dedicated sampling vessel (presently discussed), from the head spaces of the sample, flight witness and drillable blank tubes, and from any species evolved during warming of the tubes to room temperature (as well as from any sterilization processes). To assess the impact of sterilization on martian sample gases, specific heat and irradiation experiments on vessels containing martian-like gases need to be carried out. At the very least, the noble gas component of the martian atmosphere is likely to be insensitive to sterilization by either dry heat or irradiation. The feasibility of sterilizing the gases by filtering through an inert grid should be investigated. It is possible that some, or even all, of the gases returned from Mars could be sterilized then subsequently analyzed outside of containment.

MAJOR FINDING SS-14: It would be far preferable to work on sterilized gas samples outside of containment, if the technical issues can all be worked out, than to build and operate a large gas chemistry laboratory inside containment. Depending on their reactivity (or inertness), gases extracted from sample tubes could be sterilized by dry heat or $\gamma$-irradiation and analyzed outside containment. Alternatively, gas samples could be filtered through an inert grid and the filtered gas analyzed outside containment.

\section{Implications for the SRF}

\subsection{Background}

The science of the Mars Sample Return Campaign must strive for analytical results and interpretations about life on Mars and the conditions under which it occurred and was preserved, without allowing any aspect of sample processing, including sterilization, to introduce ambiguities. Consequently, the SRF should support within containment the ability to measure all these attributes of hydrous minerals and their co-occurring materials including organic molecules. Many minerals persisted or formed at low temperatures on the surface or in the shallow subsurface of Mars, that is, in high-priority, potentially habitable geological environments. The hydrous minerals in particular preserve physicochemical evidence of past habitable conditions and conditions necessary for biosignature preservation. Identification and characterization of hydrous minerals, and measurements of abundances and isotopes of $\mathrm{H}$ and $\mathrm{O}$, and other redox-sensitive elements (CHNOPS elements; other redox-sensitive elements, e.g., Fe and other FRTE; Ce) in these minerals, reveal fundamental scientific information about the conditions under which these minerals formed. These are the main measurable attributes that will be the basis for the scientific interpretations about Mars' environmental history, habitability over geologic time, ancient life on Mars, and how paleoenvironments and habitability changed over time from ancient to modern-day Mars. Both dry heat sterilization and $\gamma$-irradiation will modify volatile elements (especially $\mathrm{H}$ and $\mathrm{O}$ ), changing both their abundances, redox states, and isotope abundances, and the similar properties of co-occurring redox-sensitive elements
(CHNOPS elements, other redox-sensitive elements, e.g., Fe and other FRTE; Ce). A subsample containing hydrous minerals and complex organic compounds sterilized by either method loses some or all its necessary desired properties (fidelity to the intended purpose of the sample) sterilization will destroy those aspects of the sterilized subsample that must be measured and that are the evidence for Mars' paleoenvironmental conditions, potential habitability, and potential biosignature preservation.

MAJOR FINDING SS-15: It is fundamental to the campaign-level science objectives of the Mars Sample Return Campaign that the SRF support characterization of samples returned from Mars that contain organic matter and/or minerals formed under habitable conditions that include the ambient paleotemperatures of Mars' surface or subsurface $\left(<\sim 200^{\circ} \mathrm{C}\right)$ - such as most clays, sulfates, and carbonates-in laboratories on Earth in their asreceived-at-the-SRF condition.

Combining Major Finding SS-7 about the sterilization sensitivity of organic molecular biosignatures to both PPOprovided sterilization methods (Section 4.4) with Findings SS-9, SS-11, and SS-13, and Section 5.4, about the sterilization sensitivity of all other potential biosignatures of ancient life to both PPO-provided sterilization methods (Figure 5) yields a Major Finding.

MAJOR FINDING SS-16: The search for any category of potential biosignature would be adversely affected by either of the proposed sterilization methods.

\subsection{Key assumptions}

- Instrumentation must be available in the SRF to support sterilization-sensitive measurements on samples that cannot be approved for unsterilized release. If a subsample for measurement of a sterilization-sensitive attribute requires sterilization to be released outside containment, then the analysis must occur in the SRF on an unsterilized sample before sterilization, and the instruments for these analyses must be in the SRF.

- If a subsample is deemed to require sterilization to be released from containment, then sterilization-sensitive measurements on that subsample must be made in the SRF before sterilization. Furthermore, all prior knowledge of the subsample that is required to contextualize and interpret the measurement must be acquired before sterilization, by analytical methods (and their associated sample preparation methods) that are non-destructive of the desired attribute to be measured. This includes any pre-sterilization measurements that are necessary to the interpretation of the sterilizationsensitive measurement, even if those pre-sterilization measurements are sterilization tolerant. To provide the necessary interpretation-supporting ancillary and contextual information, for subsamples that cannot be 
approved for release from containment in an unsterilized state, instruments and associated sample preparation equipment necessary to acquire sterilizationsensitive data must be in containment even if the specific contextual and supporting measurements they enable are sterilization-tolerant. Such data include lifesciences data and geological paleoenvironmental contextual and interpretation-support information for the sterilization-sensitive attribute(s). All ancillary knowledge of a subsample necessary to interpreting a sterilization-sensitive measurement from that subsample must be acquired before sterilization. Informed anticipation of sterilization effects on samples and measurements ought to influence the sample management plan for multiple (e.g., consortium or otherwise sequential) analyses of individual subsamples or complementary suites of different subsamples sub-divided for different analyses from a homogenous parent.

\subsection{Support in the SRF for sterilization sensitive measurements-Processes}

Volatiles evolved during dry heat sterilization are usually lost to science (e.g., water from dehydration or dehydroxylation; Section 5.2). Heat-sterilized samples would no longer be suitable for sterilization-sensitive measurements such as those involving volatiles (Section 5.3, Finding SS9). If heat sterilization could be harnessed to serve as the thermal driver that expels volatiles from the solids, then the volatiles could be captured from the sterilization chamber, conserving the evolved volatiles (gases) for analysis by some form of evolved gas analyzer. Monitoring both the weight loss with temperature and the composition of the gases evolved during sterilization in the SRF would preserve scientific information about the sterilized subsamples. If a subsample has to be sterilized, then making such a measurement during sterilization will partially ameliorate the loss of information that results from the sterilization (Section 5.3, Finding SS-9).

Transferring the evolved gases from the sterilization chamber to an appropriate analytical instrument can be accomplished in any number of ways. Gas evolved in the sterilization chamber during sterilization can be captured and transferred using a gas storage and transfer vessel as discussed in Section 6. Alternatively, such volatile elements and compounds can be recovered intentionally from unsterilized samples by Thermal Conversion / Elemental Analysis (TC/EA) or Evolved Gas Analysis (EGA). TC/EA or /EGA gradually heats a solid sample, captures the evolved gases, and analyses the evolved gases using an Isotope Ratio Mass Spectrometer (IRMS) (TC/EGA-IRMS). This is similar to the way that MSL-SAM on Curiosity measured the martian soil at Rocknest in Gale Crater (Figure 10b). In TC/EA-EGA, helium (He) is used as both the purge gas and carrier gas; this gas would interfere only with analyses targeting solid-hosted He. The heating regimen can be controlled to remain at a temperature for a duration that corresponds to the temperature and time required for dry-heat sterilization. Heating the sample to the conditions required for microbial inactivation, capturing the evolved gases, and analyzing them, would satisfy the requirements of both sterilization and sterilization-sensitive science. The EGA heating sequence could then either be terminated, with the sterilized solid sample released to a laboratory outside containment for analysis (including normal TC/EGA at temperatures higher than the sterilization temperature), or (if the subsample is specifically for EGA) continued to complete the TC/EGA sequence for the subsample in a single analytical session on the same instrument. An IRMS dedicated and optimized for simple low molecular weight volatiles and their light stable isotopes is expected to be in the SRF to support time-sensitive science in containment, for identification, concentration and light stable isotope ratios of major and minor gaseous species in complex evolved-gas mixtures of volatile compounds; and compound-specific $\mathrm{C}-, \mathrm{N}-, \mathrm{S}-, \mathrm{O}-$, and $\mathrm{H}$-isotope ratios (Tosca et al., 2022). Using the TC step of TC/EGA as the implementation of dry heat sterilization can be considered sterilization by science, science by sterilization, an(other) alternative to, or novel implementation of, dry heat sterilization, and another specific pathway to dry heat sterilization.

Technical solutions in addition to those discussed here can also be explored.

MAJOR FINDING SS-17: Carbon, hydrogen, nitrogen, oxygen, sulfur, phosphorus, and other volatiles would be released from a subsample during the sterilization step. The heat and $\gamma$-ray sterilization chambers should be able to monitor weight loss from a subsample during sterilization. Any gases produced in the sample headspace and sterilization chamber during sterilization should be captured and contained for future analyses of the chemical and stable isotopic compositions of the evolved elements and compounds for all sterilized subsamples to characterize and document fully any sterilization-induced alteration and thereby recover some important information that would otherwise be lost.

Instruments and sample preparation apparatus for all receiving and curation processes, workflow steps, and functions, will be in containment (Tait et al., 2022) as will those for SSAP and sterilization. Data acquired from all these processes are science data.

If the proposed measurement for which the subsample is requested is sterilization tolerant, then the subsample can be sterilized and allocated to independent investigators for analysis outside containment.

If the proposed measurement for which the subsample is requested is sterilization sensitive and the Sample Safety Assessment allows release of the unsterilized sample, then the subsample may be analyzed in an investigator's laboratory outside the SRF. In contrast, if the proposed measurement for which the subsample is requested is sterilization sensitive and release of the unsterilized subsample is not allowed, then the subsample must be analyzed for any critically sterilization sensitive attributes in an unsterilized state within the SRF.

- Either the entire analysis must be done on an unsterilized allocation within containment in the SRF (all sample preparation and analysis must be within the SRF), or 
- the SRF must support preparation of unsterilized allocations that can be analyzed in a contained state by external BSL-4+ laboratories (e.g., synchrotron beam line at a BSL-4+ user facility).

If the subsample can be analyzed in a sealed container (e.g., in a metal or glass gas storage and transfer vessel for atmosphere and evolved gas subsamples, for sterilization followed by analysis at labs outside the SRF; glass capsule, as for synchrotron XRD), then the preparation apparatus must be within the SRF but the encapsulated subsample can be conveyed to the requesting investigator outside the SRF. If the subsample cannot be analyzed in a sealed container, then both the preparation apparatus and the analytical instrument must be within BSL-4 containment. Required functionalities of instruments and sample preparation facilities for sterilization-sensitive science in containment may exceed those required of the same instruments for Receiving, Curation, SSAP, and time-sensitive science.

\subsection{Support in the SRF for sterilization sensitive measurements-Instruments}

It is recommended that the "baseline" instrument types and sample preparation apparatus described in the Traceability Matrix (Table 4) be supported in containment in the SRF. All listed "baseline" instruments must be in the SRF (Carrier et al., 2022) for Curation (Tait et al., 2022), SSAP, or time-sensitive analyses (Tosca et al., 2022). Specific analytical goals and observation-measurement types that the same instruments would enable for sterilization-sensitive analyses in the SRF are listed in the column headings of the Traceability Matrix (Table 4).

If a subsample has or is expected to have a property that would change upon sterilization and the change in the property would modify that sample attribute such that it would corrupt the measurement of that attribute, then the measurement on the subsample is critically sterilizationsensitive and the measurement must be made on an unsterilized sample (Figure 1). The expectation is that such a measurement would await an SSAP determination that the subsample is biohazard-free and safe for release from containment to an investigator laboratory outside the SRF (YES path in Figure 12; from Carrier et al., 2022). If, however, SSAP finds the sample unsafe for release from containment, then either the measurement is not made, or contingency instruments must be procured for installation, operation, and analysis in the SRF (red NO path PLUS path for sterilization sensitive science in Figure 12; from Carrier et al., 2022).

Carrier et al. (2022, p. 20) noted

..."in the unlikely scenario where martian life or a nonliving biohazard is discovered, at least some unsterilized samples would need to stay in the SRF indefinitely, and a somewhat broader set of instrumentation would need to be brought to bear. If prepared samples for sterilizationsensitive science cannot released to outside laboratories in an unsterilized state, then the analytical functionalities (instruments) that make these measurements will be needed inside biocontainment. Therefore, the capability to allow for adding additional capabilities at a later date would be needed, whether inside the SRF or in ancillary biocontained laboratories. This would presumably necessitate additional sterilization-sensitive measurements that are not part of the current baseline set of analyses."
Such instruments would include electron probe microanalysis (EPMA), field-emission transmission electron microscopy with selected area electron diffraction, and energy dispersive spectroscopy with energy filtering (FE-TEMSAED-EDS-EF), nano-secondary ion mass spectroscopy (Nano-SIMS), and Mössbauer spectroscopy. All science supported by these instruments is described in Section 5.1 above and iMOST Goals.Objectives 1.1-1.4 and 2.2. Information about these instruments in addition to that shown in Table 4 follows.

Instrument: Electron Probe Microanalysis (EPMA) (Table 4 row 20)

Measurement: Fully quantitative spatially resolved in situ chemistry of non-volatile elements in volatile-rich phases; mineral formulas (Table 4 column $\mathrm{N}$ ).

Science reason for this sterilization-sensitive measurement: The chemical compositions of hydrous and oxidationreduction sensitive minerals in particular preserve physicochemical elemental evidence of past habitable conditions and conditions necessary to biosignature preservation.

Instrument: Transmission Electron Microscopy (TEMSAED-EDX) (Table 4 row 21)

Measurement: Spatially resolved characterization and identification of sub- $\mu \mathrm{m}$ minerals from interplanar spacings, unit cell dimensions, and space group (Table 4 column P).

Science reason for this sterilization-sensitive measurement: The crystallographic parameters of hydrous and oxidationreduction sensitive minerals in particular preserve physicochemical and textural evidence of past habitable conditions and conditions necessary to biosignature preservation.

Instrument: Nano-Secondary Ion Mass Spectroscopy (Nano-SIMS) (Table 4 row 22)

Measurement: Spatially resolved in situ determination of stable-isotope abundances and distributions at sub-micron scale (Table 4 column Q)

Science reason for this sterilization-sensitive measurement: The hydrous and oxidation-reduction sensitive minerals in particular host elements that preserve physicochemical textural and light stable isotopic evidence of past habitable conditions and conditions necessary to biosignature preservation.

\section{Instrument: ${ }^{57} \mathrm{Fe}$ Mössbauer spectrometer}

Measurement: Oxidation-reduction state of Fe (Table 4 column R)

Science reason for this sterilization-sensitive measurement: The hydrous minerals in particular host oxidationreduction sensitive elements, the oxidation states of which preserve physicochemical evidence of the oxidationreduction states in past habitable environments and conditions necessary to biosignature preservation.

\subsection{Agnostic biosignatures}

The SRF functionalities and equipment proposed for the organic and life detection objectives will also allow for "agnostic" life detection (see also Sections 3.4, 4.1, and 5.5). Some patterns and outliers in the measurements and observations discussed in Sections 3.4, 4.1, and 5.5 will identify potential biosignatures ( $c f$. Figure 5) for further investigation even if these potential biosignatures are based on different carbon chemistry than terrestrial life, or on other functionally similar information-bearing polymers 


\begin{tabular}{|c|c|c|c|c|c|c|c|c|c|c|}
\hline \multirow{5}{*}{ 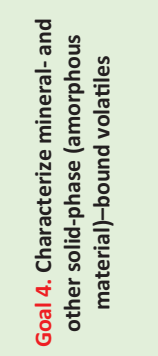 } & 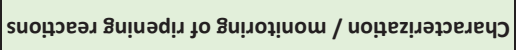 & & & & & & & & & \multirow{3}{*}{ 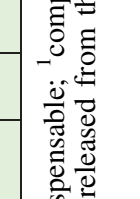 } \\
\hline & 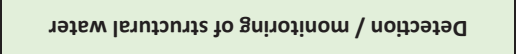 & & & & & & & & & \\
\hline & 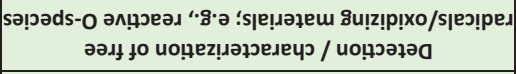 & & & & & & & & & \\
\hline & 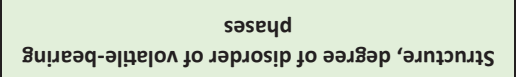 & & & & & & & & & \\
\hline & 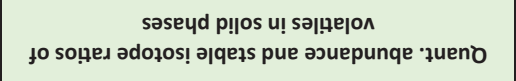 & & & $\underset{x}{x}$ & & & & & & \\
\hline & 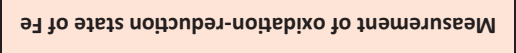 & & & & & & & & & \\
\hline 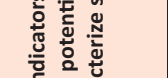 & 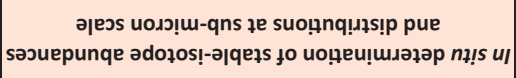 & & & & & & & & & \\
\hline 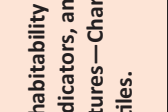 & 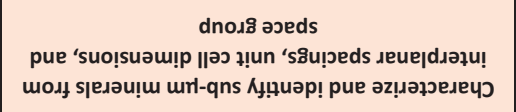 & & & & & & & & & E. \\
\hline 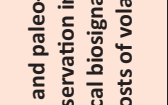 & 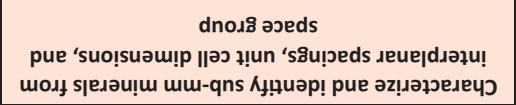 & & & & & & & & & . \\
\hline 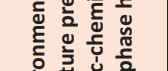 & 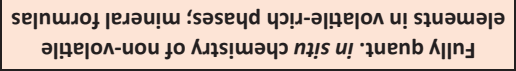 & & & & & & & & & \\
\hline 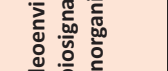 & 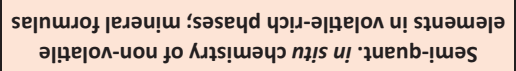 & & & & $x$ & & & & & \\
\hline 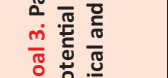 & 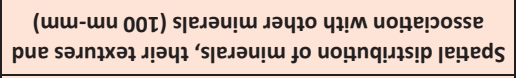 & & & & & & & & & \\
\hline & 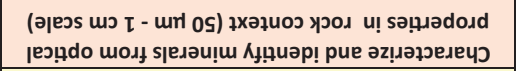 & & & & & & & & & \\
\hline 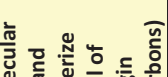 & 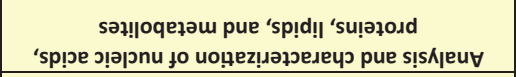 & & & & & & $x$ & $x^{x}$ & $x$ & \\
\hline & 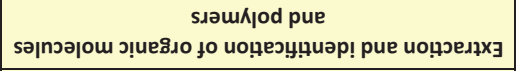 & & & & & $\underset{x}{x}$ & & & & \\
\hline 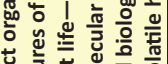 & 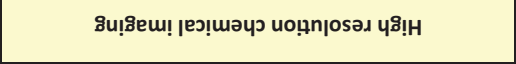 & & & & $\frac{x}{x}$ & & & & & \\
\hline 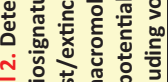 & 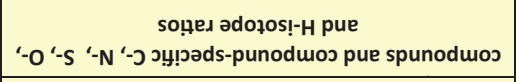 & & & $\frac{x}{x}$ & & & & & & \\
\hline 3) & 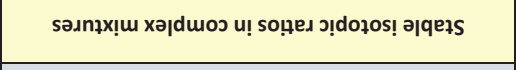 & & $\bar{x}$ & $\frac{x}{x}$ & & & & & & \\
\hline 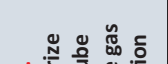 & 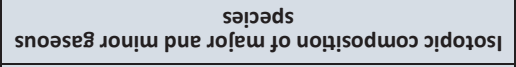 & & $\frac{x}{x}$ & $\underset{x}{x}$ & & & & & & \\
\hline & 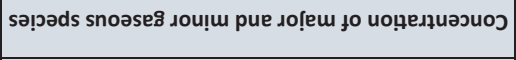 & & $\underset{x}{x}$ & $\underset{x}{x}$ & & & & & & \\
\hline & 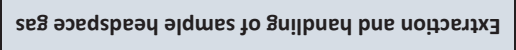 & $\underset{x}{x}$ & & & & & & & & \\
\hline 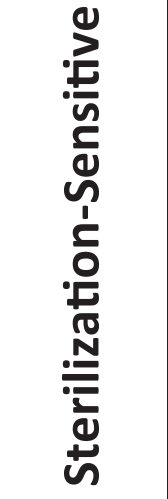 & 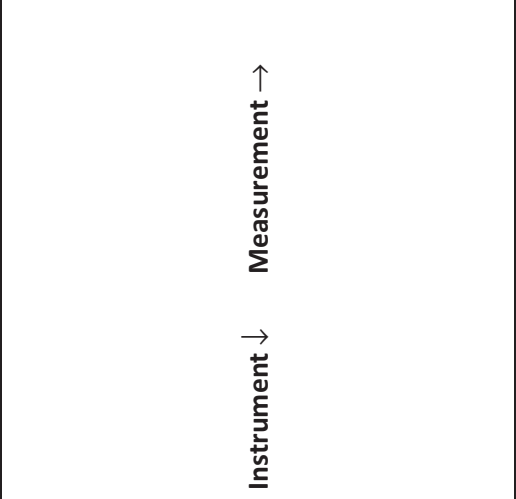 & 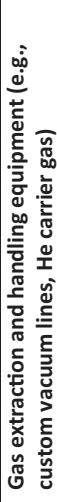 & 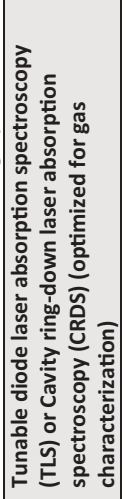 & 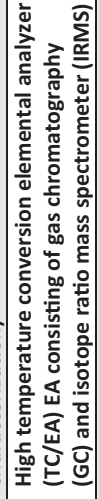 & 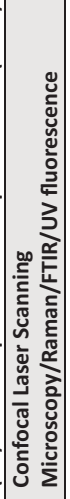 & 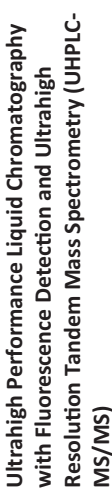 & 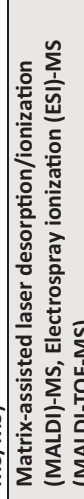 & 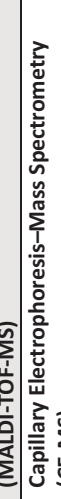 & 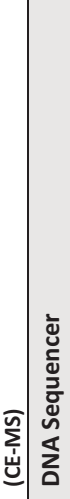 & 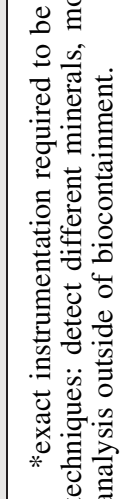 \\
\hline
\end{tabular}




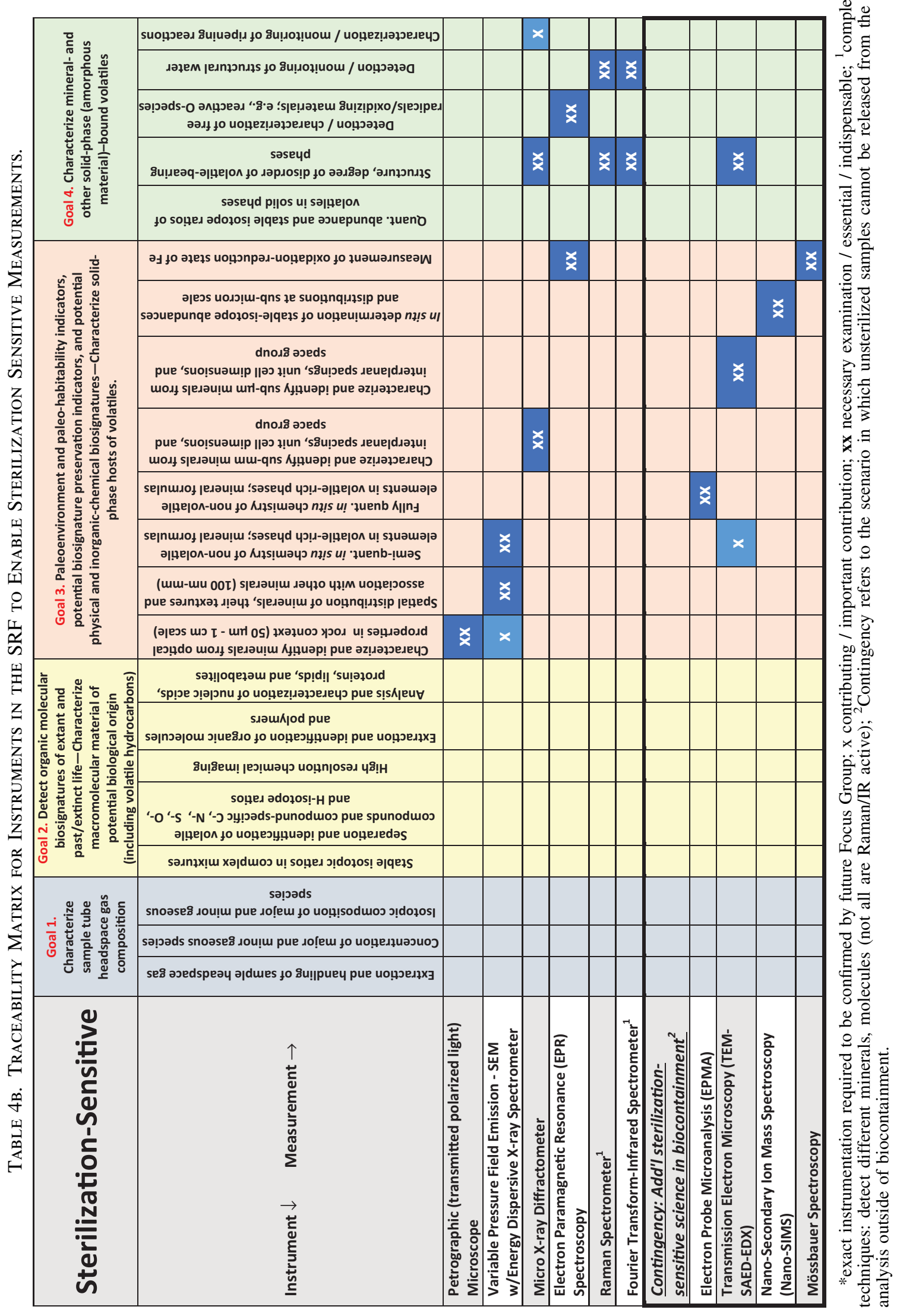




\section{The SRF: A Key Strategy}

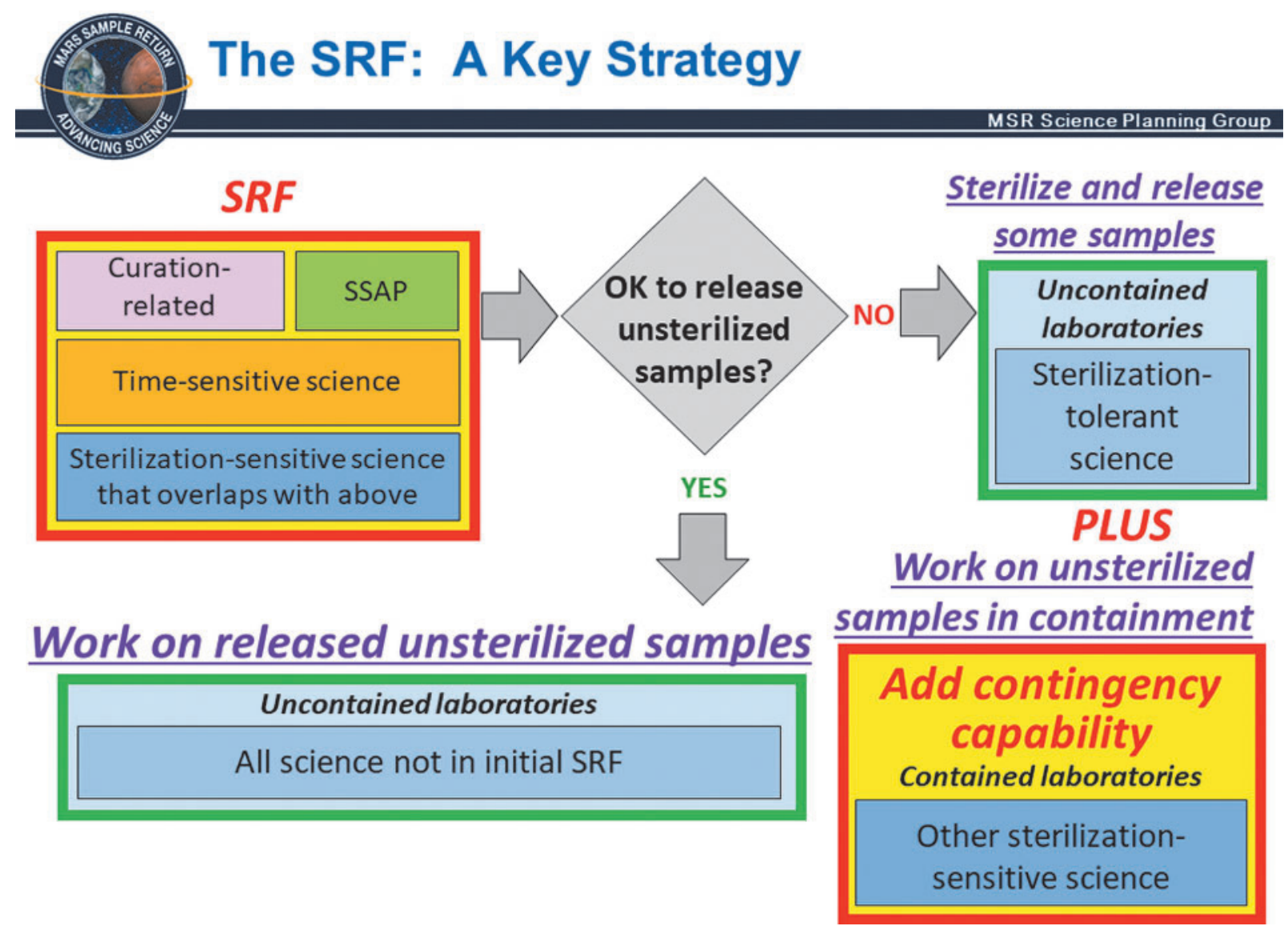

FIG. 12. A key SRF strategy is that the SRF is designed to initially accommodate only the measurements and analyses that cannot reasonably be made outside of biocontainment, including those required for initial sample characterization, SSAP tests, and time-sensitive science. Two scenarios are shown for sterilization-sensitive measurements, that are contingent upon on SSAP determination that sample is safe for unsterilized release (green YES path to uncontained outside laboratories) or unsafe for unsterilized release (red NO path to uncontained outside laboratories for sterilization tolerant science PLUS contained contingency laboratories enabling sterilization sensitive MSR Campaign measurements on unsterilized samples that cannot be deemed safe for release from containment). From Carrier et al. (2022).

(Rummel et al., 2002). In summary, all measurements that we will be making as part of the martian organic molecular biosignature/life detection search and the criteria are based on the characteristics of life as we know it on Earth and our current understanding of abiotic chemistry, but most would also detect "an object, substance and/or pattern that might have a biological origin" (Beaty et al., 2019, p. S56-S57) even if based on a different chemistry of functionally similar information-bearing polymers. The recommended SRF instrument suite would cover observation types relevant to most forms of supposed alternative life (see also Sections 3.4, 4.1, and 5.5).

There is clearly a level of agnosticism that the MSPG cannot realistically address. For example, if the alien life is constructed in such a way that it cannot be detected by conventional mass spectrometry methods then we would need entirely new types of instruments to detect this life. This extreme divergence from all known biology is outside the scope of the MSPG.

The SSAP WG will include a chapter about agnostic life detection in its report (Kminek, written communication, $1^{\text {st }}$ Apr 2021).

\section{Conclusions}

A high priority of the NASA/ESA Mars Sample Return Campaign is to establish whether life on Mars exists or existed where and when allowed by paleoenvironmental conditions. To answer these questions, analysis of the returned samples would require measurement of many different properties and characteristics by multiple and diverse instruments. To ensure that the sample properties measured accurately reflect the conditions at the time the samples were collected on Mars - in other words, to ensure sample integrity-MSR Campaign-Level Science Requirements require specific minimization of terrestrial contamination and excursions of temperature, radiation, magnetic field exposure and atmosphere (outside their natural ranges on Mars) at any stage between sample acquisition on Mars and sample arrival at the SRF. Planetary Protection requirements may determine that unsterilized subsamples cannot be safely released to non-Biosafety Level-4 (BSL-4) terrestrial laboratories. Consequently, it is necessary to determine what, if any, are the negative effects that sterilization might have on sample integrity, specifically the fidelity of the subsample 
properties that are to be measured. Sample properties that do not survive sterilization intact should be measured on unsterilized subsamples, and the Sample Receiving Facility (SRF) should support such measurements.

This report considers the effects that sterilization of subsamples might have on the science goals of the MSR Campaign. It assesses how the consequences of sterilization affect the scientific usefulness of the subsamples and hence our ability to conduct high-quality science investigations. We consider the sterilization effects of (a) the application of dry heat under two temperature-time regimes $\left(180^{\circ} \mathrm{C}\right.$ for 3 hours; $250^{\circ} \mathrm{C}$ for $30 \mathrm{~min}$ ) and (b) $\gamma$-irradiation (100 Mrad; $1 \mathrm{MGy}$ ) as provided to us by the NASA and ESA PPOs.

Measurements of many properties of volatile-rich materials are sterilization sensitive-they would be compromised by application of either sterilization mode to the subsample. Such materials include organic molecules, hydrous minerals (crystalline solids), and hydrous amorphous (non-crystalline) solids. Either proposed sterilization method will modify the abundances, isotopes, or oxidation-reduction (redox) states of the six most abundant chemical elements in biological molecules (CHNOPS elements) and of other redox-sensitive elements (e.g., $\mathrm{Fe}$ and other FRTE; Ce). As a result of these modifications, such evidence of Mars' paleoenvironmental history, potential habitability, and potential biosignatures would be corrupted or destroyed. Modifications of the abundances of some noble gases in samples heated during sterilization would also reset scientifically important radioisotope geochronometers and atmospheric-evolution measurements.

Sterilization is designed to render terminally inactive (kill) all living microorganisms and to inactivate complex biological molecules (including bacterial spores, viruses, and prions). Sterilization processes do so by breaking certain pre-sterilization chemical bonds (including strong C-C, $\mathrm{C}-\mathrm{O}, \mathrm{C}-\mathrm{N}$, and $\mathrm{C}-\mathrm{H}$ bonds of predominantly covalent character, and weaker hydrogen and van der Waals bonds) and forming different bonds and compounds, disabling the pre-sterilization biological function of the pre-sterilization chemical compound.

The group finds the following:

- No sterilization process could destroy the viability of cells while still retaining molecular structures completely intact. This applies not only to the organic molecules of living organisms, but also to most organic molecular biosignatures of former life (molecular fossils). As a matter of biological principle, any sterilization process would result in the loss of biological and paleobiological information. Thus, almost all life science investigations would be compromised by sterilizing the sample by either mode.

- Sterilization by dry heat at the proposed temperatures would lead to changes in many of the minerals and amorphous solids that are most significant for the study of paleoenvironments, habitability, potential biosignatures, and the geologic context of life-science observations. It is crucial that the returned samples are processed, curated and analyzed at temperatures below which phase transitions occur.

- Gamma-( $\gamma$-)irradiation at even sub-MGy doses induces radiolysis of water. The radiolysis products (e.g., free radicals) react with redox-sensitive chemical spe- cies of interest for the study of paleoenvironments, habitability, and potential biosignatures, thereby adversely affecting measurements of those species.

- Heat sterilization and radiation also have a negative effect on CHNOPS and redox-sensitive elements. MSPG2 is unable to identify with confidence any measurement of abundances or oxidation-reduction states of CHNOPS elements, other redox-sensitive elements (e.g., Fe and other FRTE; Ce) or their isotopes that would be affected by only one but not both of the considered sterilization methods.

At some stage during the analytical program, it is likely that a sterilization method would have to be selected for application to subsamples of the returned material prior to it being distributed beyond the SRF. For each subsample, there should be a trade-off discussion as to which modality (heat or radiation) would cause the least damage to the material for specified analyses. One consideration to take into account when a sterilization method is to be selected is the argument that significant radiation damage may have occurred naturally to the samples in Jezero Crater prior to coring and caching (the Cumberland mudstone in Gale Crater was exposed to ionizing radiation for $\sim 80$ million years (Farley et al., 2014) which is equivalent to 4 MGy of $\gamma$ exposure). In contrast, the outcrop material in Jezero Crater probably did not see temperatures much higher than $-20^{\circ} \mathrm{C}$ in recent geological history, so sterilization heating of the samples at temperatures of $180^{\circ} \mathrm{C}$ or higher would have a significant impact on compositional properties of the samples. The exposure history of the samples collected in Jezero Crater to ionizing radiation will not be known until they are returned to Earth and analyzed. If, however, burial and exhumation/erosion rates similar to those at Gale Crater are assumed for Jezero Crater, it is not at all unreasonable to expect that the near-surface sedimentary rocks in Jezero will have also been exposed to ionizing radiation for tens of millions of years.

Measurements of many attributes of volatile-rich subsamples are sterilization sensitive to both heat and $\gamma$ irradiation. Such a measurement is not useful to Mars science if what remains in the subsample is evidence of sterilization conditions and effects instead of evidence of conditions on Mars. Most life-sciences measurements are sterilization sensitive. Many measurements other than those for life-science seek to retrieve Mars' paleoenvironmental information from the abundances or oxidation-reduction states of CHNOPS elements and other redox-sensitive elements or their isotopes (and some noble gases) in returned samples. Such measurements inform scientific interpretations of (paleo)atmosphere composition and evolution, (paleo)surface water origin and chemical evolution, potential (paleo)habitability, (paleo)groundwater-porewater solute chemistry origin and evolution, potential biosignature preservation, metabolic element or isotope fractionation, and the geologic, geochronological, and geomorphic context of lifesciences observations. Most such measurements are also sterilization sensitive. The sterilization-sensitive attributes cannot be meaningfully measured in any such subsample that has been sterilized by heat or $\gamma$-irradiation. Unless such subsamples are deemed biohazard-safe for release to external laboratories in unsterilized form, all such measurements must 
be made on unsterilized samples in biocontainment. The SRF should have the capability to carry out scientific investigations that are sterilization-sensitive to both PPO-provided sterilization methods (Figure 12).

\section{Summary:}

- The SRF should have the capability to carry out or otherwise support scientific investigations that are sensitive to both PPO-provided sterilization methods.

- Measurements of most life-sciences and habitabilityrelated (paleoenvironmental) phenomena are sensitive to both PPO-provided sterilization modes. (Major Finding SS-7, SS-13, SS-15, SS-16 and Finding SS-1, SS-3, SS-4, SS-5, SS-6, SS-9, SS-11) If subsamples for sterilization-sensitive measurement cannot be deemed safe for release, then additional contingency analytical capabilities are needed in the SRF to complete MSR Campaign measurements of sterilization-sensitive sample properties on unsterilized samples in containment (Figure 12).

- Measurements of high-temperature (low-volatile) phenomena are tolerant of both PPO-provided sterilization modes (Finding SS-12). Samples for such measurements may be sterilized and released to laboratories outside containment without compromising the scientific value of the measurements.

- Capturing, transporting, and analyzing gases is important and will require careful design of apparatus. Doing so for volatiles present as headspace gases and a dedicated atmosphere sample will enable important atmospheric science (Major Finding SS-14). Similarly capturing and analyzing gases evolved during sample sterilization (i.e., gas from the sterilization chamber) would compensate for some sterilization-induced loss of science data from volatile-rich solid (geological) subsamples (Major Finding SS-17; other options incl. SS-8).

\section{Recommendations for Future Work}

The Sterilization Effects Focus Group recommends that, as soon as sterilization regimens (including the sterilization chamber atmosphere(s)) have been decided, specific investigations be initiated to fill knowledge gaps and thereby support better-informed anticipation of sterilization effects on important specific scientific measurements of specific sample types. In the interests of limiting the length of this document, conserving space in the SRF, and focusing attention on only the highest priority areas, almost all lower priority recommendations are not included here.

\section{Both PPO-provided sterilization modes}

Improve understanding of upper temperature and $\gamma$ radiation limits of survival of biological macromolecules and those that can express some biological activity after exposure to sterilization conditions, and the rate of destruction and quantification of fragmentation of key biological macromolecules in response to the specific conditions and parameters proposed of both PPO-provided sterilization modes. Analog experiments to date have been focused on the effects of radiation and heat on chemical building blocks of life (e.g., amino acids, fatty acids, nucleobases, etc.), not on macromolecules (proteins, DNA/RNA, etc.). Investigations should include target compounds in Mars-relevant mixtures (e.g., in Mars-analog regolith simulants and rocks), in addition to pure compounds. Section 2.2, 3.2, 3.3, 3.4 and Finding SS-3 and SS-7. Priority: High

The effects of perchlorates and other oxidants on the behavior and destruction rates of key biological macromolecules in response to the sterilization modes proposed for the SRF. Analog experiments to date have been focused on the effects of radiation and heat on chemical building blocks of life (e.g., amino acids, fatty acids, nucleobases, etc.), not on macromolecules (proteins, DNA/RNA, etc.). Investigations should include target compounds in Marsrelevant mixtures (e.g., in Mars-analog regolith simulants and rocks), in addition to pure compounds. Section 4.2 and Finding SS-5. Priority: High

Technology- and work-process development work should be done to support capture and characterization of the volatile byproducts generated during the sterilization process. The gas released during heat sterilization or $\gamma$-irradiation is usually not captured or analyzed. But for MSR samples, the evolved gases in the sterilization-chamber are atoms and molecules from Mars. The sterilization process can yield science if the sterilization chamber gases evolved from the sterilized subsample can be captured for science instead of lost to science. Sections 3, 4, 5, 6.1, 7 and Major Finding SS-17. Priority: High

Additional experiments at conditions that duplicate heat and $\gamma$-irradiation sterilization conditions should be conducted on analog samples of amorphous solids, poorly crystalline glasses and iron oxides, hydroxides, and oxyhydroxides, which can produce peroxides, superoxides, and/ or molecular hydrogen which could react with surrounding minerals in unpredictable and irreversible ways. Little if any experimental work has been done in this area. Investigations should include target phases in Mars-relevant mixtures (e.g., in Mars-analog regolith simulant and rocks), in addition to pure phases. Section 5.1, 5.3, 5.4, 5.5, 5.7, 6.1.2 and Finding SS-9, SS-11, SS-13, SS-15. Priority: Intermediate

\section{$\gamma$-irradiation only}

Additional studies are required to determine how much biomolecular integrity and biological information can be retained following different doses and dose rates of $\gamma$ irradiation. Investigations should include target compounds in Mars-relevant mixtures (e.g., in Mars-analog regolith simulants and rocks), in addition to pure compounds. Section 3.3, 4.3 and Finding SS-4, SS-6, SS-7. Priority: High

The attenuation of $\gamma$-rays through the vessel walls will need to be assessed depending on the material (metal or glass, thickness) for both confirmation of sterilization efficacy and concurrent modification of gaseous molecules properties and isotope systems. Section 6.3 and Finding SS-14. Priority: High

The effect of $\gamma$-irradiation on secondary minerals, particularly those with multiple hydration states, needs experimental study. Investigations should include target phases in Mars-relevant mixtures (e.g., in Mars-analog regolith simulants and rocks), in addition to pure phases. Section 5.4 and Finding SS-10, SS-11. Priority: Intermediate 


\section{Overall}

The feasibility of sterilizing the gases by filtering through an inert grid should be investigated. PP-acceptable pore sizes should be defined; the sterilization efficiency of the process should be assessed; the potential adsorption of different gases onto the grid should be investigated; potential contamination of gas samples should be assessed under operational (pressure, temperature, quantity) conditions. It is possible that some, or even all, of the gases returned from Mars could be sterilized by filtration and then subsequently analyzed outside of containment. Section 6.4, 6.5 and Finding SS-14. Priority: High

In order to facilitate sterilization-sensitive investigations involving low-T minerals and/or X-ray amorphous materials, sample preparation protocols that safely isolate and contain unsterilized sample aliquots for analysis outside the SRF (e.g., containment within X-ray transparent materials in a way that also satisfies the SSAP) should be investigated and developed where possible. Section 5.2, 5.3, 5.5 and Finding SS-9, SS-11, SS-13. Priority: High

Outside SRF containment: As soon as a $\gamma$-irradiation sterilization regimen has been decided (including the sterilization chamber atmosphere(s)), a duplicate lab devoted to $\gamma$-irradiation sterilization should be set up and eventually relocated into the SRF but outside of biological containment. That lab would be devoted to running terrestrial analog and regolith simulant samples in order to quickly understand the results of $\gamma$-irradiation at sterilization doses and dose rates on the material from Mars. Having a dedicated lab/facility to validate the $\gamma$ sterilization approach also a good idea noting that the infrastructure required for $\gamma$ sterilization is significant-it is not clear that such a lab could be simply relocated to the SRF. The $\gamma$-sterilization lab will likely need to be part of the SRF building design. Priority: High.

\section{Acknowledgments}

The MSPG2 Sterilization Effects Focus Group would like to thank the entire MSPG2 committee for their input and discussions during and after our bi-weekly meetings; and external reviewers Brian Clement, Lydia Hallis, Elisabeth Hausrath, Karen Olsson-Francis, and Sandra Siljeström, Strategic Team reviewers Gerhard Kminek, Michael Meyer, Roger Summons, and Frances Westall, and All-Group reviewers Ernst Hauber, Aurore Hutzler, Francis McCubbin, Usui Tomohiro, and Arya Udry for their reviews. We thank editor exemplar Monica Grady and fellow Focus Group Leads Kimberly Tait and Nicholas Tosca for ongoing input on this document. We especially acknowledge the subject matter experts Carl Allen, Dan Barfod, Marc Caffee, Darby Dyar, Paul Niles, Alex Pavlov, Michael Plötze, and Susanne Schwenzer for their important input; and, finally, Dave Beaty and Brandi Carrier for always being there.

A portion of this work was carried out at the Jet Propulsion Laboratory, California Institute of Technology, under a contract with the National Aeronautics and Space Administration (80NM0018D0004).

The decision to implement Mars Sample Return will not be finalized until NASA's completion of the National Environmental Policy Act (NEPA) process. This document is being made available for planning and information purposes only.

\section{Disclosure Statement}

No competing interests.

\section{Funding Information}

A portion of this work was funded by the National Aeronautics and Space Administration (NASA) and the European Space Agency (ESA).

A portion of this work was carried out at the Jet Propulsion Laboratory, California Institute of Technology, under a contract with the National Aeronautics and Space Administration (80NM0018D0004).

This work has partly $(\mathrm{H}$. B.) been carried out within the framework of the NCCR PlanetS supported by the Swiss National Science Foundation. M. A. V.'s participation in MSPG2 was supported in part by a sabbatical leave-ofabsence from Michigan State University. M.-P.Z. was supported by projects PID2019-104205GB-C21 of Ministry of Science and Innovation and MDM-2017-0737 Unidad de Excelencia 'Maria de Maeztu'- Centro de Astrobiología (CSIC-INTA) (Spain).

\section{References}

Alef K and Nannipleri P, Eds. (1995) Methods in Applied Soil Microbiology and Biochemistry. Academic Press, San Diego. USA.

Allen CC, Morris RV, Jager KM, et al. (1998) Martian regolith simulant JSC Mars-1 [abstract 1690]. In 30th Lunar and Planetary Science Conference, Lunar and Planetary Institute, Houston.

Allen CC, Albert FG, Combie J, et al. (1999) Effects of sterilizing doses of gamma radiation on Mars analog rocks and minerals. J Geophys Res Planets 104:27043-27066.

Allwood MC and Russell AD (1970) Mechanisms of thermal injury in nonsporulating bacteria. Adv App Microbiol 12:89119.

Appel TR, Lucassen R, Groschup MH, et al. (2006) Acid inactivation of prions: efficient at elevated temperature or high acid concentration. J Gen Virol 87:1385-1394.

Atreya SK, Trainer MG, Franz HB, et al. (2013) Primordial argon isotope fractionation in the atmosphere of Mars measured by the SAM instrument on Curiosity and implications for atmospheric loss. Geophys Res Lett, 40:5605-5609.

Ayllón-Quevedo F, Souza-Egipsy V, Sanz-Montero ME, et al. (2007) Fluid inclusion analysis of twinned selenite gypsum beds from the Miocene of the Madrid basin (Spain). Implication on dolomite bioformation. Sedimentary Geology 201:212-230.

Ayora C, Garcia-Veigas J, Pueyo J-J (1994) X-ray microanalysis of fluid inclusions and its application to the geochemical modeling of evaporite basins. Geochim et Cosmochim Acta 58:43-55.

Ayora C, Cendón DI, Taberner C, et al. (2001) Brine-mineral reactions in evaporite basins: Implications for the composition of ancient oceans. Geology 29:251-254.

Bada JL, Glavin DP, McDonald GD, et al. (1998) A search for endogenous amino acids in martian meteorite ALH84001. Science 279:362-365.

Bank TL, Kukkadapu RK, Madden AS, et al. (2008) Effects of gamma-sterilization on the physico-chemical properties of natural sediments. Chem Geol 251:1-7.

Bass MN (1957) Effects of gamma-irradiation on physical properties of minerals. Am Min 42:100-104. 
Battista JR (1997) Against all odds: The survival strategies of Deinococcus radiodurans. Annual Review of Microbiology 51:203-224.

Bauer KK and Vennemann TW (2014) Analytical methods for the measurement of hydrogen isotope composition and water content in clay minerals by TC/EA. Chem Geol 363:229-240.

Beaty DW, McSweeen H, Czaja AD, et al. (2016) Recommended maximum temperature for Mars returned samples [abstract 2622]. In 47th Lunar and Planetary Science Conference, Lunar and Planetary Institute, Houston.

Beaty DW, Grady MM, McSween HY, et al. (2019) The potential science and engineering value of samples delivered to Earth by Mars sample return: International MSR Objectives and Samples Team (iMOST). Meteorit Planet Sci 54:S3S152.

Benison KC (2013) Acid saline fluid inclusions: examples from modern and Permian extreme lake systems. Geofluids 13: 579-593.

Benner SA, Devine KG, Matveeva LN and Powell DH (2000) The missing organic molecules on Mars. Proc Natl Acad Sci 97:2425-2430.

Berejka AJ and Kaluska IM (2008) Materials used in medical devices. In Trends in radiation sterilization of health care products. Vienna: International Atomic Energy Agency, STI/ PUB/1313, pp 119-128.

Berns AE, Philipp H, Narres H-D, et al. (2008) Effect of gamma-sterilization and autoclaving on soil organic matter structure as studied by solid state NMR, UV and fluorescence spectroscopy. Eur J Soil Sci 59:540-550.

Bibring JP, Langevin Y, Gendrin A, et al. (2005) Mars surface diversity as revealed by the OMEGA/Mars Express observations. Science 307:1576-1581.

Bish DL and Duffy CJ (1990) Thermogravimetric analysis of minerals. In Thermal Analysis in Clay Science, Eds. JW Stucki and DL Bish, Boulder, Colorado: The Clay Minerals Society. The Clay Minerals Society Workshop Lecture Series 3, pp 96-157.

Bish DL, Blake DF, Vaniman DT, et al. (2013) X-ray diffraction results from Mars Science Laboratory: Mineralogy of Rocknest at Gale Crater. Science 341.

Bishop JL, Fairén AG, Michalski JR, et al. (2018) Surface clay formation during short-term warmer and wetter conditions on a largely cold ancient Mars. Nature Astron. 2:202-213.

Bishop JL, Dobrea EZN, McKeown NK, et al. (2008) Phyllosilicate diversity and past aqueous activity revealed at Mawrth Vallis, Mars. Science 321:830-833.

Blanco Y, De Diego-Castilla G, Viúdez-Moreiras D, et al. (2018) Effects of gamma and electron radiation on the structural integrity of organic molecules and macromolecular biomarkers measured by microarray immunoassays and their astrobiological implications. Astrobiology 18:1497-1516.

Bouniol P and Aspart A (1998) Disappearance of oxygen in concrete under irradiation: The role of peroxides in radiolysis. Cement and Concrete Research 28:1669-1681.

Bonner WA, Hall H, Chow G., et al. (1985) The radiolysis and radioracemization of amino acids on clays. Origins of Life 15: 103-114.

Borick PM and Fogarty M (1967) Effects of continuous and interrupted radiation on microorganisms. Applied Microbiology 15(4):785-789.

Borlina CS, Ehlmann BL and Kite ES (2015) Modeling the thermal and physical evolution of Mount Sharp's sedimentary rocks, Gale Crater, Mars: Implications for diagenesis on the MSL Curiosity rover traverse. J Geophys Res Planets 120: 1396-1414.
Bristow TF, Rampe EB, Achilles CN, et al. (2018) Clay mineral diversity and abundance in sedimentary rocks of Gale Crater, Mars. Sci Adv 4, doi:10.1126/sciadv.aar3330.

Burton AS, Berger EL, Locke DR, et al. (2018) Correlated amino acid and mineralogical analyses of milligram and submilligram samples of carbonaceous chondrite Lonewolf Nunataks 94101 [abstract 2425]. In 49th Lunar and Planetary Science Conference, Lunar and Planetary Institute, Houston. Cady SL and Farmer JD (1996) Fossilization processes in siliceous thermal springs: Trends in preservation along thermal gradients. In: Ciba Foundation Symposium 202 - Evolution of Hydrothermal Ecosystems on Earth (And Mars?), pp 150-173.

Callahan MP, Burton AS, Elsila JE, et al. (2013) A search for amino acids and nucleobases in the martian meteorite Roberts Massif 04262 using liquid chromatography-mass spectrometry. Meteorit Planet Sci 48:786-795.

Calvin WM, King TVV and Clark RN (1994) Hydrous carbonates on Mars?: Evidence from Mariner 6/7 infrared spectrometer and ground-based telescopic spectra. J Geophys Res Planets 99:14659-14675.

Carrier BL, Beaty DW, Hutzler A, et al. (2022) Science and curation considerations for the design of a Mars Sample Return (MSR) Sample Receiving Facility (SRF). Astrobiology 22(S1):S-217-S-237.

Cebrián G, Condon S and Manas P (2017) Physiology of the inactivation of vegetative bacteria by thermal treatments: Mode of action, influence of environmental factors and inactivation kinetics. Foods 6:107.

Che C, Glotch TD, Bish DL, et al. (2011) Spectroscopic study of the dehydration and/or dehydroxylation of phyllosilicate and zeolite minerals. J Geophys Res Planets 116.

Chen D, Bryden WA and Fenselau C (2019) Microwave supported hydrolysis prepares Bacillus spores for proteomic analysis. Int J Mass Spectrom 435:227-233.

Chikkamath S, Manjanna J, Kabadagi A, et al. (2021) Gamma (60Co) irradiation and thermal effect on redox behavior of interlayer iron in montmorillonite. Applied Clay Science 200: 105893.

Clark BC (2004) Temperature-time issues in bioburden control for planetary protection. Adv Space Res 34:2314-2319.

Cohen BA, Malespin CA, Farley KA, et al. (2019) In situ geochronology on Mars and the development of future instrumentation. Astrobiology 19:1303-1314.

Conrad PG, Malespin CA, Franz HB, et al. (2016) In situ measurement of atmospheric krypton and xenon on Mars with Mars Science Laboratory. Earth Planet Sci Lett 454:1-9.

Coshell L, Rosen MR and McNamara KJ (1998) Hydromagnesite replacement of biomineralized aragonite in a new location of Holocene stromatolites, Lake Walynugup, Western Australia. Sedimentology 45:1005-1018.

Council TC and Bennett PC (1993) Geochemistry of ikaite formation at Mono Lake, California: implications for the origin of tufa mounds. Geology 21:971-974.

Court RW, Sephton MA, Parnell J and Gilmour I (2006) The alteration of organic matter in response to ionising irradiation: Chemical trends and implications for extraterrestrial sample analysis. Geochim et Cosmochim Acta 70:1020-1039.

Craven E, Winters M, Smith AL, et al. (2021) Biological safety in the context of backward planetary protection and Mars Sample Return: conclusions from the Sterilization Working Group. Int J Astrobiol 20:1-28.

Daly MJ, Gaidamakova EK, Matrosova VY, et al. (2004) Accumulation of $\mathrm{Mn}$ (II) in Deinococcus radiodurans facilitates gamma-radiation resistance. Science 306:1025-1028. 
Decarreau A and Bonnin D (1986) Synthesis and crystallogenesis at low temperature of $\mathrm{Fe}$ (III)-smectites by evolution of coprecipitated gels: Experiments in partially reducing conditions. Clay Minerals 21:861-877.

Des Marais DJ, Nuth JA, Allamandola LJ, et al. (2008) The NASA Astrobiology Roadmap. Astrobiology 8:715-730.

Dundar M, Ehlmann BL and Leask EK (2021, in review) Machine-Learning-Driven New Geologic Discoveries at Mars Rover Landing Sites: Jezero and NE Syrtis. Geophys Res Lett.

Ehlmann BL and Mustard JF (2012) An in-situ record of major environmental transitions on early Mars at Northeast Syrtis Major. Geophys Res Lett 39:L11202.

Ehlmann BL, Mustard JF, Fassett CI, et al. (2008a) Clay minerals in delta deposits and organic preservation potential on Mars. Nat Geosci 1:355-358.

Ehlmann BL, Mustard JF, Murchie SL, et al. (2008b) Orbital identification of carbonate-bearing rocks on Mars. Science 322:1828-32.

Ehlmann BL, Mustard JF, Clark RN, et al. (2011) Evidence for low-grade metamorphism, hydrothermal alteration, and diagenesis on Mars from phyllosilicate mineral assemblages. Clays and Clay Minerals 59:359-377.

Eigenbrode JL, Summons RE, Steele A, et al. (2018) Organic matter preserved in 3-billion-year-old mudstones at Gale crater, Mars. Science 360:1096-1101.

El-Shenawy MI, Niles PB, Ming DW, et al. (2020) Oxygen and carbon stable isotope composition of the weathering $\mathrm{Mg}$ carbonates formed on the surface of the LEW 85320 ordinary chondrite: Revisited. Meteorit Planet Sci 55:1884-1898.

Emerson JB, Adams RI, Román CMB, et al. (2017) Schrödinger's microbes: Tools for distinguishing the living from the dead in microbial ecosystems. Microbiome 5:86-86.

Ertem G, Ertem MC, McKay CP, et al. (2017) Shielding biomolecules from effects of radiation by Mars analogue minerals and soils. Int J Astrobiol 16:280-285.

Evans NP, Turchyna AV, Gázquez F, et al. (2015) Coupled measurements of $\delta^{18} \mathrm{O}$ and $\delta \mathrm{D}$ of hydration water and salinity of fluid inclusions in gypsum from the Messinian Yesares Member, Sorbas Basin (SE Spain). Earth Planet Sci Lett 430: 499-510.

Farley KA, Malespin C, Mahaffy P, et al. (2014) In situ radiometric and exposure age dating of the martian surface. Science 343:1247166-1247166.

Farley KA, Williford KH, Stack KM, et al. (2020) Mars 2020 Mission Overview. Space Sci Rev 216:142.

Fox AC, Eigenbrode JL and Freeman KH (2019) Radiolysis of macromolecular organic material in Mars-relevant mineral matrices. J Geophys Res Planets 124:3257-3266.

Fraeman AA, Ehlmann BL, Arvidson RE, et al. (2016) The stratigraphy and evolution of lower Mount Sharp from spectral, morphological, and thermophysical orbital data sets. J Geophys Res Planets 121:1713-1736.

Freissinet C, Glavin DP, Mahaffy PR, et al. (2015) Organic molecules in the Sheepbed Mudstone, Gale Crater, Mars. $J$ Geophys Res Planets 120:495-514.

Frick A, Mogul R, Stabekis P, et al. (2014) Overview of current capabilities and research and technology developments for planetary protection. Advances in Space Research 54:221-240.

Friedman I and Long W (1984) Volcanic glasses, their origins and alteration processes. Journal of Non-Crystalline Solids 67:127-133.

Frost RL, Ruan H, Kloprogge JT, et al. (2000) Dehydration and dehydroxylation of nontronites and ferruginous smectite. Thermochimica Acta 346:63-72.
Frost RL, Weier ML and Martens W (2005) Thermal decomposition of jarosites of potassium, sodium and lead. Journal of Thermal Analysis and Calorimetry 82:115-118.

Glavin DP and Bada JL (1998) Isolation of amino acids from natural samples using sublimation. Anal Chem 70:31193122.

Glavin DP, Bada JL, Brinton KL, et al. (1999) Amino acids in the martian meteorite Nakhla. Proc Nat Acad Sci 96:8835-8. Glavin DP and Bada JL (2001) Survival of amino acids in micrometeorites during atmospheric entry. Astrobiology 1:259-269.

Glavin DP, Schubert M, Botta O, et al. (2001) Detecting pyrolysis products from bacteria on Mars. Earth Planet Sci Lett 185:1-5.

Glavin DP, Schubert M and Bada JL (2002) Direct isolation of purines and pyrimidines from nucleic acids using sublimation. Anal Chem 74:6408-6412.

Glavin DP, Cleaves HJ, Schubert M, et al. (2004) New method for estimating bacterial cell abundances in natural aamples by use of sublimation. Appl Environ Microbiol 70:59235928.

Glavin DP, Callahan MP, Dworkin JP, et al. (2010) The effects of parent body processes on amino acids in carbonaceous chondrites. Meteorit Planet Sci 45:1948-1972.

Glavin DP, Freissinet C, Miller KE, et al. (2013) Evidence for perchlorates and the origin of chlorinated hydrocarbons detected by SAM at the Rocknest aeolian deposit in Gale Crater. J Geophys Res Planets 118:1-19.

Golombek M, Grant J, Kipp D, et al. (2012) Selection of the Mars Science Laboratory landing site. Space Sci Rev 170:641-737.

Gooding JL (1992) Soil mineralogy and chemistry on Mars: Possible clues from salts and clays in SNC meteorites. Icarus 99:28-41.

Gorski CA, Klüpfel LE, Voegelin A, et al. (2013) Redox properties of structural $\mathrm{Fe}$ in clay minerals: 3. Relationships between smectite redox and structural properties. Environ Sci Technol 47:13477-13485.

Goudge TA, Mustard JF, Head JW, et al. (2015) Assessing the mineralogy of the watershed and fan deposits of the Jezero Crater paleolake system, Mars. J Geophys Res Planets 120: 775-808.

Gournis D, Mantaka-Marketou AE, Karakassides MA, et al. (2000) Effect of $\gamma$-irradiation on clays and organoclays: A Mössbauer and XRD study. Physics and Chemistry of Minerals 27:514-521.

Gournis D, Mantaka-Marketou AE, Karakassides MA, et al. (2001) Ionizing radiation-induced defects in smectite clays. Physics and Chemistry of Minerals 28:285-290.

Grady MM, Gibson Jr EK, Wright IP, et al. (1989) The formation of weathering products on the LEW 85320 ordinary chondrite: Evidence from carbon and oxygen stable isotope compositions and implications for carbonates in SNC meteorites. Meteoritics 24:1-7.

Grady MM, Summons RE, Swindle T, et al. (2022) The scientific importance of returning airfall dust as part of Mars Sample Return (MSR). Astrobiology 22(S1):S-176-S-185.

Grant JA, Golombek MP, Wilson SA, et al. (2018) The science process for selecting the landing site for the 2020 Mars rover. Planet Space Sci 164:106-126.

Gray BS (1972) The effects of reactor radiation on cements and concrete. In Commission of the European Communities $(C E C)$, Brussels, Belgium, pp. 17-40. (Cited by Reches, 2019; not seen by the authors of this report).

Grim RE (1953) Clay Mineralogy. New York; McGraw-Hill Book Co., Inc., 384 pp. 
Grotzinger JP, Sumner DY, Kah LC, et al. (2014) A habitable fluvio-lacustrine environment at Yellowknife Bay, Gale Crater, Mars. Science 343.

Grotzinger JP, Gupta S, Malin MC, et al. (2015) Deposition, exhumation, and paleoclimate of an ancient lake deposit, Gale Crater, Mars. Science 350.

Hammad AA (2008) Microbiological aspects of radiation sterilization. In Trends in radiation sterilization of health care products. Vienna: International Atomic Energy Agency, STI/ PUB/1313, pp 119-128.

Hassler DM, Zeitlin C, Wimmer-Schweingruber RF, et al. (2014) Mars' surface radiation environment measured with the Mars Science Laboratory's Curiosity rover. Science 343:1244797.

Hecht MH, Kounaves SP, Quinn RC, et al. (2009) Detection of perchlorate and the soluble chemistry of martian soil at the Phoenix Lander site. Science 325:64-67.

Herd CDK, Bosak T, Stack KM, et al. (2021) Sampling Mars: Notional caches from Mars 2020 strategic planning [abstract 1987]. In 52nd Lunar and Planetary Science Conference, Lunar and Planetary Institute, Houston.

Hermankova P, Hermanek M and Zboril R (2010) Thermal decomposition of ferric oxalate tetrahydrate in oxidative and inert atmospheres: The role of ferrous oxalate as an intermediate. European Journal of Inorganic Chemistry 2010:1110-1118.

Hochstein LI, Kvenolden KA and Philpott DE (1974) The effect of sterilization on biological organic, chemical and morphological information in natural samples. NASA-TM-X-72883, Ames Research Center, April 11, 74 pp.

Horgan BHN, Anderson RB, Dromart G, et al. (2020) The mineral diversity of Jezero Crater: Evidence for possible lacustrine carbonates on Mars. Icarus 339:113526.

Huang W-L, Bassett WA and Wu T-C (1994) Dehydration and hydration of montmorillonite at elevated temperatures and pressures monitored using synchrotron radiation. Am Min 79:683-691.

Huggett JM, Schultz BP, Shearman DJ, et al. (2005) The petrology of ikaite pseudomorphs and their diagenesis. Proc of the Geologists' Assoc 116:207-220.

Hurowitz JA, Grotzinger JP, Fischer WW, et al. (2017) Redox stratification of an ancient lake in Gale crater, Mars. Science 356.

ISO 11139 (2018) International Organization for Standardization. Sterilization Of Health Care Products-Sterilization of health care products-Vocabulary of terms used in sterilization and related equipment and process standards (ISO Standard No. 11139:2018).

James NP, Narbonne GM, Dalrymple RW, et al. (2005) Glendonites in Neoproterozoic low-latitude, interglacial, sedimentary rocks, northwest Canada: Insights into the Cryogenian ocean and Precambrian cold-water carbonates. Geology 33:9-12.

Johnson CM, Beard BL and Roden EE (2008) The iron isotope fingerprints of redox and biogeochemical cycling in modern and ancient earth. Ann Rev Earth Planet Sci 36:457-493.

Jull AJT, Cheng S, Gooding JL, et al. (1988) Rapid growth of magnesium-carbonate weathering products in a stony meteorite from Antarctica. Science 242:417-419.

Kaiser K and Benner R (2005) Hydrolysis induced racemization of amino acids. Limnology and Oceanography: Methods 3:318-325.

Kawano M and Tomita K (1991) Dehydration and rehydration of saponite and vermiculite. Clays and Clay Minerals 39: 174-183.

Kelly B, Brocklehurst J, Mottershead D, et al. (1969) The effects of reactor radiation on concrete. In 2nd Conference on Prestressed Concrete Pressure Vessels and Their Insulation, London, p. 1969. (Cited by Reches, 2019; not seen by the authors of this report.)
Kempf MJ, Schubert WW and Beaudet RA (2008) Determination of lethality rate constants and D-values for Bacillus atrophaeus (ATCC 9372) spores exposed to dry heat from $115^{\circ} \mathrm{C}$ to $170^{\circ} \mathrm{C}$. Astrobiology 8:1169-1182.

Kerney KR and Schuerger AC (2011) Survival of Bacillus subtilis endospores on ultraviolet-irradiated rover wheels and Mars regolith under simulated martian conditions. Astrobiology 11:477-485.

Kesler SE, Bodnar RJ and Mernagh TP (2013) Role of fluid and melt inclusion studies in geologic research. Geofluids 13:398-404.

Klein C (2002) Manual of Mineral Science (22 ${ }^{\text {nd }}$ ed.), Wiley, $641 \mathrm{p}$.

Kminek G and Bada JL (2006) The effect of ionizing radiation on the preservation of amino acids on Mars. Earth Planet Sci Lett 245:1-5.

Kminek G, Conley C, Allen CC, et al. (2014) Report of the workshop for life detection in samples from Mars. Life Sciences in Space Research 2:1-5.

Kminek MA, Meyer MA, Beaty DW, et al. (2022a) Mars Sample Return (MSR): Planning for returned sample science. Astrobiology 22(S1):S-1-S-4.

Kminek MA, Bernardini JN, Brenker FE, et al. (2022b) COSPAR Sample Safety Assessment Framework (SSAF). Astrobiology 22(S1):S-186-S-216.

Knauth LP and Beeunas MA (1986) Isotope geochemistry of fluid inclusions in Permian halite with implications for the isotopic history of ocean water and the origin of saline formation waters. Geochim et Cosmochim Acta 50:419-433.

Korcek S, Chenier JHB, Howard JA, et al. (1972) Absolute rate constants for hydrocarbon autoxidation. XXI. Activation energies for propagation and the correlation of propagation rate constants with carbon-hydrogen bond strengths. Canadian Journal of Chemistry 50:2285-2297.

Kowalski W (2009) Ultraviolet Germicidal Irradiation Handbook. Springer, Berlin.

Labeda DP, Balkwill DL and Casida LE Jr (1975) Soil sterilization effects on in situ indigenous microbial cells in soil. Can J Microbio 21:263-269.

Leshin LA, Mahaffy PR, Webster CR, et al. (2013) Volatile, isotope, and organic analysis of martian fines with the Mars Curiosity rover. Science 341.

Leuko S, Rettberg P, Bennett A, et al. (2017) Sterilization and Cleaning. EURO-CARES A Plan for European Curation of Returned Extraterrestrial Samples: Final Report of EUROCARES WP2 (D2.3), available online at http://www.eurocares.eu/reports.

Liu D and Kounaves SP (2021) Degradation of amino acids on Mars by UV irradiation in the presence of chloride and oxychlorine salts. Astrobiology 21:793-801.

Lowenstein TK, Timofeeff MN, Brennan ST, et al. (2001) Oscillations in Phanerozoic seawater chemistry: Evidence from fluid Iinclusions. Science 194:1086-1088.

Łowińska-Kluge A and Piszora P (2008) Effect of gamma irradiation on cement composites observed with XRD and SEM methods in the range of radiation dose 0-1409 MGy. Acta Physica Polonica A 114:399-411.

Lucquin A, Gibbs, K, Uchiyama J, et al. (2016) Ancient lipids document continuity in the use of early hunter-gatherer pottery through 9,000 years of Japanese prehistory. Proc Natl Acad Sci 115:3991-3996.

Mackey BM, Miles CA, Parsons SE, et al. (1991) Thermal denaturation of whole cells and cell components of Escherichia coli examined by differential scanning calorimetry. Microbiology 137:2361-2374. 
Mackey BM and Mañas P (2008) Inactivation of Escherichia coli by high pressure. In: High-Pressure Microbiology; C. Michiels, A. Aertsen, D. Bartlett, Y. Yayanos Eds.; ASM Press: Washington, DC, USA, pp. 53-85.

Maddalena R, Li K, Chater PA, et al. (2019) Direct synthesis of a solid calcium-silicate-hydrate $(\mathrm{C}-\mathrm{S}-\mathrm{H})$. Construction and Building Materials 223:554-565.

Marciniec B and Dettlaff K (2008) Radiation sterilization of drugs: An overview of the literature. In Trends in radiation sterilization of health care products. Vienna: International Atomic Energy Agency, STI/PUB/1313, pp 184-230.

Marquis RE, Sim J and Shin SY (1994) Molecular mechanisms of resistance to heat and oxidative damage. J App Bacteriol 76:40S-48S.

Martin PE, Farley KA, Baker MB, et al. (2017) A two-step $\mathrm{K}-\mathrm{Ar}$ experiment on Mars: Dating the diagenetic formation of jarosite from Amazonian groundwaters. J Geophys Res Planets 122:2803-2818.

Marty NCM, Grangeon S, Warmont F, et al. (2015) Alteration of nanocrystalline calcium silicate hydrate $(\mathrm{C}-\mathrm{S}-\mathrm{H})$ at $\mathrm{pH} 9.2$ and room temperature: A combined mineralogical and chemical study. Min Mag 79:437-458.

Mattimore V and Battista JR (1996) Radioresistance of Deinococcus radiodurans: Functions necessary to survive ionizing radiation are also necessary to survive prolonged desiccation. J Bacteriology 178:633-637.

May MS and Hattaman S (1975) Deoxyribonucleic acidcytosine methylation by host- and plasmid-controlled enzymes. J Bacteriol 122:129-138.

McNamara NP, Black HIJ, Beresford NA, et al. (2003) Effects of acute gamma irradiation on chemical, physical and biological properties of soils. Appl Soil Ecol 24:117-132.

Merlino S, Bonaccorsi E and Armbruster T (1999) Tobermorites: Their real structure and order-disorder (OD) character. Am Min 84:1613-1621.

Merlino S, Bonaccorsi E and Armbruster T (2001) The real structure of tobermorite 11A: normal and anomalous forms, OD character and polytypic modifications. European J Min 13:577-590.

Millan M, Pozarycki C, McAdam A, et al. (2020) Optimization of the sample analysis at Mars wet chemistry experiment for the detection of organics in Glen Torridon [abstract 1897]. In 51st Lunar and Planetary Science Conference, Lunar and Planetary Institute, Houston.

Milliken RE, Grotzinger JP and Thomson BJ (2010) Paleoclimate of Mars as captured by the stratigraphic record in Gale Crater. Geophys Res Lett 37.

Ming DW, Archer PD, Glavin DP, et al. (2014) Volatile and organic compositions of sedimentary rocks in Yellowknife Bay, Gale Crater, Mars. Science 343:1245267.

Moeller RC, Jandura L, Rosette K, et al. (2020) The Sampling and Caching Subsystem (SCS) for the scientific exploration of Jezero Crater by the Mars 2020 Perseverance Rover. Space Sci Rev 217:5.

MSPG (MSR Science Planning Group: co-chairs M Meyer and E Sefton-Nash) (2019) The Relationship of MSR Science and Containment. Unpublished workshop report available online at https://mepag.jpl.nasa.gov/reports/Science_in_Containment_ Report_Final.pdf.

Mustard JF, Murchie SL, Pelkey SM, et al. (2008) Hydrated silicate minerals on Mars observed by the Mars Reconnaissance Orbiter CRISM instrument. Nature 454:305-9.

Mustard JF, Poulet F, Gendrin A, et al. (2005) Olivine and pyroxene, diversity in the crust of Mars. Science 307:15941597.
Mustard JF, Adler M, Allwood, A, et al. (2013) Report of the Mars 2020 Science Definition Team. 154pp., posted July, 2013, by the Mars Exploration Program Analysis Group (MEPAG) at https://mepag.jpl.nasa.gov/reports/MEP/ Mars_2020_SDT_Report_Final.pdf.

National Research Council (2007) The Limits of Organic Life in Planetary Systems. National Academies Press, Washington, D.C.

Neal CR (2000) Issues involved in a martian sample return: Integrity preservation and the Curation and Analysis Planning Team for Extraterrestrial Materials (CAPTEM) position. $J$ Geophys Res Planets 105:22487-22506.

Neumann A, Petit S and Hofstetter TB (2011) Evaluation of redoxactive iron sites in smectites using middle and near infrared spectroscopy. Geochim et Cosmochim Acta 75:2336-2355.

Nowak A and Wronkowska H (1987) On the efficiency of soil sterilization in autoclave. Zentralblatt für Mikrobiologie 142: 521-525.

O'Neil JR and Barnes I (1971) $\mathrm{C}^{13}$ and $\mathrm{O}^{18}$ compositions in some fresh-water carbonates associated with ultramafic rocks and serpentinites: western United States. Geochim et Cosmochim Acta 85:687-697.

Pavlov AA, Vasilyev G, Ostryakov VM, et al. (2012) Degradation of the organic molecules in the shallow subsurface of Mars due to irradiation by cosmic rays. Geophys Res Lett 39:1-5.

Pavlov AA, Eigenbrode JL, Glavin DP, et al. (2014) Rapid degradation of the organic molecules in martian surface rocks due to exposure to cosmic rays. Severe implications to the search for "extant" life on Mars [abstract 2830]. In 45th Lunar and Planetary Science Conference, Lunar and Planetary Institute, Houston.

Peters K, Walters C and Moldowan J (2007) The biomarker guide II: Biomarkers and isotopes in petroleum systems and Earth history. Cambridge Univ. Press.

Plötze M, Kahr G and Stengele RH (2003) Alteration of clay minerals-gamma-irradiation effects on physicochemical properties. Appl Clay Sci 23:195-202.

Popa R (2014) Elusive definition of life: a survey of main ideas. In: Astrobiology : An Evolutionary Approach. Ed. VM Kolb, pp. 325-348. Boca Raton, FL. CRC Press.

Poulet F, Bibring JP, Mustard JF, et al. (2005) Phyllosilicates on Mars and implications for early martian climate. Nature 438:623-627.

Pushkareva R, Kalinichenko E, Lytovchenko A, et al. (2002) Irradiation effect on physico-chemical properties of clay minerals. Appl Clay Sci 21:117-123.

Ramachandran VS, Feldman RF and Sereda PJ (1964) Application of differential thermal analysis in cement research. In Research on aggregate, cement, concrete and epoxy bonding, Highway Research Record Issue Number 62; Publisher: High Research Board; pp 40-61.

Rampe EB, Ming DW, Blake DF, et al. (2017) Mineralogy of an ancient lacustrine mudstone succession from the Murray formation, Gale crater, Mars. Earth Planet Sci Lett 471:172185.

Rampe EB, Blake DF, Bristow TF, et al. (2020) Mineralogy and geochemistry of sedimentary rocks and eolian sediments in Gale Crater, Mars: A review after six Earth years of exploration with Curiosity. Geochemistry 80:125605.

Ražem D (2008) Radiation sterilization of pharmaceuticals: An overview of the literature. In Trends in Radiation Sterilization of Health Care Products. Vienna: International Atomic Energy Agency, STI/PUB/1313, p. 175-186. 
Reches Y (2019) A multi-scale review of the effects of gamma radiation on concrete. Results in Materials 2:100039.

Reiff SC and Laverne JA (2015) Radiation-induced chemical changes to iron oxides. Journal of Physical Chemistry B 119: 7358-7365.

Richmond RC, Sridhar R and Daly MJ (1999) Physicochemical survival pattern for the radiophile Deinococcus radiodurans: A polyextremophile model for life on Mars. SPIE, 3755:210-222.

Rodante F (1992) Thermodynamics and kinetics of decomposition processes for standard alpha-amino-acids and some of their dipeptides in the solid-state. Thermochim Acta 200:47-61.

Rodante F, Marrosu G and Catalani G (1992) Thermal analysis of some $\alpha$-amino acids with similar structures. Thermochim Acta 194:197-213.

Rodriguez ET, Garbev K, Merz M, et al. (2017) Thermal stability of C-S-H phases and applicability of Richardson and Groves' and Richardson C-(A)-S-H(I) models to synthetic C-S-H. Cement and Concrete Research 93:45-56.

Roedder E (1990) Fluid inclusion analysis-Prologue and epilogue. Geochim et Cosmochim Acta, 54:495-507.

Rosenberg B, Kemeny G, Switzer RC, et al. (1971) Quantitative evidence for protein denaturation as the cause of thermal death. Nature 232:471-473.

Rubin AE, Zolensky ME and Bodnar RJ (2002) The halite-bearing Zag and Monahans (1998) meteorite breccias: Shock metamorphism, thermal metamorphism and aqueous alteration on the H-chondrite parent body. Meteorit Planet Sci 37:125-141.

Ruff SW, Farmer JD, Calvin WM, et al. (2011) Characteristics, distribution, origin, and significance of opaline silica observed by the Spirit rover in Gusev crater, Mars. J Geophys Res Planets 116:E00F23.

Rummel JD, Race MS, DeVincenzi DL, et al. (2002) A Draft Test Protocol for Detecting Possible Biohazards in Martian Samples Returned to Earth. Washington, DC, pp NASA/CP2002-211842.

Rummel JD, Beaty DW, Jones MA, et al. (2014) A new analysis of Mars "Special Regions": Findings of the second MEPAG Special Regions Science Analysis Group (SRSAG2). Astrobiology 14:887-968.

Russell AD (2003) Lethal effects of heat on bacterial physiology and structure. Sci. Prog 86:115-137.

Russell MJ, Ingham JK, Zedef V, et al. (1999) Search for signs of ancient life on Mars: expectations from hydromagnesite microbialites, Salda Lake, Turkey. Journal of the Geological Society of London 156:869-888.

Rutala WA and Weber DJ (2016) Disinfection and sterilization in health care facilities: An overview and current issues. Infectious Disease Clinics of North America 30:609-637.

Rutala WA and Weber DJ (2019) Disinfection, sterilization, and antisepsis: An overview. American Journal of Infection Control 47:A3-A9.

Schäfer T, Michel P, Claret F, et al. (2009) Radiation sensitivity of natural organic matter: Clay mineral association effects in the Callovo-Oxfordian argillite. J Electron Spectr Rel Phenom 170:49-56.

Schubert WW and Beaudet RA (2011) Determination of lethality rate constants and D-values for heat-resistant Bacillus spores ATCC 29669 exposed to dry heat from $125^{\circ} \mathrm{C}$ to $200^{\circ} \mathrm{C}$. Astrobiology 11:213-223.

Schulz BP, Vickers ML, Huggett J, et al. (2020) Palaeogene glendonites from Denmark. Bulletin of the Geological Society of Denmark 68:23-35.

Schumann D, Hartman H, Eberl DD, et al. (2012) Formation of replicating saponite from a gel in the presence of oxalate: Im- plications for the formation of clay minerals in carbonaceous chondrites and the origin of life. Astrobiology 12:549-561.

Selleck BW, Carr PF and Jones BG (2007) A review and synthesis of glendonites (pseudomorphs after ikaite) with new data: Assessing applicability as recorders of ancient coldwater conditions. Journal of Sedimentary Research 77:980991.

Setlow P (2005) Spores of Bacillus subtilis: Their resistance to and killing by radiation, heat and chemicals. J App Microbiol 101:514-525.

Shaw S, Henderson CMB and Komanschek, BU (2000) Dehydration/recrystallization mechanisms, energetics, and kinetics of hydrated calcium silicate minerals: an in situ TGA/DSC and synchrotron radiation SAXS/WAXS study. Chemical Geology 167:141-159.

Shearman DJ and Smith AJ (1985) Ikaite, the parent mineral of jarrowite-type pseudomorphs. Proc of the Geologists' Assoc 96:305-314.

Sheller EL, Ehlmann BL, Hu R, et al. (2021) Long-term drying of Mars by sequestration of ocean-scale volumes of water in the crust. Science 372:56-62

Shih KL and Souza KA (1978) Degradation of biochemical activity in soil sterilize by dry heat and gamma radiation. Origins of Life 9:51-63.

Shock EL (1992) Stability of peptides in high-temperature aqueous solutions. Geochim et Cosmochim Acta 56:34813491.

Simkus DN, Aponte JC, Elsila JE, et al. (2019) Methodologies for analyzing soluble organic compounds in extraterrestrial samples: Amino acids, amines, monocarboxylic acids, aldehydes, and ketones. Life 9:47.

Simmons A. (2012) 11-Future trends for the sterilisation of biomaterials and medical devices. In: Sterilisation of Biomaterials and Medical Devices. Eds. S Lerouge and A Simmons, Woodhead Publishing, pp 310-320.

Stucki JW (2011) A review of the effects of iron redox cycles on smectite properties. Comptes Rendus Geosci 343:199-209.

Sutter B, McAdam AC, Mahaffy PR, et al. (2017) Evolved gas analyses of sedimentary rocks and eolian sediment in Gale Crater, Mars: Results of the Curiosity rover's sample analysis at Mars instrument from Yellowknife Bay to the Namib Dune. J Geophys Res Planets 122:2574-2609.

Swatkoski S, Russell SC, Edwards N, et al. (2006) Rapid chemical digestion of small acid-soluble spore proteins for analysis of Bacillus spores. Anal Chem 78:181-188.

Tait KT, McCubbin FM, Smith CL, et al. (2022) Preliminary planning for Mars Sample Return (MSR) curation activities in a Sample Receiving Facility (SRF). Astrobiology 22(S1): S-57-S-80.

Thomas PS, Heide K and Földvari M (2015) Water and hydrogen release from perlites and opal-A study with a directly coupled evolved gas analyzing system (DEGAS) Journal of Thermal Analysis and Calorimetry 120:95-101.

Tosca, NJ, Agee CB, Cockell CS, et al. (2022) Time-sensitive aspects of Mars Sample Return (MSR) science. Astrobiology 22(S1):S-81-S-111.

Trevors JT (1996) Sterilization and inhibition of microbial activity in soil. J Microbiol Methods 26:53-59.

Tsugita A and Scheffler JJ (1982) A rapid method for acid hydrolysis of protein with a mixture of trifluoroacetic acid and hydrochloric acid. Eur J Biochem 124:585-588.

Tuominen L, Kairesalo T and Hartikainen H (1994) Comparison of methods for inhibiting bacterial activity in sediment. Appl Environ Microbiol 60:3454-3457. 
U.S. Department of Health and Human Services, Centers for Disease Control, and National Institutes of Health (2020) Biosafety in Microbiological and Biomedical Laboratories (BMBL) 6th Edition (Eds. PJ Meechan and J Potts | CDC Laboratory Portal | CDC. U.S. Government Printing Office, Washington, D.C.

USNRC Technical Training Center, Biological Effects of Radiation. Reactor Concepts Manual R-200 Course, In USNRC Nuclear Regulatory Committee, 2012. Available online at https://www.nrc.gov/docs/ML0230/ML023020586.pdf.

Vaniman DT, Bish DL, Ming DW, et al. (2014) Mineralogy of a mudstone at Yellowknife Bay, Gale Crater, Mars. Science 343:1243480.

Velbel MA and Zolensky ME (2021) Thermal metamorphism of CM chondrites: A dehydroxylation-based peak-temperature thermometer and implications for sample return from asteroids Ryugu and Bennu. Meteorit Planet Sci 56:546-585.

Velbel MA, Long DT and Gooding JL (1991) Terrestrial weathering of Antarctic stone meteorites: Formation of $\mathrm{Mg}$ carbonates on ordinary chondrites. Geochim et Cosmochim Acta 55:67-76.

Velde B (1992) Introduction to Clay Minerals. London; Chapman \& Hall, 198 pp.

Walter MR and Des Marais DJ (1993) Preservation of biological information in the spring deposits: Developing a strategy for the search for fossil life on Mars. Icarus 101:129-143.

Wang XJ and You JZ (2015) Study on the molecular structure and thermal stability of purine nucleoside analogs. J Anal App Pyrol 111:1-14.

Wang X, Lim HJ and Son A (2014) Characterization of denaturation and renaturation of DNA for DNA hybridization. Environ Health Toxicol 29:e2014007.

Weber WJ, Ewing RC, Angell CA, et al. (1997) Radiation effects in glasses used for immobilization of high-level waste and plutonium disposition. Journal of Materials Research 12: 1948-1978.

Westall F, Loizeau D, Foucher F, et al. (2013) Habitability on Mars from a microbial point of view. Astrobiology 13:887-897.

Westall F, Foucher F, Bost N, et al. (2015) Biosignatures on Mars: What, where, and how? Implications for the search for martian life. Astrobiology 15:998-1029.

White RH. (1984) Hydrolytic stability of biomolecules at high temperatures and its implications for life at $250^{\circ} \mathrm{C}$. Nature 310:430.

WHO (World Health Organization) (2019) Section 5.8 Methods of sterilization. In The International Pharmacopoeia 9th Ed. World Health Organization, Geneva, Switzerland.

William K, Xi Y and Naus D (2013) A Review of the Effects of Radiation on Microstructure and Properties of Concretes Used in Nuclear Power Plants. United States Nuclear Regulatory Commission (USNRC) NUREG/CR-7171-ORNL/ TM-2013/263, $131 \mathrm{pp}$.

Wolf DC and Skipper HD (1994) Soil sterilisation. In Methods of Soil Analysis: Part 2. Microbiological and Biochemical Properties, Eds. RW Weaver, JS Angle, PS Bottomley, Soil Science Society of America, Wisconsin, pp 41-51.

Wolf DC, Dao TH, Scott HD, et al. (1989) Influence of sterilization methods on selected soil microbiological, physical, and chemical properties. J Environ Qual 18:39-44.

Wu L and Geng A (2016) Differences in the thermal evolution of hopanes and steranes in free and bound fractions. Organ Geochem 101:38-48.

Yang S, Schulz H-M, Horsfield B, et al. (2020) Geological alteration of organic macromolecules by irradiation: Implication for organic matter occurrence on Mars. Geology 48:713-717.
Yen AS, Ming DW, Vaniman DT, et al. (2017) Multiple stages of aqueous alteration along fractures in mudstone and sandstone strata in Gale Crater, Mars. Earth Planet Sci Lett 471:186-198.

Yurimoto H, Itoh S, Zolensky M, et al. (2014) Isotopic compositions of asteroidal liquid water trapped in fluid inclusions of chondrites. Geochemical Journal 48:549-560.

Zolensky ME, Bodnar RJ, Gibson EK Jr., et al. (1999) Asteroidal water within fluid inclusion-bearing halite in an H5 Chondrite, Monahans (1998). Science 285:1377-1379.

Zolensky M, Nakamura-Messenger K, Fletcher L, et al. (2008) Curation, spacecraft recovery, and preliminary examination for the Stardust mission: A perspective from the curatorial facility. Meteorit Planet Sci 43:5-21.

Zolensky ME, Bodnar RJ, Yurimoto H, et al. (2017) The search for and analysis of direct samples of early Solar System aqueous fluids. Philosophical Transactions of the Royal Society A 375:20150386, doi.org/10.1098/rsta.2015.0386.

For further information about MSPG2, please contact Michael Meyer (Michael.a.meyer@nasa.gov), Gerhard Kminek (Gerhard.kminek@esa.int), David Beaty (dwbeaty@jpl.nasa.gov), or Brandi Carrier (bcarrier@jpl.nasa.gov).

For further information on the technical content of this report, contact any of the above or Michael A. Velbel (velbel@msu.edu; VelbelM@si.edu).

$$
\begin{aligned}
& \text { Acronyms Used } \\
& \mathrm{BC}=\text { Basic Characterization } \\
& \text { BSL-4CEC }=\text { Biosafety Level } 4 \\
& \mathrm{CEC}=\text { Cation exchange capacity } \\
& \mathrm{CCM}=\text { Capture and Containment Module; } \\
& \text { a subsystem of the Earth Return } \\
& \text { Orbiter spacecraft } \\
& \text { CCRS }=\text { Capture, Containment, and Return } \\
& \text { System; a subsystem of the Earth } \\
& \text { Return Orbiter spacecraft } \\
& \text { CE-MS = Capillary Electrophoresis-Mass } \\
& \text { Spectrometry } \\
& \text { CHNOPS }=\text { Carbon, hydrogen, nitrogen, oxygen, } \\
& \text { phosphorus and sulphur, the six most } \\
& \text { abundant chemical elements } \\
& \text { in biological molecules } \\
& \mathrm{CMS}=(\text { The }) \text { Clay Minerals Society } \\
& \mathrm{CMS} \mathrm{SC}=(\text { The }) \text { Clay Minerals Society Source } \\
& \text { Clay } \\
& \text { Co- } \mathrm{I}=\text { Co-Investigator } \\
& \text { COSPAR }=\text { Committee on Space Research } \\
& \text { CRDS }=\text { Cavity ring-down laser absorption } \\
& \text { spectroscopy } \\
& \mathrm{CSG}=\text { Campaign Science Group } \\
& \mathrm{CSSC}=\text { Caching Strategy Steering Committee } \\
& \mathrm{CST}=\text { Campaign Science Team } \\
& \mathrm{DOM}=\text { Dissolved organic matter } \\
& \text { DNA }=\text { Deoxyribonucleic acid } \\
& \text { DHMR }=\text { Dry Heat Microbial Reduction } \\
& \text { DPA }=\text { Dipicolinic acid } \\
& \mathrm{EDS} \text { or } \mathrm{EDX}=\text { Energy dispersive } \mathrm{X} \text {-ray spectroscopy, } \\
& \text { usually shortened to energy } \\
& \text { dispersive spectroscopy }
\end{aligned}
$$




\section{Acronyms Used (Cont.)}

EEV/EES = Earth Entry Vehicle/Earth Entry System; a subsystem of the Earth Return Orbiter spacecraft

$\mathrm{EF}=$ Energy filtering

$\mathrm{EGA}=$ Evolved gas analyzer

$\mathrm{EPMA}=$ Electron probe microanalysis

$\mathrm{EPR}=$ Electron paramagnetic resonance

$\mathrm{ERO}=$ Earth Return Orbiter; a spacecraft managed by ESA that is part of the MSR Program.

$\mathrm{ESA}=$ European Space Agency

ESI-MS = Electrospray ionization

$\mathrm{ESR}=$ Electron spin resonance

$\mathrm{FE}=$ Field-emission

FIB $=$ Focused-ion beam

FRTE $=$ First-row transition elements

FTIR $=$ Fourier transform infrared

GC-IRMS $=$ Gas chromatograph and isotope ratio mass spectrometer

GC-MS = Gas Chromatograph-Mass Spectrometer; a laboratory instrument

GCRs $=$ Galactic cosmic rays

GSFC $=($ NASA $)$ Goddard Space Flight Center

HMWV $=$ High molecular weight volatiles

iMOST $=$ International MSR Objectives and Samples Team

$\mathrm{IR}=$ Infrared

ISRU $=$ In situ resource utilization

$\mathrm{JMIP}=$ Joint Management Implementation Plan

JSB $=$ Joint Steering Board

$\mathrm{JSC}=(\mathrm{NASA})$ Johnson Space Center

LC-MS $=$ Liquid Chromatography-Mass Spectrometry

LMWV $=$ Low molecular weight volatiles

$\mathrm{LSI}=$ Light stable isotopes

M2020 = Mars 2020; A NASA mission launched in July, 2020 and landed on Mars in Feb. 2021. The primary system is a sample-collecting rover named Perseverance.

MALDI-MS = Matrix-assisted laser desorption/ ionization mass spectroscopy

MAV/MAS $=$ Mars Ascent Vehicle/Mars Ascent System

MEPAG = Mars Exploration Program Analysis Group

MGy $=$ MegaGray $-\mathrm{a}$ unit of ionizing radiation

MOU $=$ Memorandum of Understanding

Mrad $=$ Megarad - a unit of ionizing radiation

$\mathrm{MSB}=$ MSR Science Board

MSL $=$ Mars Science Laboratory

$\mathrm{MSPG}=\mathrm{MSR}$ Science Planning Group

MSPG2 $=$ MSR Science Planning Group Phase 2

MSR $=$ Mars Sample Return
NASA $=$ National Aeronautics and Space Administration

NEPA $=$ National Environmental Policy Act

$\mathrm{NRC}=$ Nuclear Regulatory Commission (USA)

$\mathrm{OM}=$ Organic matter

$\mathrm{OS}=$ Orbiting Sample Container

$\mathrm{PCV}=$ Primary Containment Vessel; a subsystem of the Containment and Return System

PDS $=$ Planetary Data System

$\mathrm{PE}=$ Preliminary Examination

$\mathrm{PI}=$ Principal Investigator

$\mathrm{PPO}=$ Planetary Protection Officer

PSA $=$ ESA Planetary System Archive

$\mathrm{PSG}=$ Project Science Group

$\mathrm{PSP}=$ Pathway to Sampling Package

$\mathrm{RCM}=$ Reactor Concepts Manual

RNA $=$ Ribonucleic acid

RSS $=$ Returned Sample Science

RSTA $=$ Returnable Sample Tube Assembly

SAED $=$ Selected area electron diffraction

$\mathrm{SAM}=$ Sample Analysis at Mars (a scientific instrument on MSL Curiosity)

SCRs $=$ Solar cosmic rays

$\mathrm{SCV}=$ Secondary Containment Vessel; a subsystem of the Containment and Return System

$\mathrm{SE}-\mathrm{FG}=$ Sterilization Effects Focus Group (part of MSPG2)

$\mathrm{SEM}=$ Scanning electron microscope

SFR $=$ Sample Fetch Rover

SIMS $=$ secondary ion mass spectroscopy

$\mathrm{SMP}=$ Science Management Plan

$\mathrm{SRF}=$ Sample Receiving Facility

$\mathrm{SRL}=$ Sample Retrieval Lander; a spacecraft managed by NASA that is part of the MSR Program.

$\mathrm{SRW}=$ Scientifically Return Worthy

SSAP $=$ Sample Safety Assessment Protocol

STIC $=$ Sample Tube Isolation Chamber

$\mathrm{TC} / \mathrm{EA}=$ Thermal Conversion / Elemental Analysis

TEM $=$ Transmission electron microscopy

TLS $=$ Tunable diode laser absorption spectroscopy

$\mathrm{TOF}=$ Time of flight

TTC $=$ Technical Training Center

UHPLC-MS/MS = Ultrahigh Performance Liquid Chromatography with Fluorescence Detection and Ultrahigh Resolution Tandem Mass Spectrometry

USNRC $=$ United States Nuclear Regulatory Commission

UTTR $=$ Utah Test and Training Range

$\mathrm{UV}=$ Ultraviolet

WHO $=$ World Health Organization

WTA $=$ Witness Tube Assembly

$\mathrm{XRD}=\mathrm{X}$-ray diffraction 